\title{
The impact of ankylosing spondylitis on bone : determinants and consequences of vertebral deformities and fractures
}

Citation for published version (APA):

Vosse, D. (2009). The impact of ankylosing spondylitis on bone : determinants and consequences of vertebral deformities and fractures. [Doctoral Thesis, Maastricht University]. Datawyse / Universitaire Pers Maastricht. https://doi.org/10.26481/dis.20090409dv

Document status and date:

Published: 01/01/2009

DOI:

10.26481/dis.20090409dv

Document Version:

Publisher's PDF, also known as Version of record

Please check the document version of this publication:

- A submitted manuscript is the version of the article upon submission and before peer-review. There can be important differences between the submitted version and the official published version of record.

People interested in the research are advised to contact the author for the final version of the publication, or visit the DOI to the publisher's website.

- The final author version and the galley proof are versions of the publication after peer review.

- The final published version features the final layout of the paper including the volume, issue and page numbers.

Link to publication

\footnotetext{
General rights rights.

- You may freely distribute the URL identifying the publication in the public portal. please follow below link for the End User Agreement:

www.umlib.nl/taverne-license

Take down policy

If you believe that this document breaches copyright please contact us at:

repository@maastrichtuniversity.nl

providing details and we will investigate your claim.
}

Copyright and moral rights for the publications made accessible in the public portal are retained by the authors and/or other copyright owners and it is a condition of accessing publications that users recognise and abide by the legal requirements associated with these

- Users may download and print one copy of any publication from the public portal for the purpose of private study or research.

- You may not further distribute the material or use it for any profit-making activity or commercial gain

If the publication is distributed under the terms of Article $25 \mathrm{fa}$ of the Dutch Copyright Act, indicated by the "Taverne" license above, 


\section{The impact of ankylosing spondylitis on bone}

Determinants and consequences of vertebral deformities and fractures 
C Copyright Debby Vosse, Bemelen 2009

Universitaire Pers Maastricht

ISBN 978-90-5278-806-7

Cover illustratie: Foto's Fam Jöbsis, Thailand zomer 2008

Printed by Datawyse Maastricht

The printing of this thesis was supported by Abbott BV, Amgen, MerckSharp \& Dohme, Mundipharma, Novartis, Roche, Schering-Plough and Wyeth Pharmaceuticals. 


\section{The impact of ankylosing spondylitis on bone}

Determinants and consequences of vertebral deformities and fractures

PROEFSCHRIFT

ter verkrijging van de graad van doctor

aan de Universiteit Maastricht,

op gezag van de Rector Magnificus,

Prof. mr. G.P.M.F. Mols,

volgens het besluit van het College van Decanen

in het openbaar te verdedigen

op donderdag 9 april 2009 om 16:00 uur

door

Debby Vosse

geboren op 5 mei 1961 te 's Gravenhage

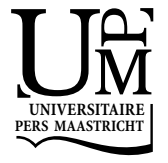




\section{PROMOTORES}

Prof. dr. J.M.J.P. van der Linden

Prof. dr. P.P.M.M. Geusens (Universiteit Hasselt/MUMC)

Prof. dr. R.B.M. Landewé

\section{BEOORDELINGSCOMMISSIE}

Prof. dr. A.C. Nieuwenhuijzen Kruseman, voorzitter

Prof. dr. J. Braun (Herne, Germany)

Prof. dr. G.J. Dinant

Prof. dr. W.F. Lems (Vrije Universiteit Medisch Centrum Amsterdam)

Dr. R.E. Weijers 
Whatever your imagination might be: you have no idea on the effect of pain and a bended back on a human. OK, but nobody seems to have such idea, except the victims

Pascal Mercier,

Night train to Lissabon, Wereldbibliotheek, 2004 



\section{Contents}

Chapter 1 General introduction 9

Chapter 2 Clinical vertebral fractures in patients with ankylosing 21 spondylitis

Chapter 3 Ankylosing spondylitis and the risk of fracture: Results from a large primary care based nested case control study

Chapter 4 Measurement of spinal mobility in ankylosing spondylitis:

Comparison of occiput-to-wall and tragus-to-wall distance

Chapter 5 Comparing morphometric X-Ray absorptiometry and radiography in defining vertebral wedge fractures in patients with ankylosing spondylitis

Chapter 6 Determinants of hyperkyphosis in patients with ankylosing spondylitis

Chapter 7 Association of markers of bone- and cartilage degradation with radiological changes at baseline and after 2 years followup in patients with ankylosing spondylitis

Chapter 8 General discussion and Summary

Chapter 9 Samenvatting

Dankwoord 135

Curriculum Vitae

Publications 



\section{General \\ introduction}

The impact of ankylosing spondylitis on bone

\section{Determinants and consequences of vertebral deformities and fractures}

Published in parts:

D. Vosse, S. van der Linden. Ankylosing spondylitis in 2015.

In: BJ van Royen, BAC Dijkmans, eds. Ankylosing Spondylitis. Diagnosis and treatment.

New York: Taylor \& Francis Group 2006:343-51

P. Geusens, D. Vosse, S. van der Linden. Osteoporosis and vertebral fractures in ankylosing spondylitis.

Curr Opin Reumatol 2007;19:335-9 


\section{INTRODUCTION}

Ankylosing spondylitis (AS), also known as Pierre-Marie Strumpell's disease ${ }^{1,2}$ and, more commonly, as Bechterew's disease ${ }^{3}$, is nowadays a well-recognized clinical entity. However, it should be remembered that this disease has been regarded as a variant of rheumatoid arthritis (RA) until approximately $1960^{4,5}$ and was then often referred to as "rheumatoid spondylitis". In 1973, the association with human leukocyte antigen (HLA)-B27 gene was discovered, thus establishing the genetic background of AS, and in 1976 a unifying concept for the "seronegative spondylarthritides" (SpA) was proposed, including idiopathic AS, reactive arthritis, psoriatic arthritis and inflammatory bowel diseases (IBD)-associated spondylitis. Besides a common genetic background, now including multiple genes, the diseases belonging to the SpA spectrum share many clinical features that are related to sacroiliitis and to spondylitis (inflammatory back pain, stiffness), spinal and peripheral enthesitis and arthritis, uveitis, psoriasis and inflammatory bowel disease. ${ }^{5}$ Also, they show a remarkable wide array of radiological features.

Imaging of the spine by conventional radiography and magnetic resonance imaging may reveal inflammation (subchondral bone marrow edema), bone loss (osteoporosis), bone destruction (erosions), cartilage damage (joint space narrowing) and intra- and extra-osseous bone formation (sclerosis, syndesmophytes) all occurring at the same time. Bone formation is typical for AS and distinguishes AS from RA in which bone destruction prevails. Bone formation may occur in the sacroiliac joints, the spinal interapophyseal and costovertebral joints, the intervertebral discs and in the spinal and peripheral entheses and ligaments. ${ }^{6,7}$ Bone involvement in AS will be discussed in greater detail below.

AS usually starts in young individuals in their late teens or early twenties, and may result in variable degrees of rigidity of the spine and spinal stature deformities. Thoracic hyperkyphosis is a typical clinical feature in long-standing disease, but not all patients with AS develop spinal deformities. Despite the availability of classification criteria for AS (see below), enabling the systematic and longitudinal collection of epidemiological data, the determinants of spinal damage are still poorly understood. $^{8}$ 


\section{CLASSIFICATION AND DIAGNOSIS OF AS}

The modified New York classification criteria for AS have received widespread acceptance for standardization of surveys of AS among populations. ${ }^{9}$ These classification criteria are used for the analysis of groups of patients and include clinical signs and symptoms of spinal involvement (inflammatory low back pain and limitation of mobility of the lumbar spine and of chest expansion) as well as radiographic sacro-iliitis (presence of erosions and sclerosis). It is also widely accepted that classification criteria for AS are inappropriate for diagnostic purposes because they lack sensitivity, which explains the 9- to 11-year diagnostic delay in many patients. However, appropriate diagnostic criteria are lacking to date, and a timely diagnosis of AS often relies on pattern recognition by an experienced clinician rather than on the application of criteria. New classification criteria for "axial SpA", a concept that includes AS in its pre-radiographic stage, are underway to shorten the delay between the initiation of symptoms and the diagnosis of AS.

\section{ASSESSMENT OF AS}

The Assessment of Spondylo Arhritis international Society (ASAS)-working group has proposed a core set of domains and measuring instruments that could be used for the assessment of AS. This core set includes domains such as pain, stiffness, fatigue, patient global, physical function, spinal mobility, acute phase reactants and imaging. A few instruments with relevance for this thesis are briefly discussed here. Clinical disease activity is often scored by the Bath Ankylosing Spondylitis Disease Activity Index (BASDAI) ${ }^{10}$, The BASDAl is a patient reported outcome (PRO) and includes six questions about fatigue, pain of the spine, pain and/or swelling of the peripheral joints and duration and severity of morning stiffness of the spine. The total score of the BASDAI ranges from 0 to 10 . Physical function is usually measured by the Bath Ankylosing Spondylitis Functional Index (BASFI). ${ }^{11}$ The BASFI is also a PRO and consists of 10 questions, all dealing with daily life activities. The final score is the average of the scores of the 10 questions. In many studies, BASDAI correlates with BASFI at a high level.

The ASAS working group has proposed the modified Stoke Ankylosing Spondylitis Spine Score as the method of choice to assess spinal damage in AS. ${ }^{12}$ This method scores the anterior sites of the lumbar (from the lower border T12 to the upper border of S1) and cervical (from the lower border C2 to the upper border of 
T1) spine at a lateral view. The anterior corners of each vertebra are scored 1 for an erosion, sclerosis and / or squaring, 2 for a non-bridging syndesmophyte and 3 for total bony bridging, giving a maximum possible score of 72 . The mSASSS is dominated by syndesmophytes.

\section{BONE INVOLVEMENT IN AS}

Sacro-iliitis, the hallmark of AS, is characterized by subchondral bone marrow edema (visible on MRI), erosive lesions of the subchondral bone, subchondral new bone formation, bony bridging trough the articular cartilage and ossification of the periarticular ligaments. The end stage is full bony fusion of the sacroiliac joints and ossification of the periarticular ligaments.

Spondylitis, another hallmark of AS, refers to inflammatory lesions of the vertebral column, and may affect the apophyseal (posterior intervertebral) and costovertebral joints, the intervertebral discs, the superficial layers of the annulus fibrosis at their attachment to the corners of the vertebral bodies and the anterior, lateral and posterior intervertebral ligaments. Bone edema is considered a sign of inflammatory activity and can cover limited or extensive parts of vertebrae. At the corners of the vertebral bodies it may be associated with marginal erosive lesions with adjacent subchondral edema and sclerosis (Romanus lesion) (Figure 1.1). At the periost of the vertebrae, erosions can be found, as well as signs of new periosteal intra-osseous bone formation which provides the typical picture of squaring of the vertebrae. Gradual ossification of the superficial layers of the annulus fibrosis (Sharpey's fibers) can result in the formation of syndesmophytes, i.e. bony bridges between adjacent vertebrae. They often start in the lower thoracic and the adjacent lumbar spine and may extend to the upper thoracic and cervical spine. This process together with ossification of the deep layers of the longitudinal ligaments may result in a complete fusion of the spine (bamboo spine). Some patients may develop spondylodiscitis and discovertebral destructive changes (Anderson lesion). New extra osseous bone formation is also described in the intervertebral disci, the interapophyseal joints and ligaments. (Figure 1.2) 


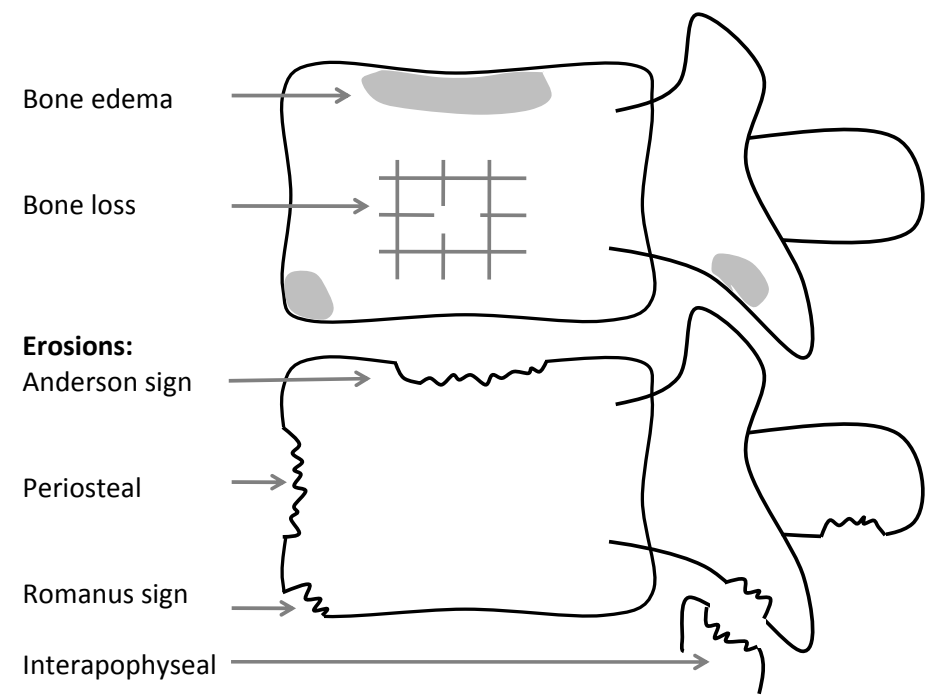

FIGURE 1.1 Bone edema, bone loss and erosion in AS.

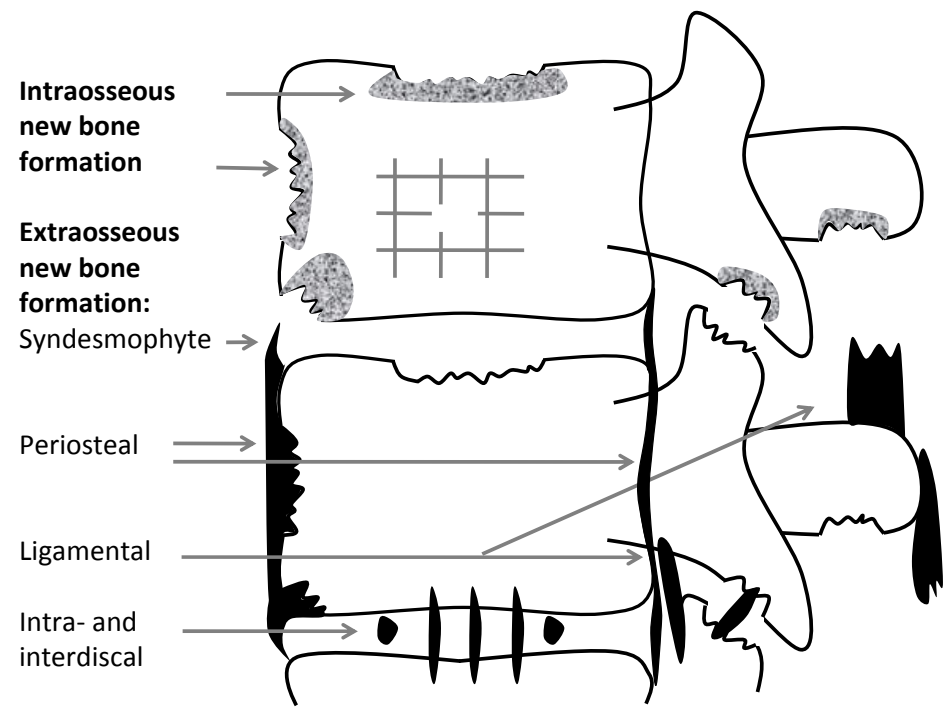

FIGURE 1.2 Intra- and extra osseous new bone formation in AS. 
Histologically, intra- and extra osseous inflammation has been described. An extra osseous granulomatous inflammatory pannus containing lymphocytes, plasma cells and multinucleated cells (osteoclasts) has been found in erosive lesions of the sacroiliac and spinal joints and at the entheses (at the corners of the vertebrae and at the periost) and ligamentous structures. Bone marrow edema has been shown to be associated with histological evident intra osseous inflammation. Parainflammatory osteoporosis has been described in the sacroiliac and interapophyseal joints, within the vertebrae and in the hip. Intra-osseous new bone formation may occur as woven bone repair remodeled to form mature lamellar bone. Extra osseous new bone formation can occur in fibrous tissue without preceding cartilage formation, or by enchondral bone formation. Very recently it was proposed that the most likely sequence of events in the regulation of new bone formation in AS is: first erosions at the site of inflammation, followed by repair reaction, followed by new bone formation. ${ }^{13}$

These assessment tools indicate that major features of AS involve the inflammatory process with functional limitation of the axial skeleton, enthesitis in the axial skeleton and peripheral joints and a combination of bone destruction and new bone formation.

\section{OSTEOIMMUNOLOGY IN AS}

The coexisting site-specific processes of bone and joint inflammation, bone destruction and bone proliferation in AS point to a regulatory interplay between inflammatory processes and bone. The rapid elucidation of cellular and molecular mechanisms underlying the interaction between inflammation and bone have

resulted in the concept of 'osteoimmunology'. ${ }^{14-16}$ Bone is a target in many inflammatory rheumatic diseases, such as RA and AS. The interaction between the inflammatory cascade (immune system) and bone is characterized by a wide range of changes in bone remodeling not only at the site of inflammation, but also at skeletal sites more distantly from inflammation. For RA and psoriatic arthritis (PsA), the knowledge about the effects of inflammation on bone has been rapidly increased by elucidating the role of osteoclasts in causing bone destruction, as well as their inflammatory triggers. ${ }^{17-19}$ To date, however, the precise relationship between inflammation and bone formation in AS remains insufficiently understood, and there is increasing evidence that inflammation and new bone formation in AS are at 
least partly uncoupled. Notwithstanding these pathophysiological uncertainties, the concept of impaired bone quality in AS is broadly accepted.

\section{ASSESSING BONE INVOLVEMENT IN AS}

The generalised effect of inflammation on bone may result in a decreased quality of bone and is associated with an increased risk of fractures, both in RA and AS. ${ }^{20}$

Bone fragility is not only a result of reduced bone mineral density (BMD). There is increasing evidence that bone fragility is also due to changes in structural properties of bone that are not captured by measuring BMD. ${ }^{21}$ The presence of syndesmophytes and other ectopic bone in AS may importantly jeopardise the reliability of BMD, and this is an additional reason why BMD measurements in AS are of limited value in order to establish poor bone quality. Another way to assess bone quality is measurement of bone metabolism by markers of bone resorption (type 1 collagen (CTX-I)) and of cartilage destruction (type II collagen (CTX II)).

Overall, there are three different types of spinal fractures in patients with AS: simple compression fractures of the vertebral body, similar to those found in postmenopausal osteoporosis; fractures of the vertebral body, the components of the dorsal arch and fractures within extra skeletal newly formed bone. However, a reliable diagnosis of vertebral fracture is evenly challenging for several reasons. First, only one out of 3-4 vertebral fractures gives typical signs and symptoms of an acute fracture. ${ }^{22-24}$ And even in the presence of symptoms that are compatible with a clinical vertebral fracture, such a fracture can clinically be misinterpreted in patients with AS, since both acute and chronic back pain are common. This may be an explanation for the paucity of fracture data in AS patients. Second, fractures of the vertebral body can easily be missed on radiographs, which is why there is a need for reliable (imaging) tools to establish vertebral fractures. ${ }^{25}$ Third, thoracic hyperkyphosis is a prevalent finding in AS and is often interpreted as inherent to the disease rather than as a consequence of concomitant bone quality impairment (osteoporosis). Additionally, poor imaging quality due to overlying soft tissues and ribs does often not allow an appropriate diagnosis of fracture of a vertebral body.

This thesis will mainly concentrate on the clinical consequences of spondylitis in terms of vertebral deformities and fractures, in terms of bone's failure to resist fracturing, and in terms of thoracic hyperkyphosis in relation to vertebral deformities and fractures. 
As an example of the difficulties we can face in the assessment of bone quality or vertebral fractures we show the morphometric X-ray absorptiometry (MXA), BMD and matching morphometric radiography (MRX) of a patient with long-standing AS. (figure $1.3 \mathrm{a}-\mathrm{c}$ ) T-score values range from -2.9 to 3.1 between only 3 adjacent vertebrae.

A

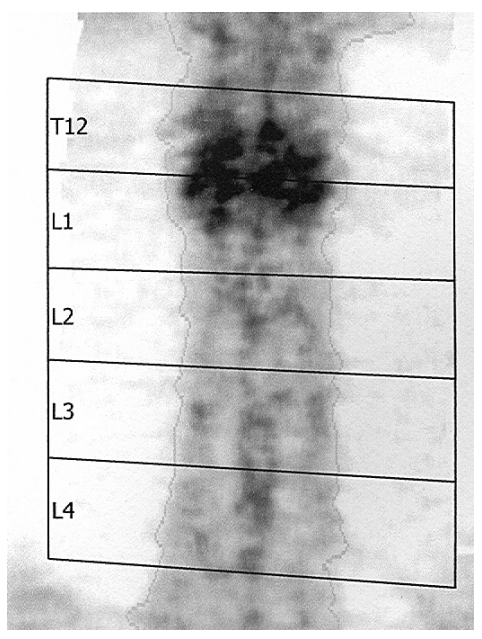

C
B

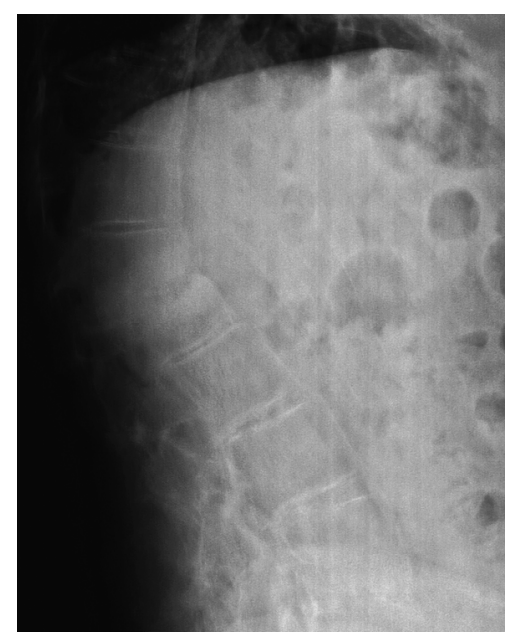

\begin{tabular}{|l|l|l|l|}
\hline region & BMD $\left(\mathrm{g} / \mathrm{cm}^{2}\right)$ & T-score & Z-score \\
\hline L1 & 1.533 & 3.1 & 3.3 \\
\hline L2 & 0.928 & -2.6 & -2.4 \\
\hline L3 & 0.913 & -2.7 & -2.5 \\
\hline L4 & 0.888 & -2.9 & -2.7 \\
\hline L1 - L2 & 1.242 & 0.3 & 0.6 \\
\hline L1 - L3 & 1.126 & -0.7 & -0.5 \\
\hline L1 - L4 & 1.058 & -1.3 & -1.1 \\
\hline L2 - L3 & 0.920 & -2.7 & -2.5 \\
\hline L2 - L4 & 0.908 & -2.8 & -2.6 \\
\hline L3 - L4 & 0.900 & -2.8 & -2.6 \\
\hline
\end{tabular}

FIGURE 1.3 BMD measurement in the lumbar spine ranging from T-score 3.1 in the fractured region (T12 - L1) to T-score -2.9 in the lower (osteoporotic) region. Radiography of the same region with clear vertebral fractures T12 - L1. 
It was hypothesized that vertebral deformities and fractures could contribute to the occurrence of hyperkyphosis of the spine. Indeed, in a small pilot study performed prior to the studies reported in this thesis in 50 patients with AS and hyperkyphosis, a high prevalence of vertebral wedged deformities in the thoracic spine was found that contributed significantly to fixed hyperkyphosis of the thoracic spine. ${ }^{26}$ This observation was the start of the work described in this thesis.

The main questions in this thesis are as follows:

- What is the prevalence of clinical vertebral fractures in AS patients and what is their clinical relevance?

- Can we reliably measure hyperkyphosis in clinical practice?

- Can different imaging techniques be used to measure vertebral deformities?

- What are the determinants of hyperkyphosis in terms of disease activity, mSASSS and vertebral wedging?

- $\quad$ To what degree are markers of bone and cartilage degradation associated with bone density, vertebral wedging, and (progression of) radiographic damage in AS?

In chapter $\mathbf{2}$ and $\mathbf{3}$ the prevalence of clinical vertebral fractures (CVF) in AS patients is studied. A questionnaire was sent to 15,097 patients from the German and Danish Ankylosing Spondylitis Society. Patients reporting a CVF were asked about the location of CVF, associated trauma, neurological complications, therapy for these complications and recovery. In addition (chapter 3 ) the prevalence of clinical vertebral and non-vertebral fractures was studied in a General Practice Research Database, including 758 AS patients.

In chapter 4 two methods assessing hyperkyphosis were compared: the occiput-to-wall distance (OWD) and the tragus to wall distance (TWD).

In chapter 5 two methods assessing vertebral deformities were compared in patients with AS: morphometric X-ray absorptiometry (MXA) and conventional lateral radiography (MRX). The relationship between disease activity, mSASSS and wedging of vertebrae and hyperkyphosis was subsequently analysed in a study (chapter 6) to determine predictive factors for hyperkyphosis in AS patients.

In chapter 7 a study which describes the relationships between biomarkers of bone and cartilage degradation and radiological damage of the spine is presented.

This thesis ends with a general discussion and summaries in English and Dutch in chapters 8 and 9 respectively. 


\section{REFERENCES}

1. Strümpel A. Lehrbuch der speziellen Pathologie und Theralpe der innerenKrankheiten. Leipzig, Vogel, 1884, Band 2, Teil 2: 152-3

2. Marie P. Sur la spondylose rhizomélique. Revue Médicale 1893;18:285

3. Bechterew von W. Steifheit der Wirbelsäule und ihre Verktümmung als besondere Erkrankungsform. Neurologisches Zentralbl 1893;12:426

4. Wright V. Aspects of ankylosing spondylitis. Br J Rheumatol 1991;30:1-4.

5. Wright V, Moll JMH. Seronegative polyarthritis. North Holland Publishing Company. Amsterdam, New York, Oxford 1976.

6. Copeman WSC. Introductory note on the nomenclature and classification of the rheumatic diseases. In: WSC Copeman (Ed). Textbook of the rheumatic diseases. Fourth edition. Livingstone. Edinburgh and London 1969:12-8.

7. Schlosstein L, Terasaki PI, Bluestone R, Pearson CM. High association of an HL-A antigen, W27, with ankylosing spondylitis. N Engl J Med. 1973;288:704-6.

8. Dougados M, van der Linden S, Juhlin R, Huitfeldt B, Amor B, Calin A, Cats A, Dijkmans B, Olivieri I, Pasero $G$, et al. The European Spondylarthropathy Study Group preliminary criteria for the classification of spondylarthropathy. Arthritis Rheum 1991;34:1218-27.

9. van der Linden S, Valkenburg HA, Cats A. Evaluation of diagnostic criteria for ankylosing spondylitis. A proposal for modification of the New York criteria. Arthritis Rheum 1984;27: 361-8.

10. Calin A, Nakache JP, Gueguen A, Zeidler H, Mielants, H, Dougados M. Defining disease activity in ankylosing spondylitis: is a combination of variables ( Bath ankylosing spondylitis disease activity index) an appropriate instrument? J Rheumatol 1994;38:878-82

11. Calin A, Garrett S, Whitelock H, Kennnedy G, O'Hea J, Mallorie P, Jenkinson T. A new approach to defining functional ability in Ankylosing Spondylitis: the development of the Bath ankylosing spondylitis functional index. J Rheumatol 1994;21:2281-5

12. Creemers MCW, Franssen MJAM, van 't Hof MA, Gribnau FWJ, vd Putte LBA, vRiel PLCM. Assessment of outcome in Ankylosing Spondylitis: an extended radiological scoring system. Ann Rheum Dis 2005;64:127-9

13. Sieper J, Appel H, Braun J, Rudwaleit M. Critical appraisal of assessment of structural damage in ankylosing spondylitis: implications for treatment outcomes. Arthritis Rheum 2008;58:649-56

14. Walsh NC, Crotti TN, Goldring SR, Gravallese EM. Rheumatic diseases: the effects of inflammation on bone. Immunol Rev. 2005;208:228-51.

15. Pettit AR, Walsh NC, Manning C, Goldring SR, Gravallese EM. RANKL protein is expressed at the pannus-bone interface at sites of articular bone erosion in rheumatoid arthritis. Rheumatology (Oxford). 2006;45:1068-76.

16. Diarra D, Stolina M, Polzer K, Zwerina J, Ominsky MS, Dwyer D, Korb A, Smolen J, Hoffmann M, Scheinecker C, van der Heijde D, Landewe R, Lacey D, Richards WG, Schett G. Dickkopf-1 is a master regulator of joint remodeling. Nat Med. 2007;13:156-63

17. Garnero P., Landewe R., Maarten B., Verhoeven A., van der Linden S., Christgau S., van der Heijde D., Boonen A., Geusens P. Association of baseline levels of markers of bone and cartilage degradation are associated with long-term progression of joint damage in patients with early rheumatoid arthritis: the Cobra study. Arthritis Rheum 2002;46:2847-56.

18. Landewé RB, Geusens P, van der Heijde DM, Boers M, van der Linden SJ, Garnero P. Arthritis instantaneously causes collagen type I and type II degradation in patients with early rheumatoid arthritis: a longitudinal analysis. Ann Rheum Dis.2006;65:40-4

19. Ritchlin CT, Haas-Smith SA, Li P, Hicks DG, Schwarz EM. Mechanisms of TNF $\alpha$ and RANKL mediated osteoclastogenesis and bone resorption in psoriatic arthritis. J Clin Invest 2003;111:821-31 
20. Sinigaglia et al. Epidemiology of osteoporosis in rheumatic diseases. Rheumatic disease clinics of $\mathrm{N}$ America. 2006, 631-58

21. Chavassieux P, Seeman E, Delmas PD. Insights into material and structural basis of bone fragility from diseases associated with fractures. How determinants of the biomechanical properties of bone are compromised by disease. Endocr Rev. 2007;28:151-64

22. Cooper C, Atkinson EJ, O'Fallon M, Melton LJ III. Incidence of clinically diagnosed vertebral fractures: a population based study in Rochester, Minnesota. J Bone Miner Res 1992;7:221-7

23. Lems WF, Geusens PPMM. Klinische relevatie van wervelfracturen. Ned Tijdschr Geneeskd 2008;152:917-9

24. Lems WF. Clinical relevance of vertebral fractures. Ann Rheum Dis 2007;66:2-4

25. Delmas PD, van de Langerijt L, Watts NB, Eastell R, Genant H, Grauer A, et al. Underdiagnosis of VFs is a worldwide problem: the IMPACT study. J Bone Miner Res 2005;20:557-63.

26. Geusens P, Vosse D, van der Heijde D, Vanhoof J, van Tubergen A, Raus J, van der Linden S. High prevalence of thoracic vertebral deformities and discal wedging in Ankylosing spondylitis patients with hyperkyphosis. J Rheumatol 2001;28:1856-61 


\section{Clinical vertebral fractures in patients with ankylosing spondylitis}




\section{ABSTRACT}

\section{Objective}

To evaluate the prevalence and characteristics of clinical manifest vertebral fractures (CVF) in ankylosing spondylitis (AS) patients.

\section{Methods}

Coordinated by the Ankylosing spondylitis International Federation in Germany and in Denmark, a self-administered questionnaire was sent to all their members about age, diagnosis, disease duration, HLA-B27 status and history of CVF. Patients who were aware of having had a CVF were asked to return the questionnaire with additional specification of the location of CVF, associated trauma, neurological complications, therapy of these complications and recovery. We also reviewed available radiographs.

\section{Results}

Out of 15.097 questionnaires, 59 patients $(0.4 \%)$, reporting 66 CVF's, returned the complete questionnaire ( 46 men, 13 women). Mean age at fracture was $50 \pm 9$ years, after a mean disease duration of $18 \pm 11$ years. CVF's with wedging, crush or transversal fracture were reported in the cervical $(n=21,36 \%)$, thoracic $(n=21,36 \%)$, lumbar spine $(n=16,27 \%)$ and one unspecified. In thirty-seven fractures (56\%) patients reported no/ low or medium trauma in relation to the fracture. In thirty-one fractures (47\%) patients reported neurological complications, occurring mostly without $(n=11,35 \%)$ or after minimal trauma $(n=7,23 \%)$. Twenty $(65 \%)$ of these patients did not have full neurological recovery.

\section{Conclusion}

$0.4 \%$ of AS patients reported CVF's at a mean age of 50 years, occurring after two decades of disease, mainly without trauma or after minimal trauma, with frequent neurological complications mostly followed by incomplete neurological recovery. 


\section{INTRODUCTION}

Ankylosing spondylitis (AS) is a chronic inflammatory disease mainly of the axial skeleton and is characterised by ossification of the spinal discs, joints and ligaments. This may lead to progressive rigidity of the spine. AS has a prevalence of $0.1 \%$ to $1.4 \%$ in Caucasian populations, correlating with the frequency of HLAB27. ${ }^{1,2}$ AS is usually diagnosed in the second or third decades of life, with a predominance of males at a ratio of 3:1.

Bone loss may be associated with inflammatory diseases such as AS and rheumatoid arthritis. ${ }^{3}$ The reported prevalence of osteoporosis in terms of low bone mineral density (BMD) in AS patients varies from $19 \%$ to $62 \%{ }^{3,4}$ This large variation may reflect the difficulties in assessing BMD in AS due to spurious increase of BMD by the progressive appearance of syndesmophytes and ossifications. On the other hand, in patients with advanced AS bone mineral density in the femur neck is reduced, indicating osteoporosis due to an inflammatory process. ${ }^{5,6,7}$ Bronson et al demonstrated that lateral lumbar spine Dual Energy X-ray Absorption (DXA) showed low trabecular BMD in the presence of elevated anteroposterior lumbar spine BMD. ${ }^{8}$ An increased prevalence of axial low BMD has been shown even in mild and early forms of AS., ${ }^{6,9}$ Lee et al showed significant intravertebral bone loss in patients with early and late disease during a mean follow-up of 15 months using quantitative computer tomography. ${ }^{10}$ Reid et al showed in a longitudinal study that men with AS (mean disease duration 12.1 years) had an annual total bone mass loss of $2.2 \%{ }^{11}$

The risk of morphometric vertebral fractures is increased in $\mathrm{AS}^{12}$ Cooper described a relative risk of 7.6 (95\% confidence interval: 4.3-12.6) among patients with AS. Other studies indicate that wedging vertebral fractures contribute to hyperkyphosis. ${ }^{13,14}$ The reported prevalence of CVF varied widely (between 10 and $17 \%)$, but has not been assessed in a systematic way. ${ }^{6,12,13,15-17}$ In several studies a high prevalence (between 29 and 91\%) of major neurological complications was reported after CVF's. ${ }^{16-19}$

This data indicates that low BMD and vertebral fractures are features of AS. The objectives of the present study were (1) to estimate the prevalence of self reported CVF in a large group of AS patients using a questionnaire, (2) to describe the clinical characteristics of patients and the location of CVF, (3) the relationship to trauma and (4) the neurological complications and its recovery. 


\section{PATIENTS AND METHODS}

In this study, a self-administered questionnaire was distributed via the Ankylosing spondylitis International Federation (ASIF) to all members of the German and Danish Ankylosing Spondylitis Society (14.127 in Germany and 970 in Denmark) by insertion in their membership journals. Nevitt et al described a good reliability of data about vertebral fractures when gathered via self-administered questionnaires. ${ }^{20}$ Patients were asked to complete and return the questionnaire if they had a history of a CVF. The questionnaire contained general items concerning AS, such as age, gender, time of diagnosis, HLA-B27 status and the question if the diagnosis of AS was confirmed by their physician, according to the modified New York criteria. ${ }^{21}$ Further, the patients were asked to fill in questions concerning the location of CVF's, their relation to trauma, neurological complications (paresthesia and/ or muscle weakness), clinical recovery and therapy of these complications. Based on the narrative description of the trauma by the patients, the degree of trauma was categorised into: (1) no or low- energy fracture (a fracture occurring without trauma or after minor trauma); (2) medium-energy fracture (a fracture occurring after a fall at the same level, squeezing or dropping medium weight objects onto fingers or toes, etc); and (3) high energy trauma (a fracture occurring after a fall from one level down to another, car accidents). The location of the fractures was based on the patient's description. Lastly, we asked the patients to send the radiographs of the fractured vertebrae for review. Vertebrae T4 to L5 were graded as normal, wedge, biconcave (diabolo) or crush deformed as defined by Genant et $a .^{22} \mathrm{~A}$ fracture was defined as a $\geq 20 \%$ reduction in anterior, middle and/or posterior height respectively. A transversal fracture was defined as an intra- or intervertebral fracture with dislocation. The clinical records of the Danish patients were checked by one of the authors (JE).

\section{Statistical analysis}

The demographic variables were organized using descriptive analysis. Correlation coefficients between categorical values were calculated with a Pearson chi-square test. The significance of percentage differences was tested by $\chi^{2}$-tests for two-bytwo tables. SPSS version 11 was used for these analyses. 


\section{RESULTS}

Fifty-nine patients out of 15.097 returned the questionnaire and reported 66 CVF's. The minimal prevalence of reported CVF in AS is thus $0.4 \%$.

Patients' demographic data are shown in Table 2.1. All responders had a diagnosis of AS, according to the modified New York criteria. The patient group consisted of predominantly male patients (78\%) of whom $81 \%$ were HLA-B27 positive. Patients reported fractures at a mean age of $50 \pm 9$ years after a mean disease duration of $18 \pm 11$ years.

TABLE 2.1 Characteristics of 59 patients with ankylosing spondylitis.

\begin{tabular}{ll}
\hline Gender, \% men & 78 \\
HLA-B27 positive & $81 \%$ \\
Age $^{\mathrm{a}}$ & $57 \pm 10$ \\
${\text { Age at diagnosis of } \mathrm{AS}^{\mathrm{a}}}^{\mathrm{a}}$ & $32 \pm 9$ \\
${\text { Disease duration of } \mathrm{AS}^{\mathrm{a}}}_{\text {Age at fracturing }^{\mathrm{a}}}$ & $25 \pm 12$ \\
Disease duration at fracturing $^{\mathrm{a}}$ & $50 \pm 9$ \\
${ }^{\mathrm{a}}=$ years (mean $\left.\pm 1 \mathrm{SD}\right)$ & $18 \pm 11$ \\
\hline
\end{tabular}

Twenty-seven (46\%) of the patients did sent radiographs of the fracture(s) that could be reviewed. The other radiographs could not be retrieved. Examples of transversal, wedge and crush fractures in respectively the cervical, thoracic and lumbar spine are shown in Figure 2.1-2.3.

Table 2.2 shows the associated trauma levels. Twenty-one fractures (32\%) were reported with no or low-energy trauma in relation to the CVF, 16 fractures (24\%) were reported to be associated with medium-energy trauma and 22 fractures (33\%) with high-energy trauma. In seven fractures (11\%) patients did not record the level of associated trauma.

We noticed a statistically significant association between the fracture localisation and the morphology of the fracture (Table 2.3). All vertebral regions were reported: 21 fractures (32\%) in the cervical spine, 27 (39\%) in the thoracic spine and 17 (26\%) in the lumbar spine. One of the patients could not specify the fracture level. Crush fractures were seen mostly in the lower regions of the spine $(n=5)$, whereas transversal luxation only occurred in the cervical spine $\left(\chi^{2}=15, p=0.05\right)$. 


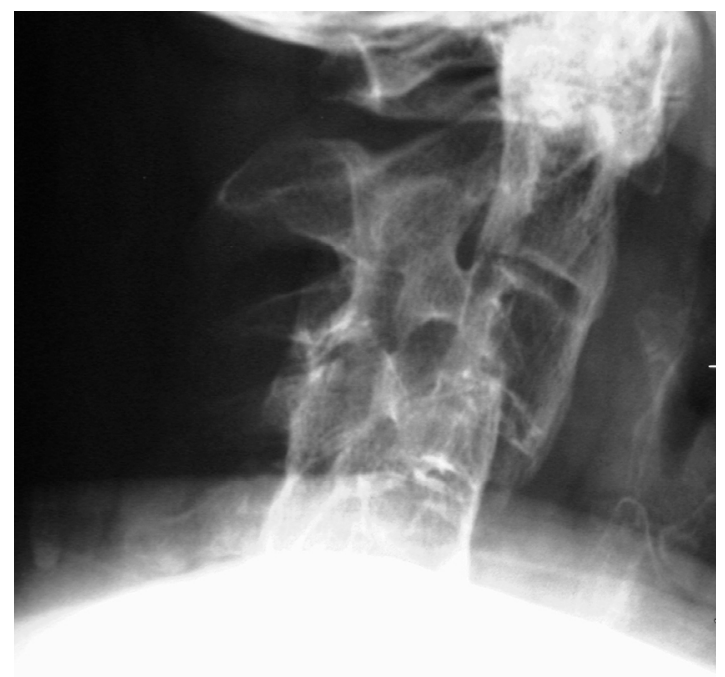

\section{FIGURE 2.1}

Radiograph of a transverse vertebral fracture in the cervical spine in a 53year-old man with AS (disease duration 16 years) after a fall from a scaffold, complicated by paralysis in both arms and legs and loss of sensation. The motoric loss recovered completely, the sensory loss only partially.

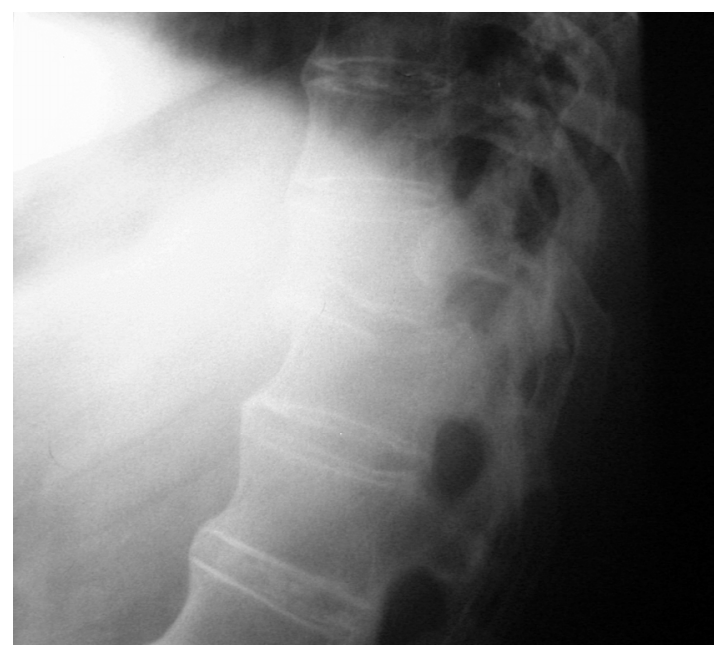

\section{FIGURE $\mathbf{2 . 2}$}

Radiograph of a wedge fracture in the thoracic spine in a 47-year-old man with AS (disease duration seven years) after a fall at the same level, with no neurological complications. 


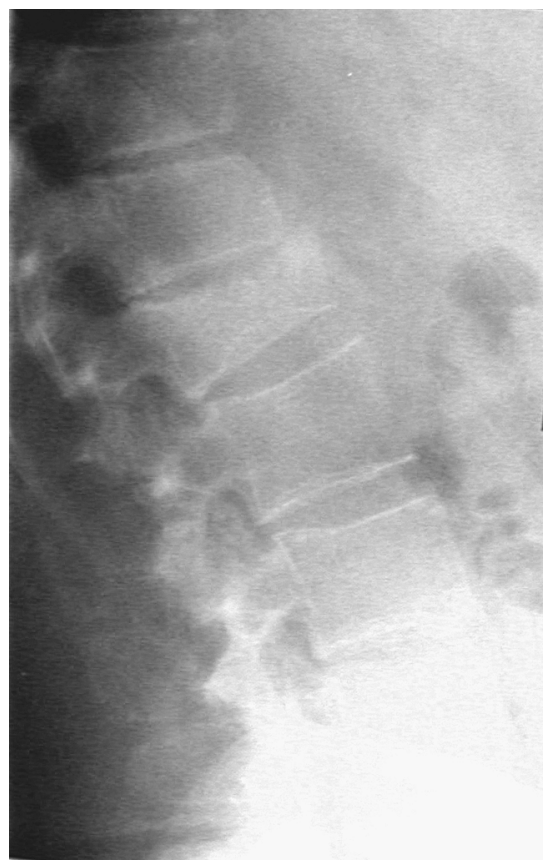

\section{FIGURE 2.3}

Radiograph of a crush fracture in the lumbar spine in a 42-year-old man with AS (disease duration 11 years) after getting out of the car, followed by paralysis and loss of sensation in both legs. There was partial recovery of motor and sensory function.

TABLE 2.2 Energy level of trauma.

\begin{tabular}{lcc}
\hline Energy level of trauma & Number of fractures & Percentage of fractures \\
\hline No / low energy & 21 & 32 \\
Medium energy & 16 & 24 \\
High energy & 22 & 33 \\
Unknown & 7 & 11 \\
\hline
\end{tabular}

TABLE 2.3 Fracture site and morphometry of fractures.

\begin{tabular}{|c|c|c|c|c|c|c|c|c|}
\hline \multirow[t]{2}{*}{ Fracture site } & \multirow[t]{2}{*}{$\begin{array}{l}\text { Number } \\
\text { of patients }\end{array}$} & \multirow[t]{2}{*}{$\begin{array}{l}\text { Percentage } \\
\text { of patients }\end{array}$} & \multirow[t]{2}{*}{$\begin{array}{l}\text { Number } \\
\text { of fractures }\end{array}$} & \multirow[t]{2}{*}{$\begin{array}{l}\text { Percentage } \\
\text { of fractures }\end{array}$} & \multicolumn{4}{|c|}{$\begin{array}{c}\text { Morphometry } \\
\text { (number reviewed) }\end{array}$} \\
\hline & & & & & crush & diabolo & wedge & luxation \\
\hline Cervical spine & 21 & 37 & 21 & 32 & 0 & 0 & 4 & 7 \\
\hline Thoracic spine T1-6 & 5 & 8 & 7 & 11 & 1 & 0 & 2 & 1 \\
\hline Thoracic spine T7-12 & 16 & 27 & 20 & 30 & 3 & 1 & 4 & 0 \\
\hline Lumbar spine & 16 & 27 & 17 & 26 & 2 & 1 & 4 & 0 \\
\hline Unknown & 1 & 1 & 1 & 1 & & & & \\
\hline
\end{tabular}


Of the 66 CVF's, 31 (47\%) were associated with neurological complications, varying from transient paresthesia to sustained loss of strength in arms or legs. Only 11 fractures (35\%) were reported with full recovery, either spontaneously or after intervention in three, whereas in 20 fractures (65\%) patients experienced no or only partial recovery, sometimes in spite of surgical intervention that was performed. (Table 2.4).

TABLE 2.4 Neurological complaints and clinical outcome of fracture.

\begin{tabular}{lcc}
\hline & $\begin{array}{c}\text { Fractures } \\
\text { Number }\end{array}$ & Percentage \\
\hline Neurologic involvement & $31 / 66$ & 47 \\
Sensory loss & $11 / 31$ & 35 \\
Paralysis & $6 / 31$ & 20 \\
Combination & $14 / 31$ & 45 \\
& & \\
Complete recovery & $11 / 31$ & 35 \\
\hline
\end{tabular}

Neurological complaints were significantly associated with the morphology of the fracture. All luxation fractures were complicated by neurological features, crush fractures mostly were without neurological complications $\left(\chi^{2}=11, p<0.05\right)$. Neurological complications occurred more frequently in patients reporting no or lowenergy trauma than in patients with high-energy trauma $\left(\chi^{2}=7.7, p<0.05\right)$.

The mean disease duration at the time of fracture after a no/ low energy-level trauma was 13.6 years versus 20.4 years after a high-energy trauma $(p=0.07)$. No significant correlations were found between neurological complaints and localisation of fracture or gender.

\section{DISCUSSION}

Osteoporosis has only recently been recognised as a feature in $\mathrm{AS}^{9}{ }^{9}$ This is associated with a significantly increased incidence of vertebral fractures in patients with AS, even after minor trauma . In contrast, Cooper et al found that the fracture risk in the appendicular skeleton was not increased, indicating that osteoporosis in AS is confined to the spine. ${ }^{12}$ We report here a minimal prevalence of CVF in AS patients of $0.4 \%$. These fractures occurred at a mean age of 50 years after mean disease duration of 18 years. They occurred even after no or minimal trauma and were 
characterised by a high number of neurological complications (47\%) with complete neurological recovery only in $35 \%$ of the cases.

The minimal prevalence of $0.4 \%$ that we report here is lower than the figure reported by Hitchon et al, who found 13 out of 266 AS patients (5\%) with clinical vertebral fractures. ${ }^{16}$ Such a high percentage could, however, be due to a referral bias by preferential referring to a specialised clinic.

A wide range of prevalence of CVF in AS is reported in literature (5 to 18\%). This wide variation could be due to patient selection, differences in the definition of vertebral fracture and differences among centres. ${ }^{6,12,13,15-17}$

Our study design had a number of limitations. Only patients who had suffered clinically from fractures were asked to respond. Overall, about one third of all fractures come to clinical attention. ${ }^{23}$ This low rate of diagnosis may also be related to mildness of symptoms or the absence of acute pain. Especially in AS patients, who suffer from back pain continuously, worsening of complaints may easily be (mis) interpreted as disease flare or muscle strain. Therefore, probably only more severe cases have been reported in our survey. The milder cases could have been missed or forgotten. Furthermore, patients may not have responded to our questionnaire because they did not read the newsletter. Therefore our figure represents really the minimal prevalence of CVF.

Interestingly, we identified a high percentage of patients with CVF's in the cervical spine and patients with transverse vertebral fractures, features that are not reported in primary osteoporosis. ${ }^{24} \mathrm{~A}$ possible explanation is that, due to the rigidity of the spine in AS, less shock absorption is possible which makes the bony spine more prone to transverse vertebral fractures. The finding that CVF's in the cervical spine do occur in AS patients is confirmed by others. ${ }^{13,17-19}$ The mean age at time of fracture was $50 \pm 9$ years after a mean of two decades of disease. This is in line with others who have described fractures occurring in the third decade after the disease AS has been diagnosed. ${ }^{6,15,19}$ Thus CVF's in AS occurs at a much earlier age as compared to primary osteoporosis, indicating that AS is a risk factor for CVF, as has also been shown for morphometric vertebral fractures. ${ }^{12}$

Only a minority of patients reported an adequate trauma before the CVF, a finding confirmed by others. ${ }^{16-19}$ Forty-seven percent of fractures were reported to be associated with neurological complications. Only 35\% of patients reported full recovery. We focused in particular on paresthesia and muscle weakness, as pain is a frequent and almost normal symptom in AS. In the literature figures on neurological complications are scarce. ${ }^{16-19,25,26}$ However, several authors reported a high prevalence for such manifestations. Hunter et al presented 22 spinal fractures in 20 
patients with neurological complaints, varying from no associated deficit to death by complete spinal cord lesion. Fox et al described a retrospective review from the Mayo Clinics in which they identified 33 patients in a period of five years with AS who underwent 41 times surgery for spinal fractures. Pre-operative neurological deficits were recorded in 13 patients, resulting from several causes and of varying severity. Nguyen et al reported 10 cases of neurological complications after vertebral fractures due to postmenopausal osteoporosis over a period of four years. ${ }^{26}$ In his literature survey he found a total of only 71 case reports. These figures suggest that the prevalence of neurological complications is much lower in this wide spread osteoporotic condition.

Neurological complications occurred significantly more after minimal or absent trauma than after adequate trauma. This suggests that no or low-energy trauma fractures occurred in patients with the most severe degree of osteoporosis. One can hypothesise that a low BMD in combination with a reduced capacity of shock absorption, makes the already rigid spine prone for developing complicated fractures. Further, CVF after low trauma or without trauma occurred at a younger age than CVF with high-energy trauma. A possible explanation could be that these patients had high disease activity and were therefore more prone to early bone loss and fractures.

Another limitation of this study is that these cases are not representative for the whole group of AS patients due to response bias. However, the frequency and severity of the complications warrants further research. Indeed, assuming that this patient group had the most dramatic clinical picture, further studies are necessary to evaluate the clinical significance of the increased risk for vertebral fractures in $\mathrm{AS}$, in order to timely diagnose and treat preventively patients at risk.

We describe 59 patients with AS, who reported 66 clinically confirmed vertebral fractures at a mean age of 50 years, notably early in the disease, mainly without trauma or after minimal trauma, with frequent neurological complications mostly followed by incomplete neurological recovery. 


\section{REFERENCES}

1. Braun J, Bollow M, Remlinger G, Eggens U, Rudwaleit M, Distler a, Sieper J. Prevalence of spondylarthropathies in HLA-B27 positive and negative blood donors. Arthritis Rheum 1998;41:58-67

2. van der Linden SM, Valkenburg $H A$, de Jongh $B M$, Cats $A$. The risk of developing ankylosing spondylitis in HLA-B27 positive individuals: a comparison of relatives of spondylitis patients with the general population. Arthritis Rheum 1984;27:241-9

3. Bessant R, Keat A. How should clinicians manage osteoporosis in ankylosing spondylitis? J Rheumatol 2002;29:1511-9

4. Gran JT, Husby G. Clinical, epidemiological, and therapeutic aspects of ankylosing spondylitis. Curr Opin Rheumatol 1998;10:292-8

5. Devogelaer JP, Maldague B, Malghem J, Nagant de Deuxchaisnes C. Appendicular and vertebral bone mass in ankylosing spondylitis. A comparison of plain radiographs with single- and dualphoton absorptiometry and with quantitative computed tomography. Arthritis Rheum 1992;35:1062-7

6. Donnelly S, Doyle DV, Denton A, Rolfe I, McCloskey EV, Spector TD. Bone mineral density and vertebral compression fracture rates in ankylosing spondylitis. Ann Rheum Dis 1994;53:117-21

7. Donnelly S, Jawed S, Meija A, Doyle DV. Effect of syndesmophyte formation on lumbar spine bone mineral density in patients with ankylosing spondylitis. Br J Rheumatol 1995;34 Suppl:117

8. Bronson WD, Walker SE, Hillman LS, Keisler D, Hoyt T, Allen SH. Bone mineral density and biochemical markers of bone metabolism in ankylosing spondylitis. J Rheumatol 1998;25:929-35

9. Will R, Palmer R, Bhalla AK, Ring EFJ, Calin A. Osteoporosis in early ankylosing spondylitis: a primary pathologic event? Lancet 1989;2:1483-5

10. Lee YS, Schlotzhauer T, Ott SM, van Vollenhoven RF, Hunter J, Marcus R, McGuire JL. Skeletal status of men with early and late ankylosing spondylitis. Am J Med 1997;103:233-41

11. Reid DM, Nicoll JJ, Kennedy NJS et al. Bone mass in ankylosing spondylitis. J Rheumatol 1986;13:932-5

12. Cooper C, Carbone L, Michet CJ, Atkinson EJ, O'Fallon WM, Melton LJ 3rd. Fracture risk in patients with ankylosing spondylitis: a population based study. J Rheumatol 1994;21:1877-82

13. Ralston SH, Urquhart GDK, Brzeski M, Sturrock RD. Prevalence of vertebral com- pression fractures due to osteoporosis in ankylosing spondylitis. BMJ 1990;300:563-5

14. Geusens P, Vosse D, van der Heijde DM, Vanhoof J, van Tubergen A, Raus J, van der Linden SM. High prevalence of thoracic vertebral deformities and discal wedging in ankylosing spondylitis patients with hyperkyphosis. J Rheumatol 2001;28:1856-61

15. Mitra D, Elvins DM, Speden DJ, Collins AJ. The prevalence of vertebral fractures in mild ankylosing spondylitis and their relationship to bone mineral density. Rheumatology 2000;39:85-9

16. Hunter T, Dubo HIC. Spinal fractures complicating ankylosing spondylitis. A long-term follow-up study. Arthritis Rheum 1983;26:751-9

17. Hitchon PW, From AM, Brenton BS, Glaser JA, Torner JC. Fractures of the thoracolumbar spine complicating ankylosing spondylitis. J Neurosurg (Spine) 2002;97:218-22

18. Fox MW, Onofrio BM, Kilgore JE. Neurological complications of ankylosing spondylitis. J Neurosurg 1993;78:871-8

19. Graham B, van Peteghem PK. Fractures of the spine in ankylosing spondylitis. Diagnosis, treatment and complications. Spine 1989;14:803-7

20. Nevitt MC, Cummings SR, Browner WS, et al. The accuracy of self-report of fractures in elderly women: evidence from a prospective study. Am J Epidemiol 1992;135:490-9

21. van der Linden SM, Valkenburg HA, Cats A. Evaluation of diagnostic criteria for ankylosing spondylitis: a proposal for modification of the New York criteria. Arthritis Rheum 1984;27:361-8 
22. Genant HK, Wu CY, Kuijk van C, Nevitt MC. Vertebral fracture assessment using a semi quantitative technique. J Bone Miner Res 1993;8:1137-48

23. Ross PD. Clinical consequences of vertebral fractures. Am J Med 1997;103(2A):30S-43S

24. Grisolia A, Bell RL, Peltier LF. Fractures and dislocations of the spine complicating ankylosing spondylitis. J Bone Joint Surg 1967;49:339-44

25. Nguyen HV, Ludwig S, Gelb D. Osteoporotic vertebral burst fractures with neurologic compromise. J Spin Dis Techn 2003;16:10-9

26. O'Neill TW, Felsenberg D, Varlow J, Cooper C, Kanis JA, Silman AJ. The prevalence of vertebral deformity in European men and women: the European Vertebral Osteoporosis Study. J Bone Miner Res 1996; 11: 1010-8 
Chapter 2 clinical vertebral fractures 
(194) 11
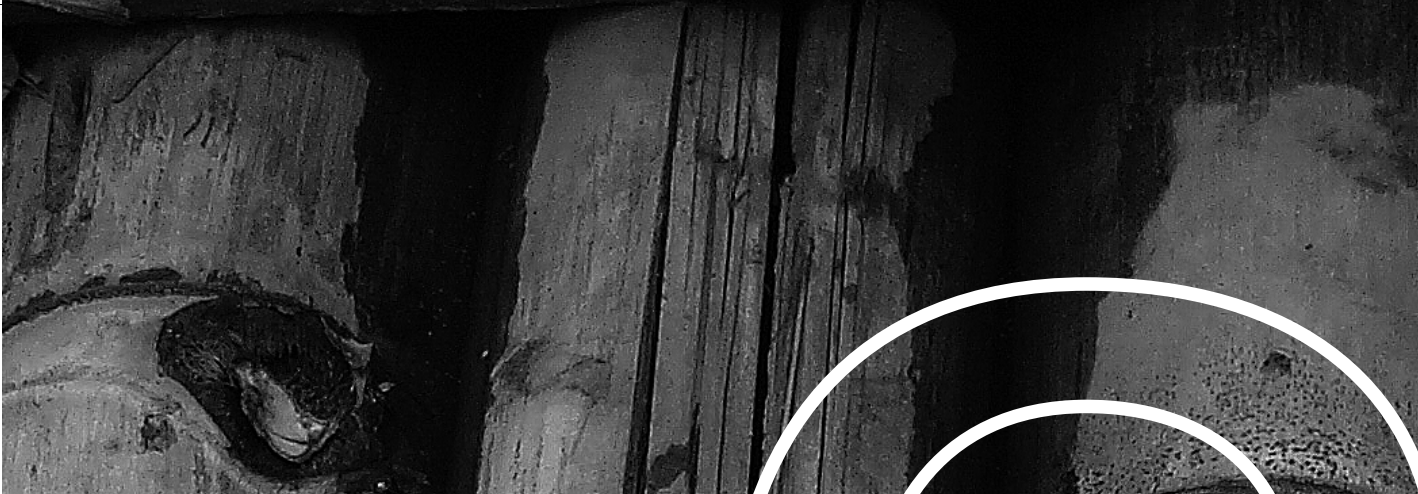

$-4$

(x)

p) 1

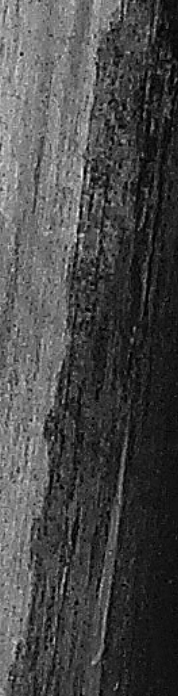

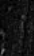
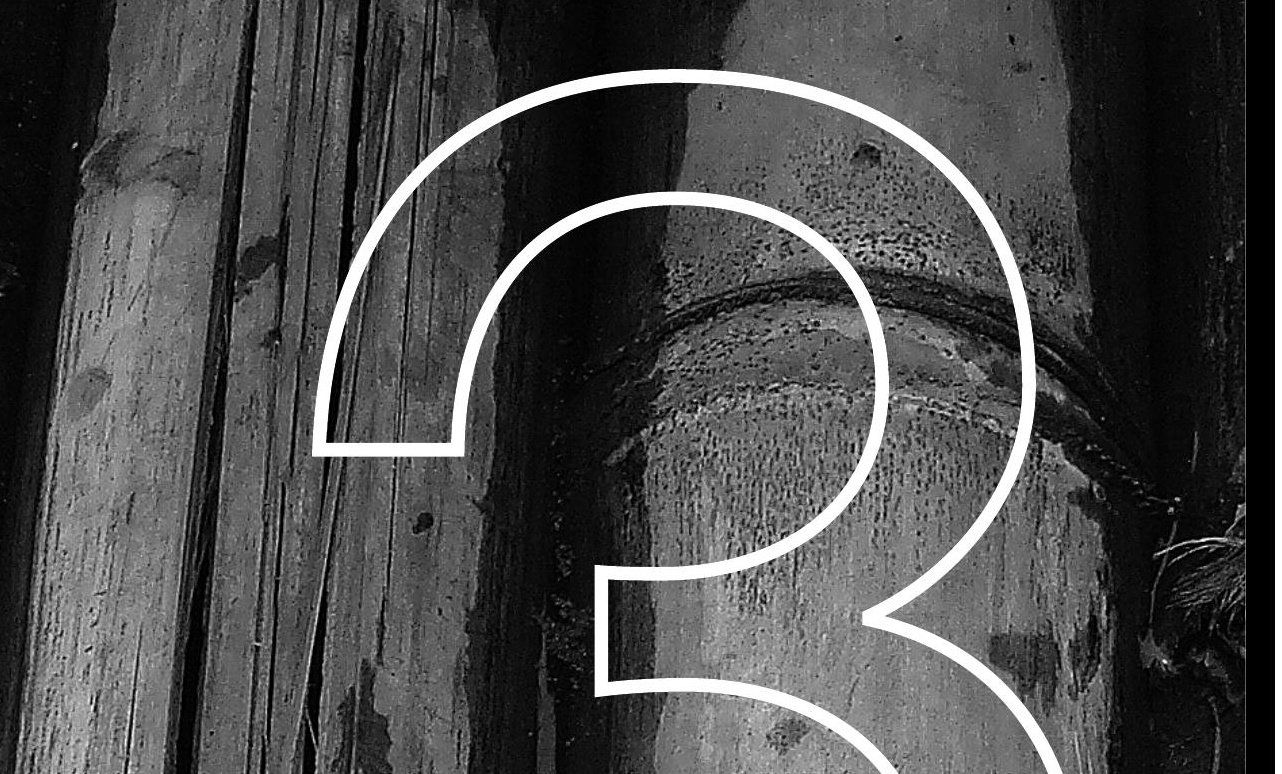


\section{Ankylosing spondylitis and the risk of fracture}

Results from a large primary care-based nested case control study 


\begin{abstract}
Background and Aims

Ankylosing spondylitis (AS) is associated with bone loss in the vertebrae and an increased prevalence of vertebral fractures, but literature about the magnitude of the risk of fracturing is limited. One retrospective cohort study provided evidence of an increased risk of clinical vertebral fractures but not for nonvertebral fractures. This study further explores the risk of clinical vertebral and non-vertebral fractures in a large population database.
\end{abstract}

\title{
Methods
}

In a primary care-based nested case-control study, 231,778 fracture cases and 231,778 age- and sexmatched controls were recruited. A history of AS was assessed from the medical records. AS was diagnosed in a total of 758 people. Odds ratios (OR) and $95 \%$ confidence intervals (Cl) were calculated after adjustment for medication, other illnesses, smoking and body mass index whenever known.

\section{Results}

The prevalence of AS was $0.18 \%$ in fracture cases and $0.15 \%$ in controls. Patients with AS had an increased risk of clinical vertebral fracture (OR: 3.26; $\mathrm{Cl}: 1.51-7.02)$. The risk for forearm and hip fracture was not significantly increased (OR: 1.21 [Cl: 0.87-1.69] and 0.77 [Cl: $0.43-1.37]$, respectively). The risk of any clinical fracture was increased in AS patients with a history of inflammatory bowel disease (IBD) (OR: 2.79, $\mathrm{Cl}:$ 1.10-7.08), whereas it was decreased in AS patients taking non-steroidal anti-inflammatory drugs (NSAID's) (OR: $0.65, \mathrm{Cl}: 0.50-0.84)$. The risk was not associated with recent back pain, psoriasis, joint replacement therapy and use of sulfasalazine.

\section{Conclusions}

Patients with AS have an increased risk of clinical vertebral fracture, but not of non-vertebral fractures, while in patients with concomitant IBD the risk of any clinical fracture is increased. The mechanism by which intake of NSAID's reduces the risk of any clinical fracture warrants further research. 


\section{INTRODUCTION}

Ankylosing spondylitis (AS) is a chronic inflammatory disease mainly of the axial skeleton and is characterised by osteoproliferation that increases the rigidity of the spine. ${ }^{1}$ AS is also associated with bone loss in the vertebrae and in the hip due to inflammation. ${ }^{2,3}$ Both the rigidity of the spine and bone loss in the vertebrae contribute to an increased vulnerability of the spine in patients with AS.

The reported prevalence of clinical vertebral fractures (CVF) varies between 10 and $17 \%$, but their occurrence has not yet been assessed in a systematic way. ${ }^{4-7,9-12}$ Cooper et al reported an increased odds ratio (OR) of 7.6 (95\% confidence interval (CI): 4.3-12.6) for CVF's on the basis of the radiologist's report, as found in the medical records of each of all 158 patients suffering from AS in the Rochester area between 1935 to $1989 .{ }^{4}$ Other studies indicate that wedged vertebral fractures measured on lateral spine radiographs contribute to hyperkyphosis. ${ }^{7,8}$ Furthermore, several studies reported a high prevalence (between 29 and 91\%) of major neurological complications after CVF's. ${ }^{6,11-14}$ Together, these data suggest not only that patients with AS have a higher risk of (clinical) vertebral fractures, but also that in AS - more frequently than in the healthy population or in patients with postmenopausal osteoporosis - a vertebral fracture may coincide with major neurological complications .

In order to evaluate the extent of the risk for clinical vertebral and nonvertebral fractures in AS we analysed the presence of AS and fractures in a primary care-based nested case-control study.

\section{PATIENTS AND METHODS}

The data in this study are derived from the General Practice Research Database (GPRD). ${ }^{15}$ This database comprises the entire computerized medical records of a sample of general practitioners in the UK. General practitioners play a key role in the health care system because they are responsible for primary health care and specialist referrals. The database comprises centralized information not only from the general practitioners themselves but also from specialist referrals and hospital attendances. This study included 683 practices currently incorporated in the GRPD and thereby comprises a $6 \%$ sample of the U.K. population. The data recorded in the GRPD include demographic information, prescription details, clinical events, preventive care provided, specialist referrals, hospital admissions, and major 
outcomes. Clinical data are stored and retrieved by means of Oxford Medical Information Systems and Read codes for diseases that are cross-referenced to the International Classification of Diseases (ICD-9). Data collection for the GRPD began in 1988 and, for this study ended in 1999.

A case-control study was conducted using information from the GRPD. Case patients were registered patients aged 18 years and older who had any clinical fracture in their medical records (vertebral-(wedge, crush or diabolo) or nonvertebral fracture). Control patients were adults without a history of fracture in their records. They were matched to case patients by age (within 1 year) and sex. A history of AS was assessed from the medical records (according to the modified New York criteria) ${ }^{16}$. The number of patients with AS was examined in both cases and controls. Prescriptions for non-steroidal anti-inflammatory drugs (NSAID's) and disease-modifying drugs (DMARD's) in the 6 months before the fracture date in patients or corresponding date for the controls were also evaluated. Furthermore, prescribing of bone-protective agents, including bisphosphonates, hormone replacement therapy and vitamin $D$ in the 6 months before, was examined. A medical history of diseases that are associated with AS, such as inflammatory bowel disease (IBD) and psoriasis, as well as history of back pain and joint replacement, were also assessed from the medical records.

\section{Statistics}

We used $\chi^{2}$ tests to test differences in proportions. Conditional logistic regression was used to estimate odds ratios (OR) for the risk of fracture in patients with AS. The analysis was controlled for a wide range of clinical variables and medication use that are possibly associated with the risk of fracture, including history of heart failure, cerebrovascular disease, diabetes mellitus, rheumatoid arthritis, psychotic disorder, depression, thyreotoxicosis, seizure and chronic obstructive pulmonary disease. Prescriptions in the 6 months before fracture for thiazides, hormone replacement therapy, nonsteroidal anti-inflammatory drugs, hypnotics/ anxiolytics, antipsychotics, antidepressants, antiepileptics, anti-Parkinson drugs, all inhaled corticosteroids and bronchodilators were also considered potential confounding variables. Smoking history and body mass index were also included if entered in the database. Because smoking history and body mass index were not part of the standard data collection, this information was missing for about half of the patients. 


\section{RESULTS}

A total of 231,436 fracture cases were selected and matched with 231,362 controls. In table 3.1 characteristics of cases and controls are shown. The groups were well matched for age and sex, but there were significant differences with regard to a number of potential confounders. The fracture cases used more medication, especially NSAIDs (13.9 vs. $9.1 \%)$, but also sulfasalazine (0.24 vs. $0.19 \%)$, corticosteroids ( 4.1 vs. $2.3 \%$ ) and hypnotics and anxiolytics ( 9.6 vs. $6.2 \%$ ), and had a higher number of relevant concomitant diseases such as IBD (0.5 vs. $0.4 \%$ ) and psoriasis (2.7 vs. $2.0 \%$ ). More fracture cases reported back pain in the preceding 6 months.

TABLE 3.1 Characteristics of fracture cases and controls

\begin{tabular}{|c|c|c|c|}
\hline Characteristics & $\begin{array}{l}\text { Fracture cases } \mathrm{n}(\%) \\
\qquad \mathrm{N}=231,436\end{array}$ & $\begin{array}{c}\text { Controls } \mathrm{n}(\%) \\
\mathrm{N}=231,362\end{array}$ & $\mathrm{p}$ value \\
\hline \multicolumn{4}{|l|}{ Age } \\
\hline$\leq 30$ & $51,573(22.3 \%)$ & $52,140(22.5 \%)$ & ns \\
\hline $31-45$ & $47,948(20.7 \%)$ & 47,885 (20.7\%) & ns \\
\hline $45-60$ & $40,965(17.7 \%)$ & 40,906 (17.6\%) & ns \\
\hline$\geq 61$ & $91,292(39.4 \%)$ & 90,847 (39.2\%) & ns \\
\hline \multicolumn{4}{|l|}{ Sex } \\
\hline Male & $110,163(47.5 \%)$ & $110,163(47.5 \%)$ & ns \\
\hline Female & $121,615(52.5 \%)$ & $12,1615(52.5 \%)$ & ns \\
\hline \multicolumn{4}{|l|}{ Drug use in 6 months before index date } \\
\hline Sulfasalazine & $564(0.19 \%)$ & $447(0.24 \%)$ & $<0.0005$ \\
\hline Nonsteroidal anti-inflammatory drugs & 32,209 (13.9\%) & $21,013(9.1 \%)$ & $<0.0001$ \\
\hline Oral glucocorticoids & $9,549(4.1 \%)$ & $5,264(2.3 \%)$ & $<0.0001$ \\
\hline Hypnotics / anxiolytics & $22,328(9.6 \%)$ & $14,466(6.2 \%)$ & $<0.0001$ \\
\hline \multicolumn{4}{|l|}{ Medical history } \\
\hline History of inflammatory bowel disease & $1,134(0.5 \%)$ & $896(0.4 \%)$ & $<0.0005$ \\
\hline Psoriasis & $6,373(2.7 \%)$ & $4,636(2.0 \%)$ & $<0.0001$ \\
\hline Recent back pain (previous 6 months) & $19,035(8.2 \%)$ & $10,362(4.5 \%)$ & $<0.0001$ \\
\hline Joint replacement therapy & $4,277(1.8 \%)$ & $2,946(1.3 \%)$ & $<0.0001$ \\
\hline
\end{tabular}

Ankylosing spondylitis was diagnosed in 758 patients, in 416 patients $(0.18 \%)$ of the fracture cases and in 342 patients $(0.15 \%)$ in the control patients $(p<0.05)$.

Table 3.2 summarizes age, sex, use of medications and relevant co morbidities for the AS patients with and without fractures. The AS patients with fractures tended to be somewhat older than the AS patients without fractures $(p=0.09)$ because of less patients younger than 30 years in the fracture group. They also used systemic 
corticosteroids more frequently ( $8.4 \%$ vs $4.1 \%)$, had IBD more frequently ( $4.8 \%$ vs $1.8 \%$ ) and suffered more frequently from back pain ( $17.3 \%$ vs $12 \%)$.

Table 3.3 provides the OR for any clinical fracture, as well as for clinical vertebral and non-vertebral fractures separately. Patients with AS had an increased crude risk of clinical vertebral fractures (OR: $3.08 ; \mathrm{Cl}: 1.56-6.08$ ) that remained significantly increased after adjustment for potentially confounding factors (OR: 3.26; $\mathrm{Cl}: 1.51-7.02)$ in comparison to persons without AS. The risk for forearm and hip fracture was not significantly increased (OR: $1.21 ; \mathrm{Cl}$ : 0.87-1.69 and 0.77; $\mathrm{Cl}$ : 0.43-1.37, respectively).

TABLE 3.2 Characteristics of fracture cases and controls with ankylosing spondylitis

\begin{tabular}{lccl}
\hline Characteristics & $\begin{array}{c}\text { Fracture cases } \mathrm{n}(\%) \\
\mathrm{N}=416\end{array}$ & $\begin{array}{c}\text { Controls } \mathrm{n}(\%) \\
\mathrm{N}=342\end{array}$ & $\mathrm{p}$ value \\
\hline Age & & & \\
$\quad \leq 30$ & $15(3.6 \%)$ & $27(7.9 \%)$ & $<0.02$ \\
$31-45$ & $91(21.9 \%)$ & $72(21.1 \%)$ & $\mathrm{ns}$ \\
$45-60$ & $121(29.1 \%)$ & $95(27.8 \%)$ & $\mathrm{ns}$ \\
$\geq 61$ & $189(45.4 \%)$ & $148(43.3 \%)$ & $\mathrm{ns}$ \\
Sex & & & \\
Male & $238(57.2 \%)$ & $204(59.6 \%)$ & $\mathrm{ns}$ \\
Female & $178(42.8 \%)$ & $138(40.4 \%)$ & $\mathrm{ns}$ \\
Drug use in 6 months before index date & & & \\
Sulfasalazine & $7(1.7 \%)$ & $9(2.6 \%)$ & $\mathrm{ns}$ \\
Nonsteroidal anti-inflammatory drugs & $171(41.1 \%)$ & $138(40.4 \%)$ & $\mathrm{ns}$ \\
Oral glucocorticoids & $35(8.4 \%)$ & $14(4.1 \%)$ & 0.02 \\
Hypnotics / anxiolytics & $58(13.9 \%)$ & $32(9.4 \%)$ & $\mathrm{ns}$ \\
Medical history & & & \\
History of inflammatory bowel disease & $20(4.8 \%)$ & $6(1.8 \%)$ & 0.04 \\
Psoriasis & $26(6.3 \%)$ & $17(5.0 \%)$ & $\mathrm{ns}$ \\
Recent back pain (previous 6 months) & $72(17.3 \%)$ & $41(12.0 \%)$ & 0.05 \\
Hip/knee joint replacement & $14(3.4 \%)$ & $16(4.7 \%)$ & $\mathrm{ns}$ \\
\hline
\end{tabular}


TABLE 3.3 Risk of fracture according to history of ankylosing spondylitis

\begin{tabular}{lcrccc}
\hline Fracture type & Ankylosing & No. of cases & No. of controls & Crude OR $(95 \% \mathrm{Cl})$ & Adjusted OR* $(95 \% \mathrm{Cl})$ \\
\hline Any & no & & & & \\
\multirow{2}{*}{ Radius/ulna } & yes & 231,436 & 231,362 & Reference & Reference \\
& no & 416 & 342 & $1.22(1.05-1.40)$ & $1.02(0.88-1.18)$ \\
Hip & yes & 82 & 44,119 & Reference & Reference \\
\multirow{2}{*}{ Vertebral } & no & 14,362 & 14,363 & Reference & Reference \\
& yes & 25 & 26 & $0.96(0.56-1.67)$ & $0.77(0.43-1.37)$ \\
& no & 8,701 & 8,678 & Reference & Reference \\
& yes & 34 & 11 & $3.08(1.56-6.08)$ & $3.26(1.51-7.02)$ \\
\hline
\end{tabular}

*Adjusted for medications and illnesses associated with fracture risk (as outlined in the methods), and smoking and body mass index, whenever known

In table 3.4 fracture risk has been stratified for relevant concomitant diseases and medications in patients with AS. The adjusted risk of any clinical fracture was increased in AS patients with a history of IBD (OR: 2.79, Cl: 1.10-7.08) but was decreased in AS patients taking non-steroidal anti-inflammatory drugs (NSAID's) (OR: 0.65, Cl: 0.50-0.84), although this protective effect became evident only after adjustment for confounding variables. The risk for any fracture was not associated with back pain, psoriasis, joint replacement therapy or use of sulfasalazine.

TABLE 3.4 Risk of any fracture in patients with ankylosing spondylitis stratified by history of inflammatory bowel disease, psoriasis or hip/knee joint replacement, GP visit for back pain in the 6 months before, or use of NSAID's or sulfasalazine in the 6 months before fracture.

\begin{tabular}{|c|c|c|c|c|}
\hline Characteristic & $\begin{array}{l}\text { No. of } \\
\text { cases }\end{array}$ & $\begin{array}{c}\text { No. of } \\
\text { controls }\end{array}$ & Crude OR $(95 \% \mathrm{Cl})$ & $\begin{array}{l}\text { Adjusted OR* } \\
(95 \% \mathrm{Cl})\end{array}$ \\
\hline History of inflammatory bowel disease & 20 & 6 & $\begin{array}{c}3.32 \\
(1.34-8.26)\end{array}$ & $\begin{array}{c}2.79 \\
(1.10-7.08)\end{array}$ \\
\hline History of psoriasis & 26 & 17 & $\begin{array}{c}1.52 \\
(0.83-2.80)\end{array}$ & $\begin{array}{c}1.23 \\
(0.65-2.34)\end{array}$ \\
\hline Knee-hip joint replacement & 14 & 16 & $\begin{array}{c}0.88 \\
(0.43-1.81)\end{array}$ & $\begin{array}{c}0.77 \\
(0.37-1.62)\end{array}$ \\
\hline GP visit for back pain in the 6 months before & 72 & 41 & $\begin{array}{c}1.76 \\
(1.20-2.58)\end{array}$ & $\begin{array}{c}1.33 \\
(0.89-1.98)\end{array}$ \\
\hline Use of NSAIDs in the 6 months before & 126 & 122 & $\begin{array}{c}1.03 \\
(0.81-1.33)\end{array}$ & $\begin{array}{c}0.65 \\
(0.50-0.84)\end{array}$ \\
\hline Use of sulfasalazine in the 6 months before & 7 & 9 & $\begin{array}{c}0.78 \\
(0.29-2.09)\end{array}$ & $\begin{array}{c}0.51 \\
(0.19-1.41)\end{array}$ \\
\hline
\end{tabular}

*Adjusted for medications and illnesses associated with fracture risk (as outlined in the methods), and smoking and body mass index, whenever known 


\section{DISCUSSION}

In this study we have shown that patients with a diagnosis of AS have an increased risk of clinical vertebral fractures without an increased risk of non-vertebral fractures. This is in line with the literature ${ }^{4}$ that, in AS, an increased risk for fractures is limited to the axial skeleton. Although the AS patients tended to be somewhat older than the control patients, the increased risk remained after adjustment for age. Similarly, as shown in the analysis other variables did not importantly confound the observed effect, which adds to the validity of the findings. Interestingly, the risk of any clinical fracture was increased in AS patients with concomitant IBD. In contrast, the risk of any clinical fracture was decreased in AS patients taking NSAID's.

With this primary care-based nested case-control study, we could confirm earlier findings in smaller groups of patients with AS. First, Cooper et al have described an increased risk compared to the normal population of spinal deformities (compression, wedging or collapse of one or more thoracic or lumbar vertebral bodies). We have described 59 AS patients reporting clinical vertebral fractures, already early in the disease, mainly without or after minimal trauma. ${ }^{6}$ These data underline the greater spinal vulnerability of patients with AS with respect to clinical vertebral fractures. As mentioned before increasing evidence supports the view that changes in the biomechanical properties of the spine, such as osteoporosis, which renders the vertebrae prone to fracture, and osteoproliferation, which renders the spine less flexible, may play an important intermediate role. We have reported earlier that wedged vertebral fractures are related to radiographic signs of osteoproliferation, indicating that - at least in part - an increased risk of fracture could be associated with more extensive disease. ${ }^{8}$ The observation that patients using systemic glucocorticoids and those with recent back pain had more fractures underpins the hypothesis of an increased risk for fractures in inflammatory disease, as has been shown in patients with RA. ${ }^{17}$ While patients with AS have an increased fracture risk limited to the spine, those with AS plus associated IBD have an increased risk of both vertebral and non-vertebral fractures. Schoon et al identified several clinical risk factors for low BMD in patients with IBD, especially Crohn's disease. ${ }^{18}$ They also showed that patients with recent onset of IBD had normal $B M D$, suggesting that low BMD develops in the course of the disease process. ${ }^{19}$ Heijckmann et al reported a high prevalence of vertebral deformities in Crohn's disease and ulcerative colitis, especially in older IBD patients. This was associated with higher glucocorticoids use. ${ }^{20}$ 
We used the GPRD database to select our patients. Validity of results is directly associated with the quality of the data. The data quality of each entry into the GRPD is measured against specific targets to ensure research standards are met.. Only data from practices that pass this quality control are compiled to form the GRPD database. ${ }^{21,22}$ A problem in a cohort study could be that previous selection may not be ruled out. By taking a very large sample we assume that possible bias is equally distributed in both groups. Theoretically, our results may have been biased by an inappropriate classification of AS. An argument that adds to the validity of our results is that we have found a positive relationship between a diagnosis of AS and the presence of a clinical fracture that was entirely in line with our primary hypothesis. Any relevant misclassification of AS would have resulted in a lack of association rather than in the spurious opposite. Furthermore, we incorporated as many confounders known in osteoporosis and AS research as possible to be able to adjust for these factors in the statistical analysis. A broad spectrum of medication and concomitant diseases were taken into account. These items seemed to be equally divided in both groups. Due to the very large sample (nearly half a million ) small proportional differences between groups could have had a large influence on the results, especially if this happened in one group (e.g. the AS with fractures group) preferably. Fortunately, the groups of AS patients with and without fractures were comparable in most aspects.

Taken together these data point to a "dose response effect" of chronic inflammatory diseases with respect to fracture risk. AS conveys a fracture risk to vertebral fractures. Concomitant Crohn's disease which is considered a more systemic disease, and that is more frequently treated with systemic corticosteroids, adds to this moderate risk, which is reflected by a higher fracture rate for vertebral and non-vertebral fractures. Another interesting observation is the protective effect of NSAID use on the fracture risk. It is well-known that NSAID's reduce the risk of heterotopic bone formation after hip arthroplasty. ${ }^{22}$ In one study continuous use of NSAID's decreased the formation of syndesmophytes thus preventing progressive rigidity of the spine, with decreased vulnerability as a consequence. ${ }^{23}$ In the orthopaedic literature the influence of NSAID's on fracture repair in mouse models has been described. ${ }^{24,25}$ Herein, it is suggested that the influence of NSAID's on bone metabolism is dose-depending. Unfortunately, we were not able to investigate a dose-response relation in our group of patients using NSAID's due to insufficient information on the dose. One other possible explanation could be that relief of inflammatory back pain and stiffness, as well as the resulting improved physical function due to NSAID use may help in maintaining bone mass by improved physi- 
cal activity. Another positive effect of improved physical condition could be a reduced risk of falling. Data suggest that a program of muscle strengthening and balance training decreased fall risk, and the use of NSAID's could have a positive effect. $^{26,27}$

In contrast to the situation in patients with RA, pharmaceutical treatment of osteoporosis in patients with AS is not yet common practice. Data that support the efficacy of osteoporosis treatment in AS are scarce. Our findings, and those of others, point to a role of osteoporosis, possibly in combination with osteoproliferation, in the occurrence of vertebral fractures in AS. This study highlights the need to develop strategies to identify patients with AS with a risk of vertebral fractures, both in terms of osteoporosis as well as excessive osteoproliferation. Doing so appropriate treatment intervention studies can be designed. The mechanism by which NSAID use is associated with reduced risk of clinical fractures warrants further research. 


\section{REFERENCES}

1. Sieper J, Appel H, Braun J, Rudwaleit M. Critical appraisal of assessment of structural damage in ankylosing spondylitis. Arthritis Rheum 2008;58:649-56

2. Will R, Palmer R, Bhalla AK, Ring EFJ, Calin A. Osteoporosis in early ankylosing spondylitis: a primary pathologic event? Lancet 1989 Dec 23/30; 2:1483-5

3. Bessant $R$, Keat $A$. How should clinicians manage osteoporosis in ankylosing spondylitis? J Rheumatol 2002;29:1511-9

4. Cooper C, Carbone L, Michet CJ, Atkinson EJ, O'Fallon WM, Melton LJ 3rd. Fracture risk in patients with ankylosing spondylitis: a population based study. J Rheumatol 1994;21:1877-82

5. Ralston SH, Urquhart GDK, Brzeski M, Sturrock RD. Prevalence of vertebral compression fractures due to osteoporosis in ankylosing spondylitis. BMJ 1990;300:563-5

6. Vosse D, Feldtkeller E, Erlendsson J, Geusens P, van der Linden S. Clinical vertebral fractures in patients with Ankylosing Spondylitis. J Rheumatol. 2004 Oct;31(10):1981-5.

7. Geusens P, Vosse D, van der Heijde DM, Vanhoof J, van Tubergen A, Raus J, van der Linden S. High prevalence of thoracic vertebral deformities and discal wedging in ankylosing spondylitis patients with hyperkyphosis. J Rheumatol 2001;28:1856-61

8. Vosse D, van der Heijde DM, Landewé R, Geusens P, Mielants M, Dougados M, van der Linden S. Determinants of hyperkyphosis in patients with Ankylosing Spondylitis. Ann Rheum Dis 2006;65:770-4. doi:10.1136/ard.2005.044081

9. Donnelly S, Doyle DV, Denton A, Rolfe I, McCloskey EV, Spector TD. Bone mineral density and vertebral compression fracture rates in ankylosing spondylitis. Ann Rheum Dis 1994;53:117-21

10. Mitra D, Elvins DM, Speden DJ, Collins AJ. The prevalence of vertebral fractures in mild ankylosing spondylitis and their relationship to bone mineral density. Rheumatology 2000;39:85-9

11. Hitchon PW, From AM, Brenton BS, Glaser JA, Torner JC. Fractures of the thoracolumbar spine complicating ankylosing spondylitis. J Neurosurg (Spine) 2002;97:218-22

12. Hunter T, Dubo HIC. Spinal fractures complicating ankylosing spondylitis. A long-term follow-up study. Arthritis Rheum 1983;26:751-9

13. Fox MW, Onofrio BM, Kilgore JE. Neurological complications of ankylosing spondylitis. J Neurosurg 1993;78:871-814. Graham B, van Peteghem PK. Fractures of the spine in ankylosing spondylitis. Diagnosis, treatment and complications. Spine 1989;14:803-7

15. Walley T, Mantgani A. The UK General Practice Research Database. Lancet 1997;350:1097-9

16. van der Linden SM, Valkenburg HA, de Jongh BM, Cats A. The risk of developing ankylosing spondylitis in HLA-B27 positive individuals: a comparison of relatives of spondylitis patients with the general population. Arthritis Rheum 1984;27:241-9

17. van Staa TP, Geusens P, Bijlsma JW, Leufkens HG, Cooper C. Clinical assessment of the long-term risk of fracture in patients with rheumatoid arthritis. Arthritis Rheum 2006;54:3104-12

18. Schoon EJ, van Nunen AB, Geusens $P$, Stockbrügger RW, Russel MGVM. Clinical determinants of bone mineral density in Crohn's disease. (thesis) Maastricht (the Netherlands): University of Maastricht; 2001

19. Schoon EJ, Blok BM, Geerling BJ, Russel MG, Stockbrügger RW, Brummer R-JM. Bone mineral density in patients with recently diagnosed inflammatory bowel disease. Gastroenterology 2000;199:1203-8

20. Heijckmann AC, Huijberts MSP, Schoon EJ, Geusens P, de Vries J. Menheere PPCA, van der Veer E, Stockbrügger RW, Dumitrescu B,Nieuwenhuijzen Kruseman AC. High prevalence of morphometric vertebral deformities in patients with inflammatory bowel disease. Eur J Gastroenterol Hepatol, in press 
21. van Staa TP, Abenheim L. The quality of information recorded on a UK database of primary care records: a study of hospitalization due to hypoglycaemia and other conditions. Pharmacoepidemiol Drug Saf 1994;3:15-21

22. van Staa TP, Abenheim L, Cooper C, Begaud B, Zhang B, Leufkens HG. The use of a large pharmacoepidemiological database to study exposure to oral corticosteroids and risk of fractures: validation of study population and results. Pharmacoepidemiol Drug Saf 2000;9:359-66

22. Neal B, Rodgers A, Dunn L, Fransen M. Non-steroidal anti-inflammatory drugs for preventing heterotopic bone formation after hip arthroplasty. Cochrane Database Syst Rev 2000:CD001160

23. Wanders A, van der Heijde D, Landewé R, Béhier J-M, Calin A, Olivieri I, Zeidler H, Dougados M. Non-steroidal anti-inflammatory drugs inhibit radiographic progression in patients with ankylosing spondylitis: A randomised clinical trial. Arthritis Rheum 2005;52:1756-65

24. Aspenberg P. Drugs and fracture repair. Acta Orthop 2005;76:741-8

25. Gaston MS, Simpson AHRW. Inhibition of fracture healing. J Bone Joint Surg (Br) 2007;89B(12):1553-60. doi: 10.1302/0301-620X.89B12.19671

26. Gillespie LD, Gillespie WJ, Robertson MC, Lamb SE, Cumming RG, Rowe BH. Interventions for preventing falls in elderly people. Cochrane Database Syst Rev 2003;(4):CD000340.

27. Wolf SL, Sattin RW, Kutner M, O'Grady M, Greenspan Al, Gregor RJ. Intense tai chi exercise training and fall occurrences in older, transitionally frail adults: a randomized, controlled trial. J Am Geriatr Soc 2003 Dec;51(12):1693-701. 
ChaPter 3 RISK of fracture 
(1) 414
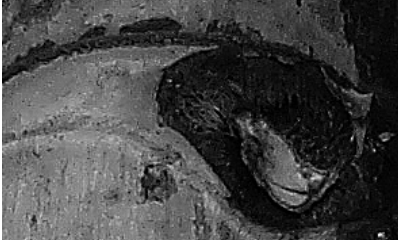

-

itis

$-7$

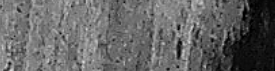

9)19

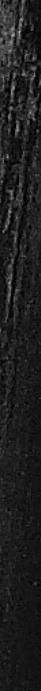

3)

$$
\text { ( }
$$

(1.

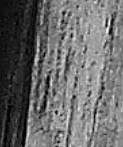

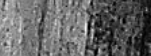




\section{Measurement of spinal mobility in ankylosing spondylitis Comparison of occiput-to-wall and tragus-to-wall distance}

L. Heuft-Dorenbosch, D. Vosse, R. Landewé, A. Spoorenberg, M. Dougados, H. Mielants, H. van der Tempel, S. van der Linden, D. van der Heijde 


\section{ABSTRACT}

\section{Objective}

To investigate if the tragus-to-wall distance (TWD) is more reliable compared to the occiput-to-wall distance (OWD) as a measurement for thoracic spine extension in ankylosing spondylitis (AS).

\section{Methods}

Data from the OASIS cohort, an international, longitudinal, observational study on outcome in AS, were used. Measurements of OWD and TWD were performed at baseline and at 6,12,18 and 24 months. Paired data of $T_{x}$ and $T_{x+6}$ months were used to perform test-retest measurements (intra-class correlations, limits of agreement and interperiod correlation matrix). Bland and Altman plots were constructed to investigate the agreement between both observations, assuming that there was no true change between 0 and 6 months. To investigate whether a change in disease activity would have influenced the results, limits of agreement were calculated in a subgroup of patients with a stable Bath ankylosing spondylitis disease activity index (BASDAI; defined as a maximum BASDAl change of \pm 1 ) between $T_{0}$ and $T_{6}$ and compared with the results of the whole group.

Limits of agreement were also calculated for kyphosed patients only.

\section{Results}

The test-retest intraclass correlations were between 0.94-0.96 for OWD and between 0.93-0.95 for TWD. The direct measurement-remeasurement correlation calculated by extrapolation of the interperiod correlation regression line was 0.92 for OWD and 0.90 for TWD. OWD and TWD showed comparable reliability on the entire value of scores. The lower $95 \%$ limit of agreement was between $-3.4 \mathrm{~cm}$ and $-2.5 \mathrm{~cm}$ for OWD and between $-3.4 \mathrm{~cm}$ and $-3.1 \mathrm{~cm}$ for TWD. The upper limit of agreement was between $3.1 \mathrm{~cm}$ and $4.2 \mathrm{~cm}$ for OWD and between $2.9 \mathrm{~cm}$ and $3.9 \mathrm{~cm}$ for TWD. In all patients as well as in kyphosed patients only, limits of agreement were comparable between OWD and TWD. The patterns of the scatterplots according to Band and Altman were similar for OWD and TWD. Measurement error was more pronounced in kyphosed patients compared to patients with a normal thoracic extension. However, over the entire range of kyphosis, measurement error was similar.

\section{Conclusions}

OWD and TWD are equally reliable in assessing thoracic spine extension. Although the TWD is in general easier to perform in AS patients compared to OWD, we recommend the OWD measurement over TWD: in OWD measurement a value of zero easily distinguishes patients with normal thoracic spine extension from kyphosed patients. 


\section{INTRODUCTION}

Reduced spinal mobility and changes in posture are characteristic features of ankylosing spondylitis (AS). The typical patient with AS has a reduced lumbar lordosis and an increased thoracic kyphosis, and as a result the head is somewhat bent forward. In the course of the disease process these postural changes tend to progress and may become irreversible due to structural changes of the spine. To quantify thoracic kyphosis, the distance between occiput and wall (occiput-to-wall distance, OWD) is assessed when the patient is standing erect with stretched knees and the back against the wall. OWD is a measure for thoracic spine extension ${ }^{1}$ and was selected as a core set instrument by the Assessment of Spondylo Arhritis international Society (ASAS)-working group. This is an international working group of clinical experts, clinical epidemiologists, representatives of the pharmaceutical industry, and representatives of patient associations. This core set was selected in 1998, and consists of different domains with specific instruments per domain, and is to be used in various settings in clinical studies in AS. To assess the domain of spinal mobility, the ASAS working group selected three instruments as core set instruments. ${ }^{2}$ In addition to the OWD, these instruments are chest expansion and modified Schober test.

In clinimetrics, important features of an instrument are (construct) validity, reliability and responsiveness. ${ }^{3}$ Reliability (synonyms: reproducibility, repeatability) is an expression of the extent to which similar results are obtained on repeated applications of the same assessment technique, assuming no true interval change in the phenomenon under study. ${ }^{1}$

An other way to assess thoracic spine extension is by measuring the tragus-towall distance (TWD). Although not included in the core set, this is part of the Bath ankylosing spondylitis metrology index (BASMI) which is also widely used. ${ }^{4,5}$

There are some arguments that favor TWD over OWD measurement. Together with thoracic spine extension, involuntary flexion and extension of the head can occur. Flexion and extension of the head take place in the atlanto-occipital joint and the cervical spinal joints and can interfere with the measurement of both OWD and TWD. We hypothesized that compared to the measurement of TWD, the measurement of OWD would be more influenced by concomitant flexion or extension of the head. The explanation for this lies in the fact that, compared to the occiput, the tragus lies closer to the sagittal axis of the flexion or extension movements (Figure 4.1). On the other hand, TWD might be influenced by unintended rotation of the head. Second, the OWD is more difficult to measure since the 
patient's hair frequently obscures the view of the occiput. Third, with the patient standing erect against the wall, if the OWD is small, the observer's view of the ruler is difficult and prone to parallax problems. Because of these arguments we wanted to test the hypothesis that the TWD instrument would be more reliable than the OWD as a measurement for thoracic spine extension.

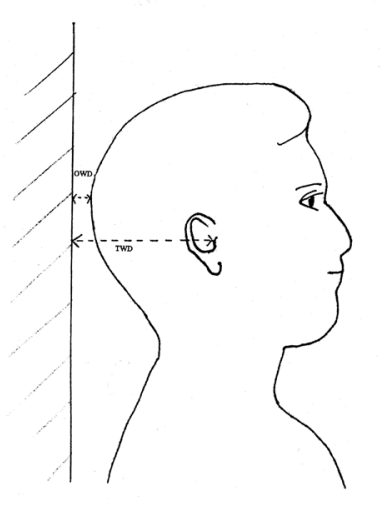

\section{PATIENTS AND METHODS}

\section{Patients}

In our study we used the data from the OASIS cohort, an international longitudinal observational study on outcome in AS with follow-up visits according to a fixed protocol. Data from this cohort have been reported. ${ }^{6}$ Participating centers are the University Hospital Maastricht, the Netherlands, the Maasland Hospital, Sittard, the Netherlands; Hospital Cochin, Paris, France; Universital Hospital Gent, Belgium; which are all secondary and tertiary referral centers. Consecutive outpatients with an established diagnosis of AS according to the modified New York criteria were enrolled in 1996 and followed thereafter.

For this study we used data from visits at baseline $\left(T_{0}\right)$ and at $6\left(T_{6}\right), 12\left(T_{12}\right), 18$ $\left(T_{18}\right)$ and 24 months $\left(T_{24}\right)$. On each study visit, all patients completed a number of questionnaires and underwent a clinical examination. The same investigator performed all clinical examinations per country. In addition to the core set variables propagated by the ASAS working group, several additional measurements were done, including the TWD. 


\section{Occiput-to-wall distance}

The patient stands with heels and buttocks touching the wall behind and with the knees straight. The patient is asked how far back he/she can get the head still keeping the chin in the normal position. In the straight position, the distance between the posterior convexity of the occiput and the wall is measured to the nearest 0.1 centimeter using a rigid ruler. ${ }^{1}$ The better of two attempts is recorded.

\section{Tragus-to-wall distance}

The patient is positioned as in measurement of the OWD. The distance between the tragus and the wall is measured to the nearest 0.1 centimeter using a rigid ruler. ${ }^{1}$ The better of two attempts is recorded.

In our study, measurement of TWD immediately followed measurement of OWD without repositioning the patient. However, we are comparing assessments with an interval of six months, and obviously there was repositioning between the first and second assessment of the OWD and the TWD. Therefore, measurement variability due to repositioning (including flexion and rotation of the head) is included in the overall measurement error.

\section{Statistical analysis}

We first assessed the mean, range, and standard deviation of both OWD and TWD. Because of the character of the disease, with slow disease progression, we assumed on a group level that no relevant changes in spinal mobility occurred during a time interval of six months, and thus changes in this time interval would be due to measurement error rather than to real changes in spinal mobility. As we did not perform a true test-retest measurement to assess the measurement error of both the OWD and TWD, we used the paired data of $T_{x}$ and $T_{x+6 m o n t h s}$. To determine if it was appropriate to do so, we used several methods. First, random-effect singlemeasure intraclass correlations (ICC; type 2.1) were calculated for $T_{x}$ and $T_{x+6 \text { months. }}$ Second, an interperiod correlation matrix was constructed. By this method the intercorrelation of the measurement periods are plotted against the intervening time intervals. These correlations can be linearly related to time, which may be represented by a well-fitting regression line. Extrapolation of this line through the $y$-axis gives the direct measurement-remeasurement correlation, which may be interpreted as a quality measure of the measurement. ${ }^{7}$ This was done twice, first for all patients, then only for patients not able to reach normal thoracic extension. Third, limits of agreement as defined by Bland and Altman (explained below) were calculated in all patients with a stable Bath Ankylosing Spondylitis Disease Activity 
Index (BASDAI) score (defined as a maximum BASDAl change of \pm 1 ) between $T_{0}$ and $T_{6}$. The results of this analysis were compared with the results of the whole group. To visualize the agreement between two observations and to check if observed differences are similar along the total range of scores, we plotted for all patients the difference between the score at $T_{0}$ and at $T_{6}$ of the OWD and the TWD against each patient's mean of the two scores. This graphic representation by means of a scatterplot of two measurements is called Bland-Altman plot. In this method the difference between two observations (on the $y$-axis) is plotted against the mean of the same two observations (on the $x$-axis). Discrepancies between the observations are thus visualized as well as any possible relationship between the various parts of the scale and the corresponding measurement error. The advantage compared to a simple plot of the results of one method against the other is that in this latter method the data points will usually be clustered and between- method differences are difficult to assess. Thereafter we calculated the limits of agreement for OWD and TWD based on the $95 \%$ limits of agreement method by Bland and Altman using the formula: $\bar{d} \pm 1.96 \times s d_{\text {diff }}$, where $\bar{d}$ represents the mean difference between the two observations and $s d_{\text {diff }}$ the standard deviation of the difference. ${ }^{8}$ Similar plots were made for the measurements comparing $T_{6}$ and $T_{12}, T_{12}$ and $T_{18}, T_{18}$ and $T_{24}$. In contrast with the OWD, which is zero in all patients with normal thoracic spine extension, the minimum TWD depends on the size of the head and the position of the ear. In patients able to touch the wall with their occiput, the possibility for measurement error due to patient variance seems to be smaller compared to patients not able to touch the wall, as the wall gives stability to the head. Thus a high proportion of patients with an OWD $=0$ may result in smaller limits of agreement. In daily practice the assessment of both OWD and TWD will largely be used in kyphosed patients. Thus we also calculated the limits of agreement for kyphosed patients exclusively. To be able to compare TWD with OWD in the same patients, we selected all patients based on an OWD $>0$ for calculations of limits of agreement for both OWD and TWD.

To assess whether the OWD and TWD instruments behave differently in different ranges of the scale, limits of agreement were calculated for the entire range of values, as well as for every quartile. 


\section{RESULTS}

At baseline, 217 patients were included. Characteristics of the patients are presented as mean with standard deviation (SD), or as median with interquartile range if appropriate (Table 4.1). The test-retest ICC was between 0.94 and 0.96 for OWD and between 0.93 and 0.95 for TWD. The direct measurement-remeasurement correlation calculated by extrapolation of the regression line was 0.92 for OWD and 0.90 for TWD. With calculations only for kyphosed patients, these figures were 0.88 for OWD and 0.92 for TWD.

TABLE 4.1 Baseline characteristics and scores on ASAS core set measures (Mean (SD)).

\begin{tabular}{|c|c|}
\hline & $\begin{array}{l}\text { Total study population } \\
(n=217)\end{array}$ \\
\hline Male / female & $150 / 67$ \\
\hline Age [years] & $43.1(12.7)$ \\
\hline Duration of complaints [years] & $19.6(11.8)$ \\
\hline Time since diagnosis [years] & $10.8(8.9)$ \\
\hline HLA B27 [present / absent / no data] & 155 / 32 / 30 \\
\hline History of IBD [present / absent / no data] & 17 / 145 / 55 \\
\hline History of uveitis [present / absent / no data] & $81 / 133 / 3$ \\
\hline History of psoriasis [present / absent / no data] & $10 / 152$ / 55 \\
\hline BASFI [0-10] & $3.4(2.6)$ \\
\hline VAS pain of the spine $(0-10)[\mathrm{cm}]$ & $3.5(2.4)$ \\
\hline Night pain [4 point likert] ${ }^{\mathrm{a}}$ (IQR) & $1.0(1.0-2.0)$ \\
\hline Chest expansion [cm] & $4.7(2.2)$ \\
\hline $10 \mathrm{~cm}$ Schober $[\mathrm{cm}]$ & $2.8(1.4)$ \\
\hline Tragus-to-wall distance $[\mathrm{cm}]^{\mathrm{a}}(\mathrm{IQR})[$ range $]$ & $12.5(11.0-16.0)[8.2-34.4]$ \\
\hline Occiput-to-wall distance [cm] ${ }^{\mathrm{a}}(\mathrm{IQR})[$ range] & $1.6(0.0-6.0)[0.0-26.1]$ \\
\hline VAS patient global $(0-10)[\mathrm{cm}]$ & $3.5(2.8)$ \\
\hline Peripheral arthritis [present / absent] ${ }^{b}$ & $57 / 160$ \\
\hline ESR $[\mathrm{mm} / \mathrm{hr}]^{\mathrm{a}}$ (interquartile range) & $10(5-19)$ \\
\hline $\mathrm{CRP}[\mathrm{mg} /]^{\mathrm{a}}$ (interquartile range) $^{\mathrm{a}}$ & $7(6-19)$ \\
\hline VAS physician on disease activity ${ }^{a}$ [0-10] (interquartile range) & $1.4(0.5-3.3)$ \\
\hline VAS patient on disease activity $(0-10)[\mathrm{cm}]$ & $3.8(2.8)$ \\
\hline Duration of morning stiffness [min] & $36(30)$ \\
\hline
\end{tabular}

Figure 4.2 shows this regression line for all patients. Scatterplots according to Band and Altman are shown for OWD and TWD for all patients for the comparison of $T_{0}$ 
and $T_{6}$ in Figures 4.3 and 4.4 respectively. The patterns of the plots were roughly similar for OWD and TWD. There is no influence of the magnitude of the OWD or TWD on the measurement error, i.e., the measurement error is similar along the entire scale. The summary results for the average scores and differences as well as the $95 \%$ limits of agreement comparing baseline and $T_{6}, T_{6}$ and $T_{12}, T_{12}$ and $T_{18}$ and $T_{18}$ and $T_{24}$ are shown in Table 4.2. Results were comparable between all paired observations. Comparing OWD and TWD at various time intervals, there is no consistent difference between the means and the SD in either the upper or the lower limit of agreement. As well, the limits of agreement for both OWD and TWD in all patients did not differ importantly. The lower $95 \%$ limit of agreement was between $-3.4 \mathrm{~cm}$ and $-2.5 \mathrm{~cm}$ for OWD and between $-3.4 \mathrm{~cm}$ and $-3.1 \mathrm{~cm}$ for TWD. The upper limit of agreement was between $3.1 \mathrm{~cm}$ and $4.2 \mathrm{~cm}$ for OWD and between $2.9 \mathrm{~cm}$ and $3.9 \mathrm{~cm}$ for TWD (Table 4.3).

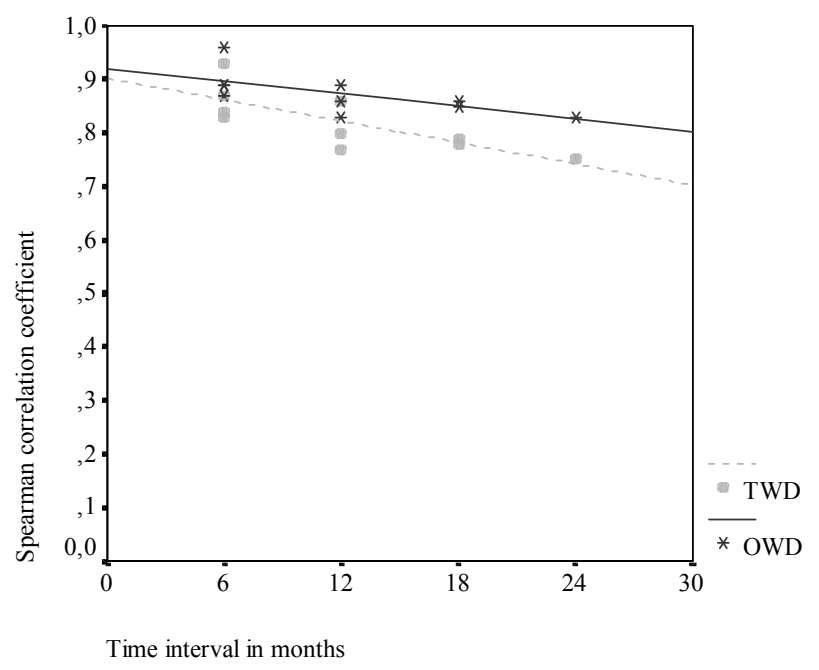

FIGURE 4.2 Graph of the spearman correlation coefficient against each interperiod with regression line for OWD and TWD. 


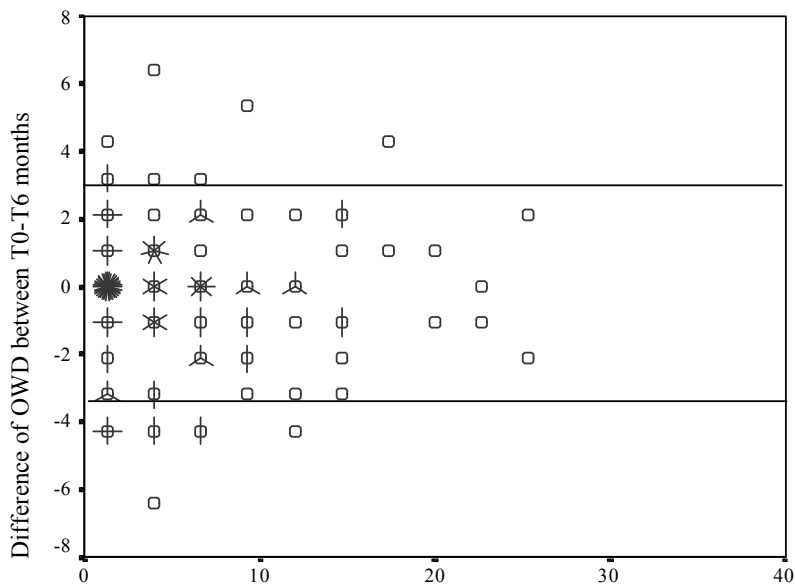

Mean OWD for T0-T6 months in centimeters

FIGURE 4.3 Graph of the difference scores against the mean score of OWD in $\mathrm{cm}$ in all patients. The upper line is indicating the upper limit (+2 SD) and the lower line (-2 SD) the lower limit of the $95 \%$ of agreement interval. $\square$ is representing one patient; each additional spike of the sunflower is representing an additional patient. (For example the data point the most left in the lower part of the figure below the line of -2SD is representing five patients).

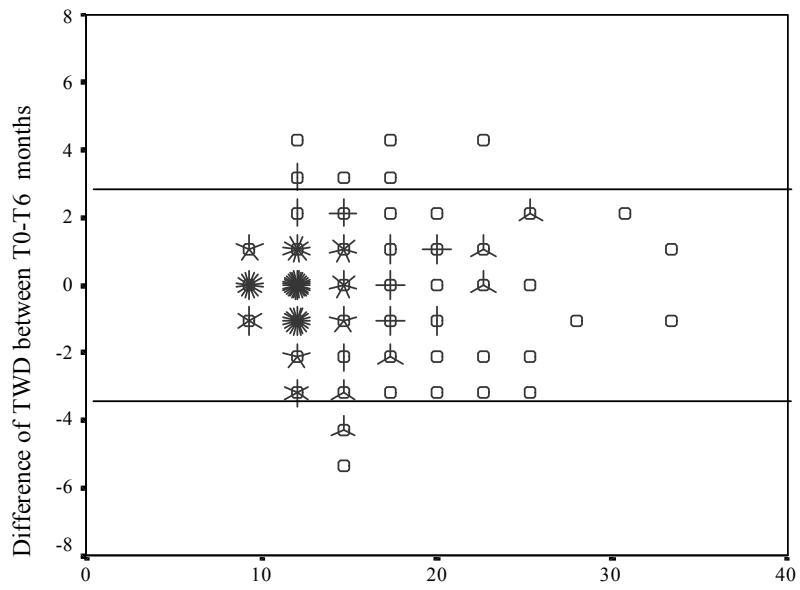

Mean TWD for T0-T6 months in centimeters

FIGURE 4.4 Graph of the difference scores against the mean score for TWD in $\mathrm{cm}$ in all patients, each spike of the sunflower representing one case. 
TABLE 4.2 Summary statistics of the average scores of occiput-to-wall distance (OWD) and tragus-towall distance (TWD) with a six months interval, summary statistics of the difference scores of OWD and TWD with a six months interval and 95\% limits of agreement of scores of OWD and TWD with a six months interval of 217 patients.

\begin{tabular}{|c|c|c|c|c|}
\hline \multirow[t]{2}{*}{ Paired data } & \multicolumn{2}{|c|}{$\begin{array}{l}\text { Average of the } 2 \text { observations } \\
\text { in } \mathrm{cm}^{\text {a }}\end{array}$} & \multirow{2}{*}{$\begin{array}{c}\text { Difference of paired } \\
{\text { observations in } \mathrm{cm}^{\text {b }}}^{\text {Mean }(S D)^{c}}\end{array}$} & \multirow{2}{*}{$\begin{array}{l}\text { 95\% limits of } \\
\text { agreement of paired } \\
\text { observations in } \mathrm{cm}\end{array}$} \\
\hline & Mean (SD) & Median (min; max) & & \\
\hline OWD $\mathrm{T}_{0}-\mathrm{T}_{6}$ & $3.8(5.5)$ & $1.2(0.0 ; 24.9)$ & $-0.2(1.7)$ & $-3.4 ; 3.1$ \\
\hline TWD $T_{0}-T_{6}$ & $14.2(4.7)$ & $12.2(8.2 ; 34.0)$ & $-0.2(1.6)$ & $-3.4 ; 2.9$ \\
\hline OWD $\mathrm{T}_{6}-\mathrm{T}_{12}$ & $3.8(5.6)$ & $1.4(0.0 ; 25.9)$ & $0.6(1.8)$ & $-2.9 ; 4.2$ \\
\hline TWD T $_{6}-\mathrm{T}_{12}$ & $14.0(4.8)$ & $12.3(7.5 ; 34.0)$ & $0.3(1.8)$ & $-3.3 ; 3.9$ \\
\hline $\mathrm{OWD} \mathrm{T}_{12}-\mathrm{T}_{18}$ & $4.1(5.7)$ & $2.0(0.0 ; 28.2)$ & $0.2(1.7)$ & $-3.1 ; 3.5$ \\
\hline $\mathrm{TWD}_{12}-\mathrm{T}_{18}$ & $14.3(5.1)$ & $12.6(6.5 ; 35.0)$ & $0.4(1.8)$ & $-3.1 ; 3.9$ \\
\hline OWD T $18-\mathrm{T}_{24}$ & $4.4(5.9)$ & $2.5(0.0 ; 29.5)$ & $0.4(1.5)$ & $-2.5 ; 3.3$ \\
\hline $\mathrm{TWD}_{18}-\mathrm{T}_{24}$ & $14.6(5.4)$ & $12.9(6.4 ; 39.0)$ & $0.3(1.7)$ & $-3.1 ; 3.7$ \\
\hline
\end{tabular}

${ }^{a}$ Average score of the two observations = (observation $1+$ observation 2 ) divided by $2 ;{ }^{b}$ Difference score between the two observations = observation 1 minus observation $2 ;{ }^{c}$ SD of the difference scores (i.e. the $S D_{\text {difference }}$ ) which is an estimate of random measurement error used to calculate the $95 \%$ limits of agreement.

TABLE 4.3 95\% limits of agreement for the whole group of patients and $95 \%$ limits of agreement for the group of patients with OWD>0.

\begin{tabular}{|c|c|c|}
\hline Paired data & $\begin{array}{l}\text { 95\% limits of agreement of paired } \\
\text { observations in all patients in } \mathrm{cm} \\
\qquad \mathrm{n}=217\end{array}$ & $\begin{array}{l}\text { 95\% limits of agreement of paired } \\
\text { observations in } \mathrm{cm} \text { in kyphosed patients } \\
\qquad \mathrm{n}=115\end{array}$ \\
\hline $\mathrm{OWD} \mathrm{T}_{0}-\mathrm{T}_{6}$ & $-3.4 ; 3.1$ & $-4.8 ; 4.2$ \\
\hline TWD $T_{0}-T_{6}$ & $-3.4 ; 2.9$ & $-4.2 ; 3.6$ \\
\hline OWD $\mathrm{T}_{6}-\mathrm{T}_{12}$ & $-2.9 ; 4.2$ & $-3.7 ; 5.3$ \\
\hline TWD $\mathrm{T}_{6}-\mathrm{T}_{12}$ & $-3.3 ; 3.9$ & $-3.3 ; 4.5$ \\
\hline OWD $\mathrm{T}_{12}-\mathrm{T}_{18}$ & $-3.1 ; 3.5$ & $-3.9 ; 4.3$ \\
\hline TWD T $_{12}-\mathrm{T}_{18}$ & $-3.1 ; 3.9$ & $-3.5 ; 4.3$ \\
\hline OWD $\mathrm{T}_{18}-\mathrm{T}_{24}$ & $-2.5 ; 3.3$ & $-4.3 ; 3.1$ \\
\hline TWD T $_{18}-\mathrm{T}_{24}$ & $-3.1 ; 3.7$ & $-3.5 ; 4.7$ \\
\hline
\end{tabular}

Analyzing the $95 \%$ limits of agreement of OWD and TWD in all patients compared to kyphosed patients shows that the $95 \%$ limits of agreement are comparable for OWD and TWD (Table 4.4). However, the 95\% limits of agreement in kyphosed patients is increased compared to all patients: for OWD -4.8 and $4.2 \mathrm{~cm}$ and for TWD -4.2 and $3.6 \mathrm{~cm}$. 
TABLE 4.4 Ranges of OWD and TWD of patients with OWD $>0$ at $T_{0}$ or $T_{6}$ are presented, as well as $95 \%$ limits of agreement between $T_{0}$ and $T_{6}$ for the whole group of patients with $O W D>0$ divided in quartiles.

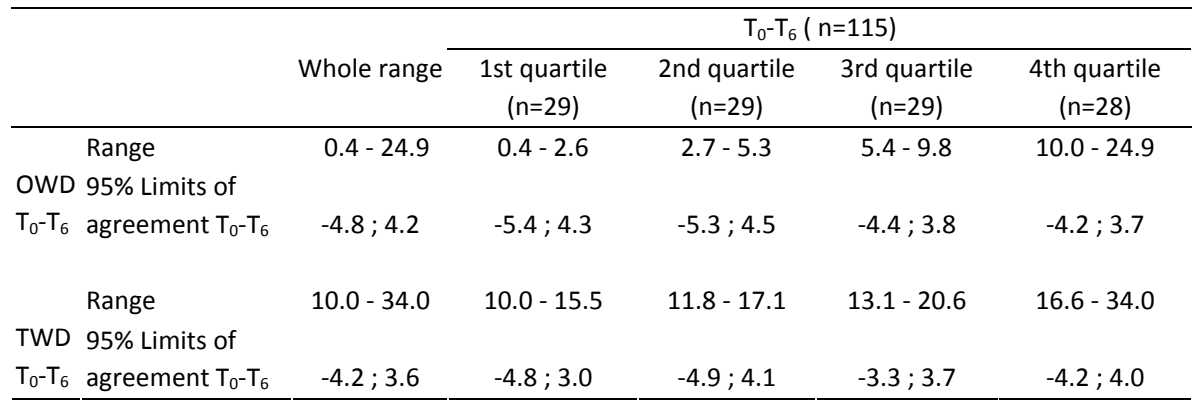

The mean change in BASDAl between $T_{0}$ and $T_{6}$ on a group level was 0.09 (SD 1.76). In 100 patients the BASDAI was stable between $T_{0}$ and $T_{6}$. In this group of patients the limits of agreement for OWD were -3.2 and 3.2 centimeter $(\mathrm{cm})$ and for TWD -3.3 and $3.3 \mathrm{~cm}$. Examining only kyphosed patients with a stable BASDAI $(n=56)$ the limits of agreement were -4.4 and $4.4 \mathrm{~cm}$ for OWD and -4.5 and 4.5 for TWD. These limits of agreement do not differ from the limits of agreement found in analysis of the whole group. It thus seems justified in this situation to use measurements with a time interval of six months for test retest purposes. Furthermore, these data suggest there was no systematic error.

Of the 217 patients, 115 (53\%) were not able to touch the wall with their occiput at both $T_{0}$ and $T_{6}$. These patients were classified as kyphosed. Table 4.4 shows the limits of agreement comparing baseline and $T_{6}$ for OWD and TWD, calculated for these patients. The results are presented for the whole range of OWD and TWD and divided into quartiles. No consistent pattern over the quartiles was detected for all time intervals. We concluded that the limits of agreement are comparable over the whole scale and thus a more severe kyphosis does not evoke more measurement error. For comparison of OWD and TWD it is appropriate to use the limits of agreement not divided in quartiles of the scale.

\section{DISCUSSION}

In measurement of both OWD and TWD it is required that the chin is "in the neutral position". We hypothesized that involuntary flexion or (hyper)extension of the head, which takes place in the atlanto-occipital joint and the cervical spinal joints 
and can occur together with thoracic spine extension, would influence the OWD more than the TWD because, compared to the occiput, the tragus lies closer to the sagittal axis about which the atlanto-occipital joint flexion and extension occur. In other words patient variance would influence the OWD more compared to TWD and thus the OWD would be more prone to measurement error. On the other hand, variation in rotation of the head could influence the TWD more compared to the OWD. However, analyzing our data, we found similar ICC and similar limits of agreement for OWD and TWD, which did not confirm a differential aspect in measurement error between the two instruments.

We did not perform a formal test-retest method in assessing the measurement error of the OWD and TWD with a short time interval. However, in our view it is appropriate to use the data with a 6-month interval in a disease with very slow progression. The various analyses we performed do underscore this assumption.

The OWD and TWD instruments did not behave differently across different ranges of the measurement. Auléley et $a{ }^{9}$ reported in an international study on 120 patients with AS a 95\% limit of agreement between -2.8 and $2.9 \mathrm{~cm}$ for OWD, which is little lower than in our group. In their investigation TWD was not studied. However, we do not know the percentage of patients with a normal OWD in that study; if this was higher this may explain the small difference, as we showed that measurement error is increased in kyphosed patients. In calculation of the $\mathrm{BASMI}^{4,5}$, an intuitively created index based on the literature, the TWD and not the OWD was used. As stated, this measurement was among 20 separate measurements historically used in the assessment of AS. Pile et al ${ }^{10}$ found an excellent inter-observer reliability represented by an inter-observer coefficient of reliability of 0.97 for TWD. No interobserver coefficient of reliability was given for OWD. Viitanen et al reported an interobserver ICC of 0.94 for both OWD and TWD and an intraobserver ICC of 0.98 for OWD and of 0.90 for TWD. ${ }^{11}$ But these investigators did not present $95 \%$ levels of agreement and a high ICC does not rule out an unacceptable level of measurement error. ${ }^{12}$

Bellamy, et al reported the median of the minimally clinically important difference estimates (MCIDE: as defined by an expert panel with use of Delphi rounds) for TWD as $3.0 \mathrm{~cm}$ and for OWD as $1.25 \mathrm{~cm} .{ }^{13}$ In both our study and the study of Auléley et $a l^{9}$, the $95 \%$ limits of agreement, are beyond the reported MCIDE from this expert panel, which suggests that the MCIDE cannot reliably be distinguished from measurement error.

Our conclusion is that we found no difference in reliability between OWD and TWD. Although we feel the TWD is in general easier to perform compared to OWD, 
we recommend the OWD measurement over TWD. Our main argument is that in OWD measurement a value of zero easily distinguishes patients with normal thoracic spine extension from kyphosed patients. This argument is especially valid in the research setting, where a value of 0 for OWD clearly means no kyphosis and a value for example, of 12 for TWD could mean no kyphosis or beginning kyphosis. We think this outweighs the minor disadvantages of the feasibility of measurement of OWD. 


\section{REFERENCES}

1. Bellamy N. Muscoloskeletal Clinical Metrology. Dordrecht / Boston/ London: Kluwer academic publisher; 1993.

2. van der Heijde D, Calin A, Dougados M, Khan MA, van der Linden S, Bellamy N. Selection of instruments in the core set for DC-ART, SMARD, physical therapy, and clinical record keeping in ankylosing spondylitis. Progress report of the ASAS Working Group. Assessments in Ankylosing Spondylitis. J Rheumatol 1999;26:951-4.

3. Bellamy N. Clinimetric Concepts in Outcome Assessment: The Omeract Filter. Journal of Rheumatology 1999;26:948-50.

4. Jenkinson TR, Mallorie PA, Whitelock HC, Kennedy LG, Garrett SL, Calin A. Defining spinal mobility in ankylosing spondylitis (AS). The Bath AS Metrology Index. J Rheumatol 1994;21:1694-8.

5. Jones SD, Porter J, Garrett SL, Kennedy LG, Whitelock H, Calin A. A new scoring system for the Bath Ankylosing spondylitis Metrology Index (BASMI). J Rheumatol 1995;22:1609.

6. Spoorenberg A, van der Heijde D, de Klerk E, Dougados M, de Vlam K, Mielants H, et al. A comparative study of the usefulness of the Bath Ankylosing spondylitis Functional Index and the Dougados Functional Index in the assessment of ankylosing spondylitis. J Rheumatol 1999;26:961-5.

7. van der Heijde DM, van 't Hof MA, van Riel PL, Theunisse LA, Lubberts EW, van Leeuwen MA, et al. Judging disease activity in clinical practice in rheumatoid arthritis: first step in the development of a disease activity score. Ann Rheum Dis 1990;49:916-20.

8. Bland JM, Altman DG. Statistical methods for assessing agreement between two methods of clinical measurement. Lancet 1986;1:307-10.

9. Auléley GR, Benbouazza K, Spoorenberg A, Collantes E, Hajjaj-Hassouni N, van der Heijde D, et al. Evaluation of the smallest detectable difference in outcome or process variables in ankylosing spondylitis. Arthritis Rheum 2002;47:582-7.

10. Pile KD, Laurent MR, Salmond CE, Best MJ, Pyle EA, Moloney RO. Clinical assessment of ankylosing spondylitis: a study of observer variation in spinal measurements. Br J Rheumatol 1991;30:29-34.

11. Viitanen JV, Heikkila S, Kokko ML, Kautiainen H. Clinical assessment of spinal mobility measurements in ankylosing spondylitis: a compact set for follow-up and trials? Clin Rheumatol 2000;19:131-7.

12. Atkinson G, Nevill A. Statistical methods for assessing measurement error(reliability) in variables relevant to sports medicine. Sports Med 1998;26:217-38.

13. Bellamy N, Buchanan WW, Esdaile JM, Fam AG, Kean WF, Thompson JM, et al. Ankylosing spondylitis antirheumatic drug trials. III. Setting the delta for clinical trials of antirheumatic drugs-results of a consensus development (Delphi) exercise. J Rheumatol 1991;18:1716-22. 
CHAPTER 4 occiput- VS. TRAgUS-TO-WALL DISTANCE 
(194) 11
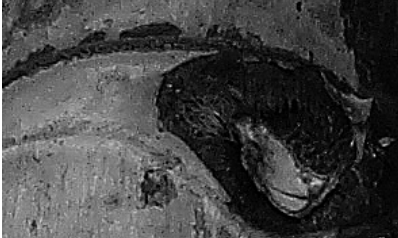

in

$-3$

+ 1

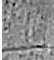




\section{Comparing}

morphometric x-ray

absorptiometry

and radiography in

defining vertebral

wedge fractures

in patients with

ankylosing

spondylitis

D. Vosse, C. Heijckmann, R. Landewé, D. van der Heijde, S. van der Linden, P. Geusens 


\begin{abstract}

\section{Objective}

To compare in patients with ankylosing spondylitis (AS) the agreement of quantitative morphometry of the vertebrae on lateral views of the spine using conventional X-ray and using a dual X-ray absorptiometry device (DXA) in determining the degree of wedging of vertebrae.
\end{abstract}

\title{
Methods
}

Thirty patients with AS underwent DXA to acquire single-energy morphometric X-ray absorptiometry (MXA) scans and conventional lateral radiography (MRX) of the thoracic and lumbar spine. Vertebral anterior and posterior heights were measured and the anterior/ posterior (AP)-ratio was calculated. We analyzed the level of agreement for vertebral wedging between MRX and MXA on the patient level and on the vertebral level, using average AP-ratios per patient, and per vertebra, as well as dichotomized APratios (above or below cut-off levels that are commonly used to identify fractures).

\section{Results}

Per-patient analysis showed good agreement between both methods in the whole spine (ICC=0.64), as well as in the thoracic (ICC $=0.66)$ and lumbar spine $(I C C=0.62)$ separately. Analysis on individual vertebrae showed differences in agreement dependent on which part of the spine was measured. The ICC on all vertebrae was $0.71,0.76$ in the lumbar and 0.43 in the thoracic vertebrae. If AP-ratios were translated into fractures (yes vs. no) using different cut off levels for a fracture (AP-ratios $0.75,0.80$ or 0.85 ) between-method agreement became fair to good (Kappa 0.26-0.35 in the thoracic and 0.47-0.80 in the lumbar vertebrae). Differences in classifications were in both directions and in all vertebral fractures according to the Genant definition. In this study with a prevalence of $5 \%$ of vertebral fractures the positive predicted value (PPV) was $39 \%$ and the negative predicted value (NPV) was $97 \%$.

\section{Conclusion}

Although the agreement between MRX and MXA in measuring global vertebral wedging, expressed as (mean) AP-ratio, was good, the reliability of both measures to assess wedging at the vertebral level was highly variable, ranging from fair to very good agreement, dependent on the level. If fracture studies are performed with either of both methods, the results of wedging at the individual vertebral level can not be generalized to the other method, except for wedging $<0.75$ at the lumbar spine. However, as the NPV was high, DXA could be of clinical value to select patients for further evaluation by X-ray to assess vertebral fractures as a sign of bone failure. 


\section{INTRODUCTION}

Ankylosing spondylitis (AS) is a chronic inflammatory disease mainly affecting the axial skeleton and is characterised by ossification of the spinal joints and ligaments. Hyperkyphosis of the upper part of the spine is a frequent clinical problem in patients with ankylosing spondylitis (AS).$^{1-3}$ In general, hyperkyphosis is associated with vertebral osteoporosis, and it is increasingly recognised that osteoporosis is a problem in patients with $\mathrm{AS}^{4-8}$ Vertebral deformities are regarded as one of the hallmarks of bone failure. In previous studies we showed that the degree of hyperkyphosis in patients with AS is independently related to two radiological measures of damage: (1) radiological damage as measured on X-rays by the modified Stoke Ankylosing Spondylitis Score (mSASSS) ${ }^{9}$ that includes erosions, osteophytes and squaring and (2) wedging of mainly thoracic vertebrae as measured by vertebral morphometry. . $^{10,11}$

Several methods are available to establish vertebral deformities or fractures and to distinguish them from vertebrae with a normal shape. They differ in the technique used (morphometric radiography (MRX) and morphometric X-ray absorptiometry (MXA) and in the definition of fractures. Recently, Duboeuf et al reviewed these issues in the assessment of vertebral fractures. ${ }^{12}$ They discussed five scoring methods based on conventional morphometric radiography (MRX) and applied them on different densitometric devices (Hologic QRD, Hologic Delphi, Lunar Expert and Lunar Prodigy). One of the most common approaches is described by Genant et al, in which a semiquantative technique to assess vertebral deformities on conventional radiography is used plus the general interpretation of the image. ${ }^{13}$ This method uses fixed values of deformities $(0.60,0.75,0.80)$. McCloskey et al developed a semi-automated technique ${ }^{14}$ taking into account the size of adjacent vertebrae in calculating fractures. Eastell et al defined fractures based on deviations of $>3$ SD as compared to a population-based data base. ${ }^{15}$ The other two methods are the Melton approach, using reference radiographs of 200 healthy women aged 50 years and older, where vertebral heights are compared with the mean value of the control group for that vertebra, and the Minne approach, dividing all individual heights (anterior, middle and posterior from T4 to L5) by the height of the fourth thoracic vertebrae, resulting in relative heights which are compared with the relative heights of a reference group. ${ }^{16,17}$ Rea published the use of morphometric X-ray absorptiometry to describe vertebral deformities. ${ }^{18,19}$ All methods were tested in postmenopausal women with or without osteoporosis, and could appropriately distinguish between normally and abnormally shaped verte- 
brae. These methods use a threshold of $15-40 \%$ height loss as fracture definition. In spite of the wealth of definitions and methods for morphometry a gold standard in terms of technique (MRX or MRA) and definition of fracture is still lacking. ${ }^{20}$ Comparative studies using these techniques have not yet been performed in AS.

In the present study we studied the agreement between two methods (MRX and MXA) for measuring vertebral wedge fractures in patients with AS.

\section{PATIENTS AND METHODS}

We invited 30 patients (52\% male patients, 83\% HLA-B27 positive) with AS visiting the outpatient department of Rheumatology of the University Hospital Maastricht to take part in this cross-sectional study. They all met the modified New York criteria for AS. ${ }^{21}$ Mean age of the patients was 52 years $( \pm 11)$; mean disease duration after diagnosis 17 years $( \pm 10)$. The patients are evaluated by a study nurse according to a standard protocol which included measurement of bone mineral density (Hologic QDR 4500, NHANES-III reference group, Bedford, MA). In addition, DXA was used to acquire MXA scans of the whole spine. These 30 patients also participated in the Outcome in AS International Study (OASIS) cohort, an international longitudinal, observational study on outcome in AS. ${ }^{22}$ In this study patients were followed according to a fixed protocol and data included lateral radiographs of the cervical, thoracic, and lumbar spine. Both DXA scans and radiographs were performed in the same period In the OASIS cohort only a very small group of patients used steroids $(6 / 215 ; 2.8 \%)$ at baseline. Only one of them participated in this study.

On both MRX and MXA vertebral anterior and posterior heights were measured (Figure 5.1a). For MXA Hologic software using the single-energy absorptiometry was used to set markers on the vertebral corners by one observer (DV). Anterior (Ha) and posterior ( $\mathrm{Hp}$ ) height of the vertebrae was measured in millimeters using Hologic software (Figure 5.1c). Anterior and posterior heights of the vertebrae were measured on lateral radiographs of the thoracic (T4 toT12) and lumbar spine (L1 to L4) in millimeters using a ruler by the same observer (DV) (Figure 5.1b). Vertebral wedging was assessed on both methods by calculating the $\mathrm{Ha} / \mathrm{Hp}$ ratio. Interpretation of kappa's was based on Altman. ${ }^{23}$

To assess interobserver reliability of measuring anterior and posterior height on MXA two readers measured the total spine of 30 AS patients. These patients were chosen by an independent observer who tried to include the entire spectrum 
of possible AS deformities. In a previous experiment using MRX we have established that inter-observer reliability $(\mathrm{ICC}=0.84(95 \% \mathrm{Cl}$ : $0.74-0.96)$ for $\mathrm{Ha} / \mathrm{Hp}$ ratios) was very good. ${ }^{11}$

A

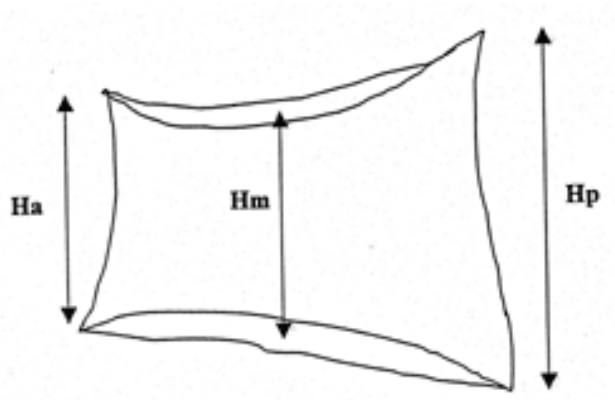

B

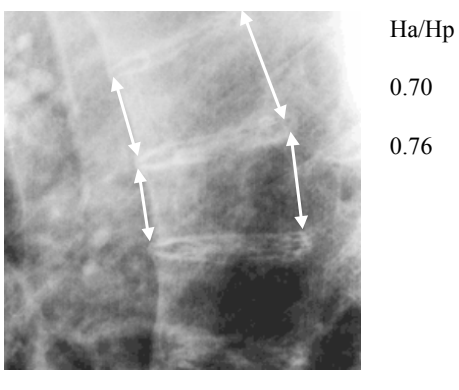

C

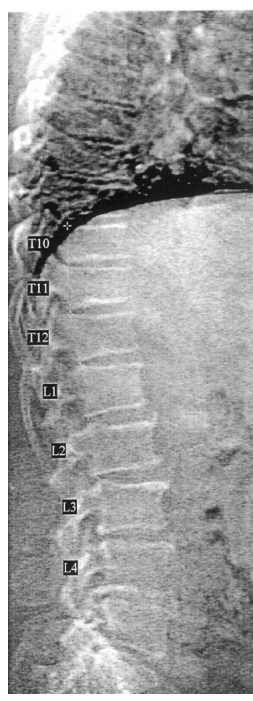

QM Results:

\begin{tabular}{|c|c|c|c|c|c|}
\hline & Post & Mid & Ant & & Mid \\
\hline & $\begin{array}{l}\text { Hght } \\
(\mathrm{mm})\end{array}$ & $\begin{array}{l}\text { Hght } \\
(\mathrm{mm})\end{array}$ & $\begin{array}{l}\text { Hght } \\
(\mathrm{mm})\end{array}$ & Wedge & Wedge \\
\hline $\mathrm{T} 10$ & 20.2 & 17.0 & 18.6 & 0.92 & 0.84 \\
\hline T11 & 23.3 & 18.7 & 18.4 & 0.79 & 0.80 \\
\hline $\mathrm{T} 11$ & 27.2 & 20.2 & 21.6 & 0.79 & 0.74 \\
\hline L1 & 28.8 & 23.2 & 23.6 & 0.82 & 0.81 \\
\hline L2 & 28.6 & 23.9 & 24.6 & 0.86 & 0.84 \\
\hline L3 & 27.9 & 24.7 & 25.8 & 0.92 & 0.88 \\
\hline L4 & 26.7 & 24.9 & 29.8 & 1.12 & 0.93 \\
\hline Std & $1 \mathrm{~mm}$ & $1 \mathrm{~mm}$ & $1 \mathrm{~mm}$ & 0.05 & 0.05 \\
\hline
\end{tabular}

FIGURE 5.1 A. Measurement of vertebral heights.

B. Measurement of vertebral morphometry on radiography (MRX).

C. Measurement of vertebral morphometry on densitometry (MXA).

\section{Statistical analysis}

We analyzed agreement between MRX and MXA on two main levels: the patient level $(n=30)$ and at the vertebral level $(n=390)$. On the patient level we correlated 
wedging deformities measured on MRX and MXA on different levels with BMD. On the patient level as well as on the vertebral level we calculated intraclass correlation coefficient (ICC) on $\mathrm{Ha} / \mathrm{Hp}$ ratio for the lumbar and thoracic spine separately, as well as for the total spine. Furthermore, we calculated Cohen's kappa's on dichotomized fracture scores with the following cut-off ratios for the $\mathrm{Ha} / \mathrm{Hp}$ ratio for a fracture: $0.75,0.80$ and 0.85 . Kappa's were calculated for the lumbar and thoracic spine separately as well as for the total spine. In an attempt to improve the agreement between MRX and MRA in establishing a fracture we assumed MRX as the dependent variable and used receiver operating characteristic (ROC)-analysis to find out the optimal cut-off level for $\mathrm{Ha} / \mathrm{Hp}$-ratio in determining a fracture by MRA. Different cut-off levels (0.60-0.85) for MRX were tested, so that different combinations of cut-off levels for MRA and MRX were obtained. We analysed if wedging deformities of vertebrae assessed by MRX versus MXA were correlated to $B M D$. Furthermore, linear regression analysis was performed to investigate the independent contribution of mean thoracic wedging on MRX and MXA to explain variation in the dependent variable OWD. Not normally distributed variables were first normalized by the Van der Waerden technique.

Specificity, sensitivity, positive (PPV) and negative predictive values (NPV) were calculated.

\section{RESULTS}

Complete morphometric radiography and morphometric X-ray absorptiometry data were available in all 30 patients. Of 390 available vertebrae, 335 could be analysed. Most missing data (concerning 55 vertebrae) occurred in the T4-T6 region, and were equally distributed across methods. Eight of the 55 non-eligible vertebrae occurred in the T10-T12 region, and were preferentially occurring on MRX while eligible on MXA.

Inter-observer reliability for $\mathrm{Ha} / \mathrm{Hp}$ ratios on MXA on vertebral level was very good (ICC=0.84 (95\%Cl: 0.51-0.95)).

Table 5.1 shows the correlation between deformities in separate levels and in the total spine measured on MRX and MXA. Good correlations are found between methods on concurrent levels (thoracic 0.71 ; lumbar 0.75 ; total 0.72 ). This analysis also confirms our previous findings that overall hyperkyphosis is mainly explained in the thoracic spine ( 0.89 for MRX and 0.82 for MXA). We did not find any correlation between deformities and BMD. 
TABLE 5.1 Correlation between deformities in separate levels and in the total spine measured on MRX and MXA.

\begin{tabular}{|c|c|c|c|c|c|c|c|}
\hline & \multirow[t]{2}{*}{ BMD } & \multicolumn{3}{|c|}{ Mean wedging } & \multicolumn{3}{|c|}{ Mean ratio } \\
\hline & & $\begin{array}{c}\text { thoracic } \\
\text { spine }\end{array}$ & $\begin{array}{l}\text { lumbar } \\
\text { spine }\end{array}$ & $\begin{array}{l}\text { total } \\
\text { spine }\end{array}$ & $\begin{array}{l}\text { thoracic } \\
\text { spine }\end{array}$ & $\begin{array}{l}\text { lumbar } \\
\text { spine }\end{array}$ & $\begin{array}{l}\text { total } \\
\text { spine }\end{array}$ \\
\hline BMD & 1 & -0.12 & -0.26 & -0.20 & 0.19 & -0.15 & 0.12 \\
\hline $\begin{array}{l}\text { Mean wedging } \\
\text { thoracic spine }\end{array}$ & & 1 & -0.12 & $0.89^{a}$ & $0.71^{\mathrm{a}}$ & 0.17 & $0.61^{a}$ \\
\hline $\begin{array}{l}\text { Mean wedging } \\
\text { lumbar spine }\end{array}$ & & & 1 & 0.26 & -0.05 & $0.75^{a}$ & $0.40^{\mathrm{b}}$ \\
\hline $\begin{array}{l}\text { Mean wedging } \\
\text { total spine }\end{array}$ & & & & 1 & $0.58^{a}$ & $0.48^{a}$ & $0.72^{a}$ \\
\hline $\begin{array}{l}\text { Mean ratio } \\
\text { thoracic spine }\end{array}$ & & & & & 1 & 0.17 & $0.82^{a}$ \\
\hline $\begin{array}{l}\text { Mean ratio } \\
\text { lumbar spine }\end{array}$ & & & & & & 1 & $0.65^{a}$ \\
\hline $\begin{array}{l}\text { Mean ratio } \\
\text { total spine }\end{array}$ & & & & & & & 1 \\
\hline
\end{tabular}

${ }^{a}$ correlation is significant at $p \leq 0.01 ;{ }^{b}$ correlation is significant at $p \leq 0.05$

Table 5.2 shows the agreement in measuring the absolute $\mathrm{Ha} / \mathrm{Hp}$-ratio on MRX versus MRA on a per patient level and on a vertebral level. Per patient analysis showed good agreement between both methods, in the total spine (ICC $=0.64)$ as well as in thoracic $(I C C=0.66)$ and lumbar $(I C C=0.62)$ parts separately. Analysis on separate vertebrae $(n=335)$ showed a different pattern of agreement dependent on the part of the spine that was examined. For the total spine $(I C C=0.71)$ as well as for the lumbar (ICC=0.76) part, a good level of agreement was achieved. For the thoracic part the level of agreement $($ ICC $=0.43$ ) was moderate. Bland-Altman analysis on the vertebral level showed that measurement error was independent of the magnitude of wedging (Figure 5.2). Bland Altman analysis on the patient level, however, showed that measurement error increased by decreasing $\mathrm{Ha} / \mathrm{Hp}$ ratio (Figure 5.3). 
TABLE 5.2 Agreement between radiographic and DXA morphometry (absolute $\mathrm{Ha} / \mathrm{Hp}$ ratios) at patient and at vertebral level.

\begin{tabular}{lcc}
\hline & \multicolumn{2}{c}{ Intraclass correlation MRX versus MXA $(95 \% \mathrm{Cl})$} \\
& Per patient & Per vertebra \\
\hline Thoracic & $0.66(0.41-0.82)$ & $0.43(0.31-0.53)$ \\
Lumbar & $0.62(0.28-0.81)$ & $0.76(0.67-0.83)$ \\
Total spine & $0.64(0.57-0.70)$ & $0.71(0.47-0.85)$ \\
\hline
\end{tabular}

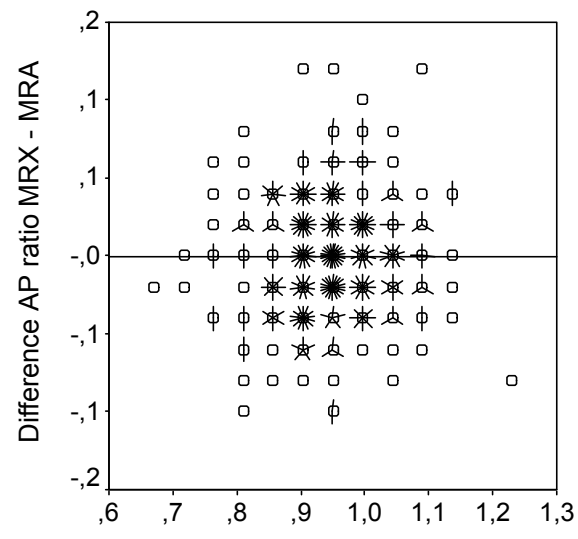

FIGURE 5.2

Bland-Altman plot of vertebral wedging (ratio of anterior vertebral height and posterior vertebral height) of separate thoracic and lumbar vertebrae.

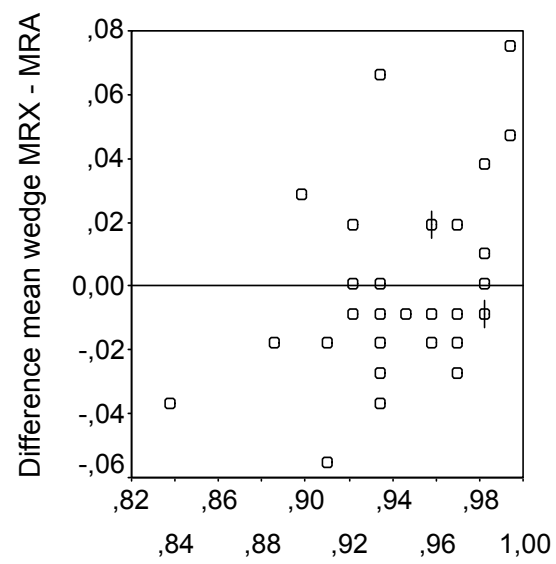

FIGURE 5.3

Bland-Altman plot of mean wedging (ratio of anterior vertebral height and posterior vertebral height) of the total spine.

Average of mean wedge MRX - MRA 
Subsequently, we dichotomized $\mathrm{Ha} / \mathrm{Hp}$ ratios at different cut off levels for the presence or absence of fracture $(0.75 ; 0.80 ; 0.85)$, and we tested the agreement again. Agreement tended to improve by a more conservative cut-off level for fracture, more so in the lumbar spine than in the thoracic spine (Table 5.3). For moderate wedging in the lumbar spine (cut-off: 0.75 ) there was a good agreement (kappa $=0.80$ ) but for less severe deformations only fair to moderate agreement between both methods was found. On separate vertebrae the differences in classification were significant. Differences were in both directions: fractures measured on MXA but not on MRX and vice versa. Using the Genant cut-off level of 0.80 for $\mathrm{Ha} / \mathrm{Hp}$-ratio, 28 fractures were identified in 335 separate vertebrae by either method, only 7 matched (25\%) (Table 5.4). All identified fractures, both discrepant and matching, were localised in the T6-LI region.

TABLE 5.3 Between-methods agreement in measuring fractures using different cut off levels as fracture definition.

\begin{tabular}{lccc}
\hline Ha / Hp ratio cut off levels for fracture & Thoracic & Lumbar & Total spine \\
\hline 0.75 & $0.35^{\mathrm{a}}$ & 0.80 & 0.49 \\
0.80 & 0.31 & 0.56 & 0.37 \\
0.85 & 0.26 & 0.55 & 0.32 \\
\hline a values are Cohen's kappa's & &
\end{tabular}

TABLE 5.4 Relationship between fractures measured on MRX and MXA in 335 vertebrae.

\begin{tabular}{|c|c|c|c|c|}
\hline & & \multicolumn{2}{|c|}{ Fracture on $\mathrm{MRA}^{\mathrm{a}}$} & Total \\
\hline & & Yes & No & \\
\hline \multirow[t]{2}{*}{ Fracture on $\mathrm{MRX}^{\mathrm{a}}$} & Yes & 7 & 10 & 17 \\
\hline & No & 11 & 307 & 318 \\
\hline Total & & 18 & 317 & 335 \\
\hline
\end{tabular}

${ }^{\mathrm{a}} \mathrm{Ha} / \mathrm{Hp}$ ratio $\leq 0.80$

We further examined the influence of different cut-off levels using MRX at different cut-off levels as the dependent variable, and testing an optimal cut-off level for MRA by ROC-analysis. However, none of the found combinations arrived at higher levels of agreement (results not shown).

Finally, parallel to a previous study we looked at the correlation between morphometry and hyperkyphosis (expressed as OWD) in MXA. As expected we found a correlation between mean thoracic wedging measured on MRX and MXA and OWD ( $\rho=0.51$ in MRX versus 0.39 in MXA). However, in a linear regression model contribution of mean thoracic wedging measured on MXA did not reveal 
independent contribution to explaining hyperkyphosis (st $ß=-0.488$ [MRX] versus st $\left.\beta=-0.138[M X A] ; R^{2}=0.255\right)$. If we assumed $M R X$ to be the gold standard, with a prevalence of $5 \%$ of wedged fractures in this study sensitivity was $41 \%$, specificity 97\%, PPV 39\% and NPV 97\%.

\section{DISCUSSION}

In this study we compared assessment of morphometric radiography (MRX) on lateral radiographs of the spine and morphometric X-ray absorptiometry (MXA) on single-energy $\mathrm{X}$-ray absorptiometry scans in identifying vertebral deformities and fractures. We used Genant's method by calculating $\mathrm{Ha} / \mathrm{Hp}$ ratios to describe vertebral deformities and defined different cut-off levels for vertebral fractures. If the mean $\mathrm{Ha} / \mathrm{Hp}$ ratio per patient is calculated per method, and both methods are compared, substantial agreement was achieved. However, the focus of interest is the separate vertebral level and here agreement was only fair.

A similar level of between method agreement as in this study is described in literature. Ferrar et al described an appropriate assessment of vertebral fractures on MXA scans, considering spinal radiographs as gold standard. ${ }^{24}$ Rea et al reported a direct comparison of visual MXA and MRX in 24 patients. They found that the prevalence of new fractures could not be detected as precisely on MXA as compared to MRX, especially in subjects with vertebral deformities. In our study we did not use a gold standard, but we looked at direct agreement for $\mathrm{Ha} / \mathrm{Hp}$ ratios assessed by both MRX and MXA. Though the interobserver ICC for both methods was good, the agreement between methods in identifying a vertebral fracture was not. Using a $\mathrm{Ha} / \mathrm{Hp}$ ratio $\leq 0.80$ as cut off point 7 fractures were scored in both methods, on MXA 11 another fractures were identified and again another 10 on MRX. All identified fractures, both discrepant and matching, were localised in the thoraco-lumbar spine (T6-LI). Fifty-five individual vertebrae were not analysable, but this did not interfere with our results as they were all localised in the upper thoracic region and no discrepancies were found there.

We analysed if agreement between both MRX and MXA was better in more severe deformities, but no improvement in agreement was seen, except for moderate deformities in the lumbar spine.

In a previous study we showed that hyperkyphosis in patients with AS has two major determinants: radiological damage and thoracic wedging. ${ }^{11}$. For the purpose of this study we analysed whether wedging as assessed by MRX and MRA both 
correlated with hyperkyphosis (occiput-to-wall distance (OWD)). Both methods indeed contributed to OWD, but in MRX the results were somewhat better than in MRA. As both methods are highly correlated to one and other and MXA does not adjust extra information, using both methods to explain hyperkyphosis seems not necessary.

To assess the radiological damage in our AS patients mSASSS is used. In addition, to evaluate bone failure, bone density can be used. The presence of vertebral fractures also reflects bone failure. ${ }^{25}$ In spite of the lack in agreement the two methods, this study indicates there is a role for MXA in assessing the presence of vertebral fractures i.c. bone failure. Indeed, the high NPV indicates that in patients without any vertebral fracture on MXA we do not need X-ray to confirm the absence of fracture in cross sectional studies. How far this is also true in the clinical situation of acute back pain remains to be studied.

One might argue that obtaining agreement among methods will be more problematic in AS patients as compared to non-AS patients, since AS patients may have spinal syndesmophytes and vertebral corner lesions that may jeopardise an appropriate assessment of the vertebral height. We were however able to demonstrate that two trained readers reached a high level of agreement in measuring vertebral height in both MRX and MXA. In both experiments we asked an independent observer to select cases in the training sets of both methods and tried to include the entire spectrum of possible AS deformities so that interference by syndesmophytes and other lesions is probably of minor importance.

Most authors find an acceptable performance of the different methods they used to identify vertebral fractures. Most of them used visual assessment of spinal radiographs as gold standard. In his review Duboeuf et al mentioned reasonable to good sensitivity, specificity and kappa-scores. ${ }^{12}$ Nevertheless, our results were less convincing. Both methods identify vertebral deformities, but it seems they mainly detect different ones. One explanation for the discrepancy could be the poor image quality of MXA of radiographs in the thoracic region. Especially in the upper parts image quality can be insufficient. However, this can only be part of the explanation since all fractures were identified in the mid- and lower parts of the spine, and here image quality is good. In 1998 Chappard et al. published an evaluation of spine morphometry obtained by both MRX and MXA. ${ }^{26}$ They found in primary osteoporotic patients the same poor agreement for the thoracic level as we did, which underscores the argument that it is not primarily the presence of syndesmophytes that jeopardized agreement. Due to a lack of resolution, rib interposition and motion of the diaphragm the image quality is insufficient. Furthermore, Ferrar et al 
stated that densitometric morphometry is less accurate on mild deformities compared to severe deformities. ${ }^{27}$ One could argue that imaging quality, especially in MXA, can also be influenced by bone mineral density. Low BMD could cause vague images of vertebrae or, more specific, of vertebral corners. This problem is probably less prominent in MRX, as we know that low BMD can not adequately be diagnosed on plain X-rays. So we examined the possible correlation between MXA, $M R X$ and $B M D$, but no correlation was found. Low BMD can therefore not entirely explain the found differences.

Our study showed that the two methods we used to identify vertebral deformities in AS patients are not exchangeable at the level of T6-L1. We agree with other authors that a gold standard in vertebral morphometry would be recommendable. ${ }^{25}$ As in rheumatoid arthritis we should need to standardise the method(s) we will use to assess vertebral deformities in patients with AS. With the new, potentially disease modifying, drugs we must be able to monitor radiographic progression of the disease in all its aspects, including deformities.

In summary, although the agreement between MRX and MXA in measuring global vertebral deformity expressed as (mean) AP-ratio is acceptable, both measures do not reliably assess whether or not there is a fracture. The results obtained by one method do not comply with the results obtained by the other technique. Consensus on which methods should be used and how they should be applied to assess vertebral deformities in patients with AS is warranted. However, for the assessment of vertebral deformities as a sign of bone failure MRA is an accurate method to use. 


\section{REFERENCES}

1. Carette S, Graham D, Little H, Rubenstein J, Rosen P. The natural disease course of ankylosing spondylitis. Arthritis Rheum 1983;26:186-90

2. Wilkinson M, Bywaters EGL. Clinical features and course of ankylosing spondylitis. Ann Rheum Dis 1958;17:209-16

3. Spencer DG, Park WM, Dick HM, Papazoglou SN, Buchanan WW. Radiological manifestations in 200 patients with ankylosing spondylitis: correlation with clinical features and HLA-B27. J Rheumatol 1979;6:305-15

4. Bronson WD, Walker SE, Hillman LS, Keisler D, Hoyt T, Allen SH. Bone mineral density and biochemical markers of bone metabolism in ankylosing spondylitis. J Rheumatol 1998;25:929-35

5. Lee YS, Schlotzhauer T, Ott SM, van Vollenhoven RF, Hunter J, Marcus R, McGuire JL. Skeletal status of men with early and late ankylosing spondylitis. Am J Med 1997;103:233-41

6. Devogelaer JP, Maldague B, Malghem J, Nagant de Deuxchaisnes C. Appendicular and vertebral bone mass in ankylosing spondylitis. A comparison of plain radiographs with single- and dualphoton absorptiometry and with quantitative computed tomography. Arthritis Rheum 1992;35:1062-7

7. Will R, Palmer R, Bhalla AK, Ring EFJ, Calin A. Osteoporosis in early ankylosing spondylitis: a primary pathologic event? Lancet 1989;2:1483-5

8. Maghraoui A, Borderie D, Cherruau B, Eduoard R, Dougados M, Roux C. Osteoporosis, body composition and bone turnover in Ankylosing Spondylitis. J Rheumatol 1999; 26:2205-9

9. Creemers MCW, Franssen MJAM, van 't Hof MA, Gribnau FWJ, vd Putte LBA, vRiel PLCM. Assessment of outcome in Ankylosing Spondylitis: an extended radiological scoring system. Ann Rheum Dis 2005;64:127-9. doi:10.1136/ard.2004.020503

10. Geusens P, Vosse D, van der Heijde DM, Vanhoof J, van Tubergen A, Raus J, van der Linden SM. High prevalence of thoracic vertebral deformities and discal wedging in ankylosing spondylitis patients with hyperkyphosis. J Rheumatol 2001;28:1856-61

11. Vosse D, vd Heijde D, Landewé R, Geusens P, Mielants H, Dougados M, vd Linden S. Determinants of hyperkyphosis in patients with ankylosing spondylitis. Ann Rheum Dis 2006;65:770-4. doi 10.1136/ard.2005.044081

12. Duboeuf F, Bauer DC, Chapurlat RD, Dinten JMP, Delmas P. Assessment of vertebral fracture using densitometric morphometry. J Clin Densitom. 2005;8:362-8

13. Genant HK, Wu CY, Kuijk van C, Nevitt MC. Vertebral fracture assessment using a semi quantitative technique. J Bone Miner Res 1993;8:1137-48

14. McCloskey EV, Spector TD, Eyres KS, Fern ED, O'Rourke N, Vasikaran S, Kanis JA. The assessment of vertebral deformity: a method for use in population studies and clinical trials. Osteoporosis Int 1993;3:138-47

15. Eastell R, Cedel SL, Wahner HW, Riggs BL, Melton JL III . Classification of vertebral fractures. J Bone Miner Res 1991;6:207-15

16. Melton III LJ, Kan SH, Frye MA, Wahner HW, O'Fallon MO, Riggs BL. Epidemiology of vertebral fractures in women. Am J Epidemiol 1989;129:1000-11

17. Minne HW, Leidig G, Wuster C et al. A newly developed spine deformity index (DSI) to quantitate vertebral crush fractures in patients with osteoporosis. Bone Min 1988;3:335-49

18. Rea JA, Chen MB, Li J,Potts E, Fan B, Blake GM, Steiger P, Smith IG, Genant HK, Fogelman I. Morphometric $X$-ray absorptiometry and morphometric radiography of the spine: a comparison of analysis precision in normal and osteoporotic subjects. Osteoporosis Int 1999;9:536-44

19. Rea JA, Chen MB, Marsh E, Fan B, Blake GM, Steiger P, Smith IG, Genant HK, Fogelman I. Vertebral morphometry: a comparison of long-term precision of morphometric X-ray absorptiometry and morphometric radiography in normal and osteoporotic subjects. Osteoporos Int. 2001;12:158-66 
20. Kleerekoper M, Parfitt AM, Ellis BI. Measurement of vertebral fracture rates in osteoporosis. In: Christiansen C et al ,eds. Copenhagen International Symposium on osteoporosis, 1984:103-9

21. van der Linden S, Valkenburg HA, Cats A. Evaluation of diagnostic criteria for ankylosing spondylitis: a proposal for modification of the New York criteria. Arthritis Rheum 1984; 27:361-8

22. Spoorenberg A, van der Heijde D, de Klerk E, Dougados M, deVlam K, Mielants $H$, van der Tempel $\mathrm{H}$, van der Linden $\mathrm{Sj}$. A comparative study of the usefulness of the Bath Ankylosing spondylitis Functional Index and the Dougados Functional Index in the assessment of ankylosing spondylitis. J Rheumatol 1999;26:961-5

23. Bland JM, Altman DG. Statistical methods for assessing agreement between two methods of clinical measurements. Lancet 1986;1:307-10

24. Ferrar L, Jiang G, Eastell R, Peel NFA. Visual identification of vertebral fractures in osteoporosis using morphometric X-ray absorptiometry. J Bone Miner Res 2003;18:933-8

25. Lems WF. Clinical relevance of vertebral fractures. Ann Rheum Dis 2007;66:2-4. doi 10.1136/ard.2006.058313

26. Chappard C, Kolta S, Fechtenbaum j, Dougados M, Roux C. Clinical evaluation of spine morphometric X-ray absorptiometry. Br H Rheum 1998;37:496-501

27. Ferrar L, Jiang G, Barrington NA, Eastell R. Identification of vertebral deformities in women: comparison of radiological assessment and quantitative morphometry using morphometric radiography and morphometric X-ray absorptiometry. J Bone Min Res 2000;15:575-85 


\section{APPENDIX}

\section{LETTER TO THE EDITOR}

\section{A Scott-Russell, E Dennison, P Taylor, C Cooper}

Sir, we read with interest the paper by Vosse et al ${ }^{1}$ published in your November issue, detailing a comparative study of MXA and radiography in defining vertebral wedge fractures in patients with ankylosing spondylitis. We would like to report our experience in general rheumatology patients here.

We studied forty six patients referred to the osteoporosis centre at Southampton General Hospital for an MXA (morphometric x-ray analysis) scan who had also undergone a lumbar spine $x$-ray (MRX) (T12-L4) within six months of the scan. Using a six point semi-quantitative analysis2 we were able to both compare the intravertebral assessment (IVA) with the plain radiograph and review the x-ray report provided by the radiology department under usual clinical care. The same investigator (ASR) analysed both the radiographs and MXA, using a cut-off ratio $\mathrm{Ha}$ / $\mathrm{Hp}$ or $\mathrm{Hm} / \mathrm{Hp}$ of 0.8 to define fracture.

Among this group, 31 patients had no fracture on either radiograph or MXA, using the criteria above. However three of these $x$-rays had been reported as showing a fracture. The remaining fifteen patients had a total of 21 fractures on $x-$ ray analysis of which 20 correlated exactly on MXA and MRX (Table 1). The prevalence of vertebral fracture in our population was $33 \%$.

TABLE 1 Relationship between fractures measured on MRX, MXA and x-ray report in 230 vertebrae.

\begin{tabular}{lccccccc}
\hline & & \multicolumn{3}{c}{ Fracture on MXA } & \multicolumn{4}{c}{ Fracture on x-ray report } \\
& & Yes & No & Total & Yes & No & Total \\
Fracture & Yes & 20 & 1 & 21 & 16 & 6 & 22 \\
& No & 4 & 31 & 35 & 6 & 29 & 35 \\
& & & & & & & \\
& Total & 24 & 32 & & 22 & 35 \\
\hline
\end{tabular}

20 of 25 fractures reported corresponds to an $80 \%$ correlation between MRX and MXA.

If we assumed MRX to be the gold standard then the sensitivity, specificity, positive predictive value and negative predictive value of MXA was $95 \%, 88.5 \%, 83 \%$ and $97 \%$ respectively. 
In clinical practice, a doctor frequently relies upon the $x$-ray report. We went on to look at the correlation between the x-ray report and MRX using the latter as the gold standard (Table 1). The sensitivity, specificity, positive predictive value and negative predictive value of the usual $x$-ray report was $73 \%, 83 \%, 73 \%$ and $83 \%$ respectively.

In this pragmatic study we would reiterate Vosse et al's suggestion that the negative predictive value of MXA is high and therefore if no fracture is found, further imaging is not required, although we would acknowledge that standard radiograph analysis is not necessarily the gold standard in detecting lumbar vertebral fracture and indeed MXA may pick up some additional fractures. The extent of agreement is dependent on the strictness of the definition of fracture used. We feel MXA has a place aiding quick assessment of fracture risk with less radiation exposure than conventional radiographs, especially in analysis of the lumbar spine.

\section{References}

1. Vosse D, Heijckmann C, Landewe R, van der Heijde D, van der Linden S, Geusens P. Rheumatology 2007:46:1667-1671

2 Genant HK, Wu Cy, Kujik van C, Nevitt MC. J Bone Miner Res 1993;8:1137-46

\section{REPLY TO THE EDITOR}

Debby Vosse, Caroline Heijckmann, Robert Landewé, Désirée van der Heijde, Sjef van der Linden, Piet Geusens

We appreciate the comments by Scott-Russell, Dennison, Taylor and Cooper and would like to reply to their letter as follows:

They report their experience with morphometry in forty six patients referred to a osteoporosis centre. Using the same definition of a vertebral fracture (deformity of $\geq \mathbf{2 0} \%$ in height) as we did, they found similar figures for specificity and negative predictive value, but higher figures for sensitivity and positive predictive value. This could be explained by several differences between the two studies.

The most obvious argument, of course, is the difference between study populations. We have studied ankylosing spondylitis (AS) patients with inherent structural damage of the spine, including processes reflecting bone formation as well as bone loss and destruction, whereas Scott et al have studied post menopausal women. However, there are more arguments: 
- $\quad$ First, positive and negative predictive values are context-dependent, and the prevalence of fractures in our population is much lower with consequences for the positive predictive value.

- Second, we only looked for wedging fractures ( $\mathrm{Ha} / \mathrm{Hp}$ ratio) and not for diabolo fractures ( $\mathrm{Hm} / \mathrm{Hp}$ ratio). It would be interesting to explore if diabolo deformities are easier to recognise, especially in AS patients.

- Third, another explanation for the discrepancy could be the poor image quality of vertebrae in the thoracic region (especially in the upper parts) .

- At last, there is a difference in analysing the fractures on a patient level as compared to a vertebral level. Scott-Russell et al performed per patient analyses, whereas we analysed on both levels. Our per patient analysis showed good agreement between both methods, for the total spine $(I C C=0.64)$ as well as for thoracic (ICC $=0.66)$ and lumbar (ICC $=0.62$ ) parts separately. Analysis on separate vertebrae $(n=335)$ showed a different pattern of agreement dependent on the part of the spine that was examined. For the total spine (ICC $=0.71$ ) as well as for the lumbar (ICC $=0.76)$ part, an acceptable level of agreement was achieved. For the thoracic part the level of agreement $($ ICC $=0.43$ ) was only moderate. All identified fractures, both discrepant and matching, were localised in this thoracic (T6 - LI) region. If we recalculate in the same way Scott et al did, our results are similar to theirs except for lower sensitivity.

In conclusion, we agree with Scott et al that MRX as well as MXA are valuable in the assessment of vertebral deformities, especially at the lumbar spine level. In view of the negative predictive value of MXA, we believe that MXA is helpful to select patients in whom X-rays are necessary to verify the degree of vertebral deformities and differentiate them from other causes, such as Scheuerman's disease or normal variations in height. Further studies will be needed to demonstrate the degree of mutual exchangeability of both techniques. 
(19.) 11
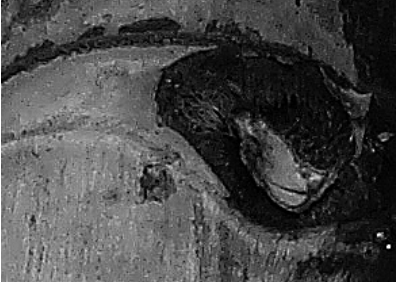

$y^{2}+2.36$

Let

+ 1

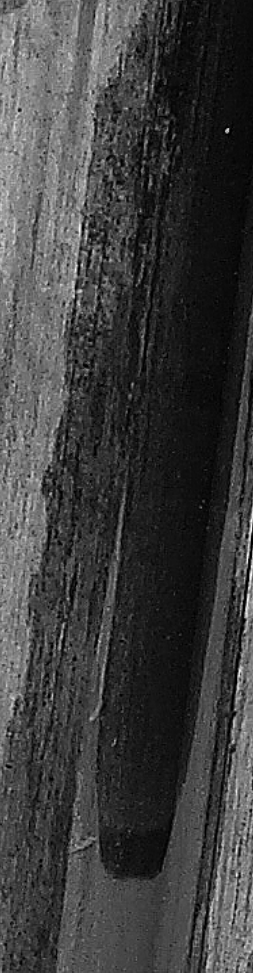

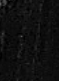




\section{Determinants \\ of hyperkyphosis \\ in patients with \\ ankylosing \\ spondylitis}

D. Vosse, D. van der Heijde, R. Landewé, P. Geusens, H. Mielants, M. Dougados,

S. van der Linden 


\section{ABSTRACT}

\section{Objective}

To determine clinical and radiographic determinants of hyperkyphosis in patients with Ankylosing spondylitis (AS).

\section{Methods}

Of 135 patients with AS participating in the OASIS cohort spinal hyperkyphosis was assessed by the occiput-to-wall distance (OWD) and defined as OWD>0. Disease activity was assessed by the BASDAI. Wedging of the vertebrae was calculated as the $\mathrm{Ha} / \mathrm{Hp}$ ratio as described by Genant Structural damage of the spine was assessed by the mSASSS. Hip involvement was assessed by the BASRI and defined as a score $>2$. Data were analysed by multiple regression analysis on van der Waerden-normal OWD values, with mean $\mathrm{Ha} / \mathrm{Hp}$ ratio, mSASSS, hip involvement and BASDAl as explanatory variables, and age, sex and disease duration after diagnosis as co-variates.

\section{Results}

61 patients (45.2\%) had an OWD >0 cm. Of these, $81 \%$ were male patients versus $57 \%$ in the group with normal OWD $(p<0.001)$. Forty-two patients had wedged thoracic vertebrae. Of those 42 patients, 27 (44\%) patients showed an increased OWD, as compared to 15 (20\%) of the 74 AS patients with normal OWD ( $p=0.005)$. OWD was significantly correlated with mean wedging of the thoracic spine $(\rho=-0.45$, $p=0.01)$, mSASSS $(\rho=0.56, p=0.01)$ and hip involvement $(\rho=0.2, p=0.05)$. Multivariate analysis showed that mSASSS (standardised beta $(s t ß)=0.52 ; p<0.001$ ), wedging of the thoracic spine $(s t ß=-0.28 ; p=0.01)$, and BASDAI ( $s t ß=0.15 ; p=0.05$ ) are independent determinants of OWD.

\section{Conclusion}

Radiological damage of the cervical and lumbar spine, thoracic wedging and actual disease activity are determinants of hyperkyphosis in patients with AS. These findings could be important in determining treatment goals in AS. 


\section{INTRODUCTION}

Hyperkyphosis of the upper part of the spine is a frequent clinical problem among patients with ankylosing spondylitis (AS). ${ }^{1,2,3}$ In our prevalence cohort of patients with AS (Outcome in AS International Study (OASIS) cohort) with a mean disease duration of 9.4 years, $49 \%$ of the patients have some degree of hyperkyphosis, if it is expressed as an Occiput-to-Wall Distance (OWD) of more than $0 \mathrm{~cm}$. ${ }^{4}$ The prominent position of the head and neck may give functional and psychological impairments for the patients. ${ }^{5}$ They may be unable to see straight ahead, may have difficulties in activities of daily living, Further, severe hyperkyphosis could result in compression of the abdominal viscera. ${ }^{6}$

The degree of hyperkyphosis in patients with AS is related to radiological damage. ${ }^{7}$ In general, hyperkyphosis is also associated with vertebral osteoporosis, and it is increasingly recognised that osteoporosis is a problem in patients with $\mathrm{AS}^{8-12}$ Vertebral deformities are regarded as one of the classical hallmarks of vertebral osteoporosis. In a population-based study, the relative risk for vertebral morphometric deformities in patients with AS was 7.6 as compared to the control population. ${ }^{13}$ Other investigators found a prevalence of vertebral deformities in 10 to $17 \%$ of the patients with AS seen in the clinic. ${ }^{14-17}$ In a pilot study we have shown that thoracic vertebral deformities but not lumbar vertebral deformities are related to an increase of OWD in patients with $A S^{17}$ However, it is not known how all potentially contributory factors (such as disease activity, structural damage visible on radiographs, hip involvement and vertebral wedging) interrelate with respect to explaining increased OWD in patients with AS. Therefore we investigated the independent contribution of various factors that may explain hyperkyphosis in a cross-sectional study of patients with AS.

\section{PATIENTS AND METHODS}

We included 139 patients of the Outcome in AS International Study (OASIS) cohort, an international longitudinal, observational study on outcome in AS, with a male to female ratio of 2:1, a mean disease duration of 9.4 years (defined as years since diagnosis) and a mean duration of complaints of 17.9 years. Consecutive patients in four secondary and tertiary referral centres, fulfilling the modified New York criteria for AS were included. ${ }^{18}$ Patients were followed according to a fixed protocol. ${ }^{4}$ Data from the 4-year assessment were used in the present analysis and in- 
clude Bath Ankylosing spondylitis Disease Activity Index (BASDAI) ${ }^{19}$, Bath Ankylosing spondylitis Functional Index (BASFI) ${ }^{20}$, lateral radiographs of the cervical, thoracic, and lumbar spine and radiographs of the pelvis. To assess structural damage the modified Stoke Ankylosing spondylitis Spine Score (mSASSS) was used. ${ }^{21}$ This method scores the anterior site of the lumbar ( lower border T12 - upper border S1) and cervical (lower border C2 - upper border T1) spine at a lateral view. The anterior corners of each vertebra are examined and scored 1 for an erosion, sclerosis and / or squaring, 2 for a syndesmophyte and 3 for total bony bridging, giving a maximum possible score of 72 . The mSASSS was applied by one observer (AW) (Figure 6.1). In a previous experiment we have determined that intra-observer (intraclass correlation coefficient $(I C C)=0.98$ ) and inter-observer $(I C C=0.99)$ reliability on mSASSS status scores of this observer were excellent. ${ }^{22}$ Radiographic hipinvolvement determined according to the Bath Ankylosing spondylitis Radiology Index (BASRI)-hip ${ }^{23}$ was as follows: 0: no involvement; 1: (possible) focal joint space narrowing, 2: definite narrowing leaving a circumferential joint space $>2 \mathrm{~mm} ; 3$ : narrowing with circumferential joint space $\leq 2 \mathrm{~mm}$ or bone-on-bone apposition of $<1 \mathrm{~cm}$; 4: bone deformity or bone-on-bone apposition $\geq 1 \mathrm{~cm}$. Grades 1 and 2 increase by one grade if two of the following bony changes are present: erosions, osteophytes, protrusion. Scores are applied to both hips. For the purpose of this article, hip involvement was defined as a BASRI-hip $>2$. Anterior $(\mathrm{Ha})$ and posterior (Hp) height of the vertebrae was measured on lateral radiographs of the thoracic (T4-12) and lumbar spine (L1-5) in millimetres by one observer (DV) (Figure 6.2) Imaging of the first three thoracic vertebrae mostly is inadequate so we omitted them in the analyses. Wedging of a vertebra was calculated as the $\mathrm{Ha} / \mathrm{Hp}$ ratio. This was defined as mild if the $\mathrm{Ha} / \mathrm{Hp}$ ratio was $>0.75$ and $\leq 0.80$, as moderate if the $\mathrm{Ha} / \mathrm{Hp}$ ratio was $>0.60$ and $\leq 0.75$, and as severe if the $\mathrm{Ha} / \mathrm{Hp}$ ratio was $\leq 0.60{ }^{24}$ We calculated the mean wedge (mean $\mathrm{Ha} / \mathrm{Hp}$ ratio) of all thoracic and lumbar vertebrae per patient, as well as for the lumbar and thoracic spine separately. 


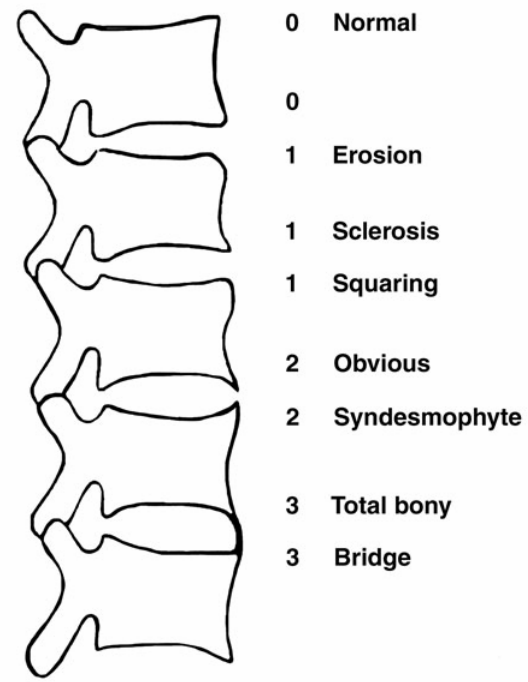

FIGURE 6.1

Assessment of mSASSS.

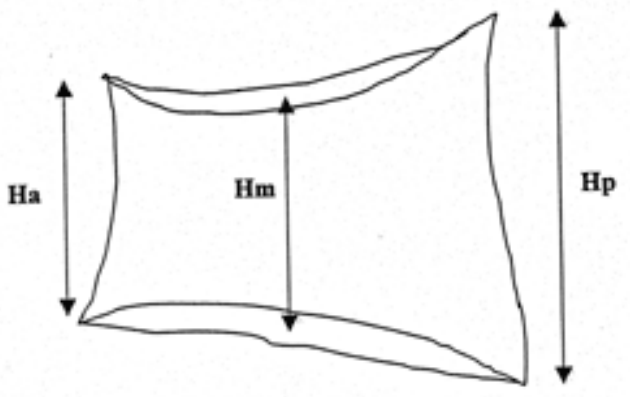

FIGURE 6.2

Measurement of vertebral heights.

To assess interobserver reliability of measuring anterior and posterior height two readers measured 70 vertebrae in ten patients with AS. These vertebrae were chosen by an independent observer who tried to include the entire spectrum of deformities. The smallest detectable difference (SDD) calculated according to the limits of agreement method by Bland \& Altman was 0.14 for $\mathrm{Ha} / \mathrm{Hp}$ ratio. The ICC for mean vertebral wedging was $0.93(95 \% \mathrm{Cl}$ : 0.85-0.96) for absolute heights and 0.84 (95\% Cl: 0.74-0.96) for $\mathrm{Ha} / \mathrm{Hp}$ ratios.

To quantify hyperkyphosis the distance between occiput and wall (OWD) was assessed with the patient standing with the heels and back against the wall, with hips and knees as straight as possible. The chin was held at the usual carrying level 
and the patient undertook maximal effort to touch the head against the wall. The distance between the wall and the occiput was measured in centimetres with one decimal. The better of two tries was recorded. ${ }^{25,26}$ Patients were grouped as having a normal OWD $(=0 \mathrm{~cm})$ or an increased OWD $(>0 \mathrm{~cm})$.

\section{Statistical analysis}

We used Chi-square tests to test differences is proportions. Spearman's correlation coefficients were calculated to investigate univariate associations between OWD and mean wedging, mSASSS and BASDAI. Linear regression analysis was performed to investigate the independent contribution of BASDAl, mean wedging, hip involvement, and mSASSS to explain variation in the dependent variable OWD. Covariates in the analysis were age, disease duration and sex.

Not normally distributed variables were first normalised by the Van der Waerden technique.

\section{RESULTS}

Of the 139 patients, four patients could not be included because of incomplete data. Table 6.1 presents some baseline characteristics of the patients. Of the 135 patients with complete data 50 of the 90 (56\%) male patients and 11 of the 45 (24\%) female patients had an OWD>0 cm ( $p=0.001)$. As compared to patients with a normal OWD, patients with an increased OWD were older, had a higher mean disease duration, and were more often of male gender. Disease activity (BASDAI) was similar in the two groups with a higher level of physical limitation (BASFI) and radiographic damage of the spine (mSASSS). In our cohort 12 patients (9\%) had severe radiological hip involvement; eight of them had an OWD $>0 \mathrm{~cm}$.

Overall, forty-two patients showed 89 vertebral wedgings defined as a $\mathrm{Ha} / \mathrm{Hp}$ ratio $\leq 0.80$. When comparing fracture rate in patients with normal OWD $(n=74)$ to increased OWD ( $n=61), 15(20 \%)$ patients in the normal OWD group had vertebral fractures compared to 27 (44\%) patients with OWD>0 cm. Of these 89 fractures 59 (66\%) were mild, $29(33 \%)$ moderate and $1(1 \%)$ severe. All fractures were found in the thoracic spine except for four fractures ( 3 moderate and 1 mild) in the first lumbar vertebra and one mild fracture in the fourth lumbar vertebra (Table 6.2). When comparing the number of fractures with OWD we found significant correlations, both analysing all fractures and analysing fracture groups (no, 1 or $>1$ fracture and yes/ no fractures) versus OWD ( $p=0.002, p=0.01, p=0.003)$. 
TABLE 6.1 Clinical and radiological data of all patients in relation to normal and increased occiput-towall distance.

\begin{tabular}{lccl}
\hline & $\begin{array}{c}\text { Patients OWD }=0 \\
(\mathrm{n}=74)\end{array}$ & $\begin{array}{c}\text { Patients OWD }>0 \\
(\mathrm{n}=61)\end{array}$ & \multicolumn{1}{c}{-value $^{\mathrm{a}}$} \\
\hline Age (mean \pm SD) & $45.7(10.5)$ & $53.5(11.9)$ & $\mathrm{p}<0.001$ \\
Mean disease duration after diagnosis, years $( \pm \mathrm{SD})$ & $13.3(9.7)$ & $16.5(9.6)$ & $\mathrm{p}=0.06$ \\
Sex, \% Males & $57 \%$ & $81 \%$ & $\mathrm{p}<0.001$ \\
Mean BASDAI $( \pm \mathrm{SD})$ & $3.3(2.3)$ & $3.6(2.4)$ & $\mathrm{p}=0.28$ \\
Mean BASFI $( \pm \mathrm{SD})$ & $2.8(2.3)$ & $4.8(2.5)$ & $\mathrm{p}<0.001$ \\
Mean mSASSS $( \pm \mathrm{SD})$ & $8.0(10.9)$ & $28.5(22.0)$ & $\mathrm{p}<0.001$ \\
Mean wedge Thoracic spine $( \pm \mathrm{SD})$ & $0.94(0.04)$ & $0.90(0.06)$ & $\mathrm{p}<0.001$ \\
Mean wedge Lumbar spine $( \pm \mathrm{SD})$ & $1.03(0.05)$ & $1.05(0.06)$ & $\mathrm{p}=.0 .013$ \\
At least one wedged vertebra (Number of patients) & $15(74)$ & $27(61)$ & $\mathrm{p}=0.005$ \\
Severe hip involvement (Number of patients) & $4 / 70$ & $8 / 53$ & $\mathrm{p}=0.12$ \\
\hline
\end{tabular}

${ }^{a}$ For the difference between patients with $O W D=0$ vs. patients with OWD>0. OWD: occiput-to-wall distance; BASDAI: Bath Ankylosing spondylitis Disease Activity Index; BASFI: Bath Ankylosing spondylitis Functional Index; mSASSS: modified Stoke Ankylosing spondylitis Spine Score; SD: standard deviation

TABLE 6.2 Distribution of the number of vertebral fractures and rating of their severity.

\begin{tabular}{|c|c|c|c|c|c|}
\hline & $\begin{array}{l}\text { Number of } \\
\text { fractures }\end{array}$ & $\begin{array}{l}\text { Percentage of } \\
\text { total fractures }\end{array}$ & $\begin{array}{l}\text { Mild }^{\mathrm{a}} \\
\text { fracture }\end{array}$ & $\begin{array}{l}\text { Moderate }^{b} \\
\text { fracture }\end{array}$ & $\begin{array}{l}\text { Severe }^{c} \\
\text { fracture }\end{array}$ \\
\hline T4 & 4 & 3 & 4 & & \\
\hline T5 & 3 & 2 & 2 & & 1 \\
\hline T6 & 13 & 10 & 6 & 7 & \\
\hline T7 & 15 & 11 & 8 & 7 & \\
\hline T8 & 14 & 10 & 6 & 8 & \\
\hline T9 & 7 & 5 & 5 & 2 & \\
\hline T10 & 9 & 7 & 8 & 1 & \\
\hline T11 & 12 & 9 & 9 & 3 & \\
\hline T12 & 7 & 5 & 7 & & \\
\hline L1 & 4 & 3 & 1 & 3 & \\
\hline \multicolumn{6}{|l|}{ L2 } \\
\hline \multicolumn{6}{|l|}{ L3 } \\
\hline L4 & 1 & 1 & 1 & & \\
\hline L5 & & & & & \\
\hline
\end{tabular}

Spearman's correlation coefficients were calculated to investigate univariate associations between OWD and mean wedging in the thoracic and lumbar spine, mSASSS, hip involvement and BASDAI. Clearly, OWD showed significant correlations with all factors except with the mean lumbar wedging and with the BASDAI. (Table 6.3). In order to explore the independent contribution of different variables 
to explain variation in OWD (as a continuous measure), linear regression analysis was performed. Because age, sex and disease duration may spuriously be associated with OWD, these variables were included as co-variates. Table 6.4 shows the main results of this analysis. Variation in OWD was primarily explained by mSASSS. There was, however, an independent contribution of both mean thoracic wedging and cross-sectional assessed BASDAI. In this analysis severe hip involvement did not independently contribute to explaining variation in OWD, although a positive trend could be recognised.

TABLE 6.3 Univariate correlation coefficients between occiput-to-wall distance, wedging, disease activity, and radiological hip involvement.

\begin{tabular}{lccccc}
\hline & mSASSS & $\begin{array}{c}\text { Mean wedging } \\
\text { thoracic spine }\end{array}$ & $\begin{array}{c}\text { Mean wedging } \\
\text { lumbar spine }\end{array}$ & BASDAl & Hip score $>2$ \\
\hline OWD & $0.56^{\mathrm{a}}$ & $-0.45^{\mathrm{a}}$ & 0.16 & 0.10 & $0.20^{\mathrm{b}}$ \\
mSASSS & 1 & $-0.32^{\mathrm{a}}$ & 0.05 & 0.05 & 0.16 \\
Mean wedging & & 1 & -0.10 & 0.10 & -0.02 \\
$\quad$ thoracic spine & & 1 & -0.001 & 0.10 \\
$\begin{array}{l}\text { Mean wedging } \\
\quad \text { lumbar spine }\end{array}$ & & & 1 & -0.03 \\
BASDAl & & & & 10 \\
\hline
\end{tabular}

${ }^{a} p \leq 0.01 ;{ }^{b} p \leq 0.05$

TABLE 6.4 Multivariate analysis of variables determining occiput to wall distance in patients with ankylosing spondylitis.

\begin{tabular}{lcc}
\hline Variable & Standardised beta & P-value \\
\hline mSASSS & 0.47 & 0.01 \\
Mean wedging thoracic spine & 0.28 & 0.01 \\
BASDAI & 0.15 & 0.05 \\
Hip involvement & 0.12 & 0.08 \\
\hline
\end{tabular}

Adjusted for age, sex and disease duration after diagnosis; Model $\mathrm{R}^{2}=0.42$ 
OWD was merely associated with wedging of the thoracic part of the vertebral column. However, the mSASSS does not take the thoracic spine into account, but only the cervical and lumbar spine. We analysed the contribution of the mSASSS of the cervical spine and of the lumbar spine separately in explaining OWD by regression models, including the same variables as in the main model. The contribution of both site-specific mSASSSs in explaining variation in OWD was approximately similar (st $ß=0.62$ for the cervical mSASSS and 0.57 for the lumbar mSASSS).This is not unexpected since the cervical and lumbar mSASSS were highly correlated $(\rho=0.64)$.

\section{DISCUSSION}

In the entire OASIS cohort spinal hyperkyphosis (OWD>0) occurs in half of the patients. ${ }^{4}$ In our study we found a clear correlation between radiological damage assessed on the anterior site of the cervical and lumbar spine (mSASSS) and hyperkyphosis. Furthermore, the mean thoracic wedging was significantly and independently contributory to explaining OWD, while lumbar wedging deformities did not contribute to the OWD. Wedging was assessed in the thoracic spine as well as in the other parts, but mSASSS does not score thoracic spine. The reason is that radiographic changes in this particular area of the spine are difficult to score and reproducibility is not good. Braun et al published data on MRI changes in the thoracic spine and they found that the thoracic spine, as compared to the cervical and lumbar spine, was prominently involved. ${ }^{27}$ Missing the thoracic spine scores would potentially have been critical if we had not found a correlation between mSASSS and OWD, since in such a scenario preferential thoracic spine damage could still be an explanation. But we found a correlation between radiological changes and OWD, even without including thoracic spine data, and we believe that if we had included the thoracic spine, these data would only have strengthened our findings.

In a multivariate analysis, in addition to mSASSS and mean thoracic wedging, disease activity (BASDAI) independently, although marginally, contributed to spinal hyperkyphosis. Considering the hip involvement in AS as a possible factor leading to limitation of movement, one can assume the influence of fixed flexion of the hips on the OWD. Therefore, we investigated the correlation between hip involvement and hyperkyphosis. We analysed this by comparing OWD in patients with severe hip involvement $(B A S R I>2)$ versus no or mild hip involvement $(B A S R I \leq 2)$. This 
analysis showed a trend, but did not reach statistical significance in both the univariate and multivariate analyses, possibly due to the low prevalence of hip involvement. It should be stressed that the variables that we have investigated here only in part explain hyperkyphosis. Other potentially contributory factors include inflammation of ligaments, muscles and entheses. And in a previous article we described the role of disc deformities in hyperkyphosis. ${ }^{17}$ In this study we did not analyse these soft tissues, as we focused on vertebral wedging and radiographic damage.

A shortcoming of our study is the cross-sectional design. It would be preferable to have a prospective follow-up of patients with AS in an early phase of their disease and to observe the development of the spine deformity. On the other hand, others could not find a relation between radiological damage and disease duration, age at diagnosis or acute phase response in such prospective studies. ${ }^{7}$ In previous analyses Boonen et al ${ }^{28}$ concluded that there was no change in selfreported health status over a period of four years. In a long-term follow-up study of the OASIS cohort, in which patients were followed every two months during the first two years and every year thereafter, mean BASDAI did not change (st $\beta=0.007$; $95 \% \mathrm{Cl}:-0.013$ to 0.027 ), which is why we believe a cross-sectional approach is justified.

Possible confounders of the relationship between wedging and OWD are age and sex, since OWD may increase with age, and since AS is a predominantly male disease with a more serious course in male as compared to female patients. ${ }^{1}$ However, we did not find a relationship between age, sex and OWD, neither univariate, nor multivariate.

In AS the burden of illness is a result of longstanding inflammation and its consequence. Further, cumulative inflammation results in radiological damage reflected in mSASSS scores. In our study we found an independent significant relation between these factors and hyperkyphosis.

In analogy with peri-articular bone loss in RA we hypothesise that vertebral wedging is the result of peri-articular bone loss in the spine. ${ }^{29}$ Inflammatory processes are found to be associated with increased bone loss and bone turnover. ${ }^{9,30}$ This results in reduced bone mineral density (BMD).

Osteoporosis is shown to be associated with inflammatory rheumatic diseases, such as $\mathrm{RA}^{31,32}$ and $\mathrm{AS}^{11}$ Vertebral deformities are considered to be the main feature of osteoporosis. Our study confirmed an independent significant relation between wedging of (thoracic) vertebrae and hyperkyphosis. 
In conclusion, we found three independent significant contributory factors to hyperkyphosis: structural damage of the spine, wedging of thoracic vertebrae and cross-sectional disease activity. In addition we found a significant higher BASFI in patients with an OWD>0 $\mathrm{cm}$. Therefore, in order to prevent or limit functional decline future studies on new therapies in the treatment of AS should include prevention, if possible, of the development of structural damage as well as prevention of the development of vertebral osteoporosis, and its effect on the development of hyperkyphosis. 


\section{REFERENCES}

1. Carette S, Graham D, Little H, Rubenstein J, Rosen P. The natural disease course of ankylosing spondylitis. Arthritis Rheum 1983; 26:186-90

2. Wilkinson M, Bywaters EGL. Clinical features and course of ankylosing spondylitis. Ann Rheum Dis 1958; 17:209-16

3. Spencer DG, Park WM, Dick HM, Papazoglou SN, Buchanan WW. Radiological manifestations in 200 patients with ankylosing spondylitis: correlation with clinical features and HLA-B27. J Rheumatol 1979;6:305-15

4. Spoorenberg A, van der Heijde D, de Klerk E, Dougados M, deVlam K, Mielants H, van der Tempel $\mathrm{H}$, van der Linden Sj. A comparative study of the usefulness of the Bath Ankylosing spondylitis Functional Index and the Dougados Functional Index in the assessment of ankylosing spondylitis. J Rheumatol 1999;26:961-5

5. McMaster MJ. Osteotomy of the cervical spine in ankylosing spondylitis. J Bone Joint Surg [Br] 1997;79:197-203

6. Kim KT, Suk KS, Cho YM, Hong GP, Park BJ. Clinical outcome Results of pedicle subtraction osteotomy in Ankylosing spondylitis with kyphotic deformity. Spine 2002;27:612-8

7. Averns HL, Oxtoby J, Taylor HG, Jones PW, Dziedzic K, Dawes PT. Radiological outcome in ankylosing spondylitis: use of the Stoke Ankylosing spondylitis Spine Score (SASSS). Br J Rheumatol 1996; 35:373-6

8. Bronson WD, Walker SE, Hillman LS, Keisler D, Hoyt T, Allen SH. Bone mineral density and biochemical markers of bone metabolism in ankylosing spondylitis. J Rheumatol 1998;25:929-35

9. Lee YS, Schlotzhauer T, Ott SM, van Vollenhoven RF, Hunter J, Marcus R, McGuire JL. Skeletal status of men with early and late ankylosing spondylitis. Am J Med 1997; 103:233-41

10. Devogelaer JP, Maldague B, Malghem J, Nagant de Deuxchaisnes C. Appendicular and vertebral bone mass in ankylosing spondylitis. A comparison of plain radiographs with single- and dualphoton absorptiometry and with quantitative computed tomography. Arthritis Rheum 1992; 35:1062-7

11. Will R, Palmer R, Bhalla AK, Ring EFJ, Calin A. Osteoporosis in early ankylosing spondylitis: a primary pathologic event? Lancet 1989; 2:1483-5

12. Maghraoui A, Borderie D, Cherruau B, Eduoard R, Dougados M, Roux C. Osteoporosis, body composition and bone turnover in Ankylosing Spondylitis. J Rheumatol 1999; 26:2205-9

13. Cooper C, Carbone L, Michet CJ, Atkinson EJ, O'Fallon WM, Melton LJ 3rd. Fracture risk in patients with ankylosing spondylitis: a population based study. J Rheumatol 1994;21:1877-82

14. Ralston SH, Urquhart GDK, Brzeski M, Sturrock RD. Prevalence of vertebral compression fractures due to osteoporosis in ankylosing spondylitis. BMJ 1990;300:563-5

15. Donnelly S, Doyle DV, Denton A, Rolfe I, McCloskey EV, Spector TD. Bone mineral density and vertebral compression fracture rates in ankylosing spondylitis. Ann Rheum Dis 1994; 53:117-21

16. Mitra D, Elvins DM, Speden DJ, Collins AJ. The prevalence of vertebral fractures in mild ankylosing spondylitis and their relationship to bone mineral density. Rheumatology 2000; 39:85-9

17. Geusens P, Vosse D, van der Heijde DM, Vanhoof J, van Tubergen A, Raus J, van der Linden SM. High prevalence of thoracic vertebral deformities and discal wedging in ankylosing spondylitis patients with hyperkyphosis. J Rheumatol 2001;28:1856-61

18. van der Linden SM, Valkenburg HA, Cats A. Evaluation of diagnostic criteria for ankylosing spondylitis: a proposal for modification of the New York criteria. Arthritis Rheum 1984; 27:361-8

19. Calin A, Nakache JP, Gueguen A, Zeidler H, Mielants, H, Dougados M. Defining disease activity in ankylosing spondylitis: is a combination of variables ( Bath ankylosing spondylitis disease activity index) an appropriate instrument? J Rheumatol 1994;38:878-82 
20. Calin A, Garrett S, Whitelock H, Kennnedy G, O'Hea J, Mallorie P, Jenkinson T. A new approach to defining functional ability in Ankylosing Spondylitis: thr development of the Bath ankylosing spondylitis functional index. J Rheumatol 1994;21:2281-5

21 Creemers MCW, Franssen MJAM, van 't Hof MA, Gribnau FWJ, vd Putte LBA, vRiel PLCM. Assessment of outcome in Ankylosing Spondylitis: an extended radiological scoring system. Ann Rheum Dis 2005;64:127-9. doi:10.1136/ard.2004.020503

22. Wanders AJB, Landewé RBM, Spoorenberg A, Dougados $M$, vdLinden $S$, Mielants $H$, vdTempel $H$, vdHeijde DMFM. What is the most appropriate radiological scoring method for Ankylosing Spondylitis? A comparison of the available methods based on the OMERACT filter. Arthritis Rheum. 2004;50:2622-32.

23. MacKay K, Mack C, Brophy S, Calin A. The Bath ankylosing spondylitis radiology index (BASRI). A new, validated approach to disease assessment. Arthritis Rheum 1998; 41:2263-70

24. Genant HK, Wu CY, Kuijk van C, Nevitt MC. Vertebral fracture assessment using a semi quantitative technique. J Bone Miner Res 1993;8:1137-48

25. Bellamy N. Musculoskeletal clinical metrology. Dordrecht: Kluwer Academic publishers; 1993

26. Heuft-Dorenbosch L, et al. Measurement of Spinal Mobility in Ankylosing Spondylitis: comparison of occiput-to-wall and tragus-to-wall distance. J Rheumatol 2004;31:1779-84

27. Braun J, Baraliakos W, Golder W et al. Analysing chronic spinal changes in ankylosing spondylitis: a systematic comparison of conventional $x$ rays with magnetic resonance imaging using established and new scoring systems. Ann Rheum Dis 2004;63:1046-1055. doi: 10.1136/ard.2003.019968

28. Boonen A, van der Heijde D, Landewé R, Mielants $H$, Dougados $M$, vd Linden Sj. Health status in patients with ankylosing spondylitis shows no relevant change over a period of 4 years. Clin Exp Rheumatol 2004;22:682 P4.12(abstract)

29. Haugeberg G, Strand A, Kvien TK, Kirwan JR. Reduced loss of hand bone density with prednisolone in early rheumatoid arthritis. Results from a randomized placebo-controlled trial. Arch Intern Med.2005;165:1293-97

30. Toussirot E, Ricard-Blum S, Dumoulin G, Cedoz JP, Wendling D. Relationship between urinary pyridinium cross-links, disease activity and disease subsets of ankylosing spondylitis. Rheumatology 1999;38:21-37

31. Deodhar AA, Woolf AD. Bone mass measurement and bone metabolism in rheumatoid arthritis: a review. Br J Rheumatol 1996;35:309-22

32. Laan RFJM, Buijs WCAM, Verbeek ACM, et al. Bone mineral density in patients with recent onset rheumatoid arthritis: influence of disease activity and functional capacity. Ann Rheum Dis 1993;52:21-6 



\section{Association of markers}

of bone- and cartilage degradation with radiological changes at baseline and after 2 years follow-up in patients with ankylosing spondylitis 


\section{ABSTRACT}

\section{Objective}

There is a lack on knowledge of factors that reliably can predict radiological changes in patients with ankylosing spondylitis (AS). We have investigated whether urinary C-terminal cross linking telopeptide of type I (CTX-I) and type II (CTX-II) collagen, as specific biochemical markers of bone and cartilage degradation respectively, are associated with radiological damage and progression, and with bone mineral density (BMD) in patients with AS.

\section{Methods}

Eighty three patients with AS (mean (SD) age: 50.4 (12) years, 65\% male, mean (SD) disease duration after diagnosis: 16.7 (10) years) who participate in an ongoing cohort study of patients with AS (OASIS: Outcome in Ankylosing spondylitis International Study cohort) were assessed for urinary CTX-I and -II. Results of both biochemical markers were compared with baseline scores for radiological damage (modified SASSS, primarily reflecting syndesmophyte formation and -growth), and with scores for radiological progression after two years follow-up. Markers were also associated with disease activity parameters and bone mineral density (BMD).

\section{Results}

Mean duration of complaints was 28.6 years. At that time $54 \%$ of patients had signs of radiological damage, and $35 \%$ of them showed radiological progression after 2 years. Baseline radiological damage ( $\rho=0.24 ; p \leq 0.05$ ) correlated with CTX-II, but not with CTX-I. CTX-II correlated with serological markers of inflammation (ESR $\rho=0.29$ and CRP $\rho=0.30 ; p \leq 0.01$ ), but not with baseline BASDAI or BMD. There was a negative correlation between CTX-I and BMD of the trochanter $(\rho=-0.31 ; p \leq 0.01)$ In multivariate analyses CTX-II significantly and independently contributed to explaining variation in radiological damage (st $ß=0.27 ; p=0.03$ ) and progression $(s t ß=0.27 ; p=0.05)$.

\section{Conclusion}

In AS, cartilage degradation plays a role in explaining radiological damage and -progression in the spine. 


\section{INTRODUCTION}

Ankylosing spondylitis (AS) is a chronic inflammatory disease mainly affecting the axial skeleton and is characterised by ossification of the spinal joints and ligaments. Bone loss in diseases such as AS and rheumatoid arthritis (RA) is related to inflammation. ${ }^{1-4}$ Since inflammation in AS resides primarily in the spine, inflammationinduced bone failure may lead to vertebral fractures and deformities, and consequently to hyperkyphosis of the upper part of the spine. Nowadays, it is increasingly recognized that osteoporosis plays a role in vertebral deformities in patients with $\mathrm{AS}^{5-8}$ In RA, radiological damage includes cartilage destruction and bone erosion, which is considered to be the result of chronic inflammation. It has been shown that specific biochemical markers of type I collagen degradation (CTX-I) (reflecting bone) and type II collagen degradation (CTX II) (reflecting cartilage) could predict radiographic progression in RA. ${ }^{9-11}$ In AS the pathophysiological processes underlying radiological progression are unclear. Whilst excessive bone formation (syndesmophytes) is most characteristic of AS, erosions and destruction of "vertebral units" (vertebral bone plus intervertebral disc) may occur. A few cross-sectional studies have analysed biochemical markers of bone turnover and have reported conflicting data, but there seems to be increased bone resorption. ${ }^{12,13}$ Only two studies have addressed markers of cartilage turnover, but the association with radiological damage or BMD was not investigated $\mathrm{n}$ these studies. $^{14,15}$

The aim of the present study was to investigate among AS patients the relationships between CTX-I and CTX-II with disease activity, radiological damage and 2-year radiological progression.

\section{PATIENTS AND METHODS}

Eighty three AS patients, participating in the Outcome in AS International Study (OASIS) cohort, were participating in this analysis. OASIS is an international longitudinal, observational study on the outcome of AS. ${ }^{16}$ This study was approved by the hospital ethics committee and informed consent was obtained from all subjects. The patients are followed at regular intervals according to a standardized protocol. The 48 months assessment was used for the baseline evaluation of the present analysis, and the 72-month assessment for the evaluation of radiological progression. Data that were collected include erythrocyte sedimentation rate (ESR), C- 
reactive protein (CRP), Bath Ankylosing spondylitis Disease Activity Index (BASDAI) ${ }^{17}$, and Bath Ankylosing spondylitis Functional Index (BASFI) ${ }^{18}$. The 44 joint count was used to assess the number of swollen joints. Lateral radiographs of the cervical and lumbar spine obtained at 48- and 72 months were used to measure radiographic progression. At the baseline visit second morning void urine samples were collected. The samples were stored at $-20^{\circ}$ Celsius and analyzed simultaneously.

At 48 months bone mineral density (BMD) was assessed by dual X-ray absorptiometry (DXA) (Hologic QDR 4500, NHANES-III reference group, Bedford, MA).

\section{Radiological assessment}

To assess structural damage the modified Stoke Ankylosing spondylitis Spine Score (mSASSS) was used. ${ }^{19}$ This method scores the anterior site of the lumbar (lower border T12 to the upper of S1) and cervical (lower border C2 to the upper border of T1) spine at a lateral view. The anterior corners of each vertebra are examined and scored 1 for erosion, sclerosis and / or squaring, 2 for a syndesmophyte and 3 for total bony bridging, giving a maximum possible score of 72 . In a previous experiment we have determined that intra-observer and inter-observer reliability on mSASSS status scores of this method were excellent. ${ }^{20}$

\section{Markers}

Urinary CTX-I was measured by the CrossLaps enzyme linked immunosorbent assay (ELISA) (Nordic Biosciences, Herlev, Denmark). ${ }^{21}$ This assay uses a polyclonal antiserum raised against the $\beta$-isomerized EKAH $\beta D G G R$ sequence of the C-telopeptide of $\alpha 1$ chains of human type I collagen. Intra- and interassay coefficients of variation were lower than $6 \%$ and $9 \%$ respectively. Urinary CTX-II was measured by a competitive ELISA (CartiLaps; Nordic Biosciences, Herlev, Denmark) based on a mouse monoclonal antibody raised against the EKGPDP sequence of human type II collagen C-telopeptide. ${ }^{22}$ This sequence is found exclusively in type II collagen and not in the other collagens, including type I collagen, or other structural proteins. The antibody used in this assay is absolutely specific for peptides containing a free Cterminal proline. Intra- and interassay coefficients of variation were lower than $8 \%$ and $10 \%$ respectively. Urinary CTX-I and CTX-II levels were corrected by the urinary creatinine concentration. Urinary creatinine was measured by a standard colorimetric method. All measurements were performed in duplicate in a specialized central laboratory (Synarc, Lyon, France) and intra and inter assay coefficients of variation are below $10 \%$. 


\begin{abstract}
Statistical analysis
Spearman's correlation coefficients were calculated to investigate univariate associations. Partial correlations with adjustment for disease duration, were calculated for CTX-I-or CTX-II levels versus ESR, CRP, mSASSS at baseline, BMD and 2year change in mSASSS. Linear regression analysis was performed to investigate which variables independently contributed to explaining radiological damage or progression. Independent variables entered in the model were: CTX-I; CTX-II, CRP, BASDAI and mSASSS. Not normally distributed variables underwent a normalization procedure using the Van der Waerden technique.
\end{abstract}

\title{
RESULTS
}

Table 7.1 shows the baseline characteristics of the 83 patients. Mean BASDAI was compatible with low to moderate disease activity Mean (SD) levels of CTX-I and CTX-II were 190 (114) $\mu \mathrm{g} / \mathrm{mmol}$ creatinine and 298 (260) ng/mmol.creatinine respectively. Elevated levels of CTX-I were found in $44(53 \%)$ patients, elevated levels of CTX-II in 60 (72\%) patients with a range from 74,1-1717,0 $\mathrm{gg} / \mathrm{mmol} \mathrm{Cr}$ for CTX-I and from 11,5-628,1 ng/mmol Cr for CTX-II. As a reference, CTX-I and -II levels of age and sex matched controls are $168 \mu \mathrm{g} / \mathrm{mmol}$ creatinine and 158 $\mathrm{ng} / \mathrm{mmol}$ creatinine, respectively, in our laboratory.

A significant percentage (54\%) of patients had an increased mSASSS at baseline, $35 \%$ of patients showed some radiological progression over 2 years, ranging from 1 to 12 mSASSS units. Table 7.2 shows that CTX-II, but not CTX-I, significantly correlated with radiological damage at baseline, as well as with 2-year radiological progression, and that these correlations remained significant after adjustment for disease duration. CTX-II also correlated with ESR and CRP and this correlation also remained significant after adjustment for disease duration. A negative correlation between CTX-I and BMD was found, especially for the area of the trochanter, which mainly consists of trabecular bone. Adjustment for disease duration did not influence this observation. Patients with increased levels of CTX-I or CTX-II did not differ significantly in mSASSS scores or change compared to those with normal levels. 
TABLE 7.1 Baseline characteristics of 83 patients with ankylosing spondylitis.

\begin{tabular}{lc}
\hline Mean (SD) age, & $50(12)$ \\
Sex, \% males & 65 \\
HLA-B27, \% present & 83 \\
Mean (SD) disease duration after diagnosis, years & $17(10)$ \\
Mean (SD) disease duration after start complaints, years & $29(12)$ \\
Mean (SD) BASDAI & $3.6(2.3)$ \\
Mean (SD) BASFI & $4.1(2.3)$ \\
Mean (SD) CRP, mg/L (Normal value < 10 mg/L) & $17(15)$ \\
Mean (SD) ESR (SD), mm/hr & $11(9.2)$ \\
Mean (SD) CTX-I, $\mu$ g/mmol creatinine & $190(114)$ \\
Mean (SD) CTX-II, ng/mmol creatinine & $298(260)$ \\
Mean (SD) mSASSS & $19(20)$ \\
Number (\%) of patients with mSASSS>0 & $45(54)$ \\
Mean (SD) 2-year change in mSASSS & $1.0(2.1)$ \\
Mean (SD) bone mineral density, gm/cm ${ }^{2}$ & \\
- Femoral neck & $0.75(0.11)$ \\
- Trochanter & $0.67(0.16)$ \\
- Total & $0.90(0.12)$ \\
\hline CTX-I: C-terminal peptide of collagen Type I; CTX-II: C-terminal peptide of collagen Type II, mSASSS: \\
modified Stoke Ankylosing spondylitis Spine Score, CRP: C-reactive protein, ESR: erythrocyte \\
sedimentation rate, BASDAl: Bath Ankylosing spondylitis Disease Activity Index, BASFI: Bath Ankylosing \\
spondylitis Functional Index
\end{tabular}

TABLE 7.2 Correlation matrix for the relation between CTX-I and CTX-II versus measures of disease activity and radiographic damage or progression in 83 patients with ankylosing spondylitis.

\begin{tabular}{|c|c|c|c|c|}
\hline \multirow[t]{2}{*}{ parameters } & \multicolumn{2}{|r|}{ CTX-I } & \multicolumn{2}{|r|}{ CTX-II } \\
\hline & Crude & $\begin{array}{l}\text { After adjustment } \\
\text { for disease } \\
\text { duration }\end{array}$ & Crude & $\begin{array}{l}\text { After adjustment } \\
\text { for disease } \\
\text { duration }\end{array}$ \\
\hline mSASSS at baseline & 0.03 & 0.02 & $0.24^{\mathrm{a}}$ & $0.28^{\mathrm{a}}$ \\
\hline 2-year change in mSASSS & -0.06 & -0.05 & $0.26^{\mathrm{a}}$ & $0.28^{a}$ \\
\hline CRP & -0.03 & -0.05 & $0.30^{\mathrm{b}}$ & $0.31^{b}$ \\
\hline ESR & -0.03 & -0.02 & $0.29^{b}$ & $0.30^{b}$ \\
\hline BASDAI & -0.18 & -0.22 & 0.01 & 0.03 \\
\hline BASFI & -0.21 & -0.26 & 0.02 & 0.03 \\
\hline Swollen joint count & -0.10 & -0.08 & -0.08 & -0.10 \\
\hline Bone mineral density, femoral neck & -0.24 & -0.13 & 0.16 & 0.18 \\
\hline Bone mineral density, trochanter & $-0.31^{\mathrm{a}}$ & $-0.30 *$ & -0.15 & 0.01 \\
\hline
\end{tabular}

${ }^{a} \mathrm{p} \leq 0.05 ;{ }^{b} \mathrm{p} \leq 0.01$. Figures are (partial) correlation coefficients. CTX-I: C-terminal peptide of collagen Type I; CTX-II: C-terminal peptide of collagen Type II, mSASSS: modified Stoke Ankylosing spondylitis Spine Score, CRP: C-reactive protein, ESR: erythrocyte sedimentation rate, BASDAI: Bath Ankylosing spondylitis Disease Activity Index, BASFI: Bath Ankylosing spondylitis Functional Index 
In a multivariate analysis, with baseline mSASSS as the dependent variable, CTX-II significantly and independently contributed in explaining radiological damage (Table 7.3). The total amount of variance explained, however, was small (5.6\%). In this analysis serological markers of inflammation or clinical disease activity at baseline did not contribute to explaining radiological progression. Expectedly, disease duration was significantly associated with mSASSS at baseline. A separate multivariate analysis with 2-year change in mSASSS as the dependent variable yielded exactly similar results, with CTX-II weakly but significantly contributing to explaining variation in radiographic progression (stß: $0.27 ; p=0.05$ ). The significant contribution of CTX-II disappeared when mSASSS at baseline was added to the model.

TABLE 7.3 Multivariate analysis of variables contributing to spinal damage at baseline or progression after two years follow-up (by modified Stoke Ankylosing spondylitis Spine Score) in 83 patients with ankylosing spondylitis.

\begin{tabular}{lccccc}
\hline & \multicolumn{2}{c}{ Baseline damage } & & \multicolumn{2}{c}{ Progression 0-2 years } \\
\cline { 2 - 3 } \cline { 5 - 6 } Variable: & Standardized beta & $\mathrm{p}$-value & & Standardized beta & $\mathrm{p}$-value \\
\hline CTX-II, ng/mmol creatinine & 0.27 & 0.03 & & 0.27 & 0.05 \\
CTX-I, $\mu$ g/mmol creatinine & -0.04 & 0.76 & & -0.04 & 0.75 \\
Disease duration, years & 0.33 & 0.004 & & 0.26 & 0.04 \\
CRP, mg/l & 0.11 & 0.37 & & 0.04 & 0.80 \\
BASDAI & 0.11 & 0.35 & & 0.04 & 0.77
\end{tabular}

Full model $R^{2}: 0.056$

Full model $\mathrm{R}^{2}: 0.061$

All variables except BASDAI were normalized using a van der Waerden normalization procedure. CTX-I: C-terminal peptide of collagen Type I; CTX-II: C-terminal peptide of collagen Type II, CRP: C-reactive protein, BASDAI: Bath Ankylosing spondylitis Disease Activity Index, mSASSS: modified Stoke Ankylosing spondylitis Spine Score.

\section{DISCUSSION}

The first observation of this study is that both CTX-I and CTX-II were increased in AS as compared to the age- and sex-matched unaffected population. Second, CTX-I and CTX-II were moderately correlated, suggesting that in AS cartilage- and bone degradation occur to some extent simultaneously as the result of a mutual trigger. Third, CTX-II was correlated with serological measures of disease activity (inflammation). In their relationship with radiological damage and progression (mSASSS), both markers also acted differently: CTX-II was to some degree associated with radiological damage and -progression in AS -which points to a role for cartilage in 
explaining characteristic structural abnormalities in AS- whilst CTX-I, which reflects bone degradation, appeared not to be associated with radiological damage or progression at all.

In view of the evidence in RA that points to a tight relation between inflammation and bone- and cartilage degradation ${ }^{9-11}$, it is not surprising to find elevated CTX-I and -II levels in an inflammatory disease like AS. The elevated CTX-I levels, for example, confirm that inflammation results in loss of bone density, and the correlation we found between CTX-I and BMD is consistent with this observation. The elevated levels of CTX-II, and the association of CTX-II with markers of inflammation, also raise the suggestion that cartilage degradation in AS is up-regulated by inflammatory stimuli. These observations are consistent with observations in the literature that the suppression of inflammation by TNF-blocking drugs improves bone mineral density ${ }^{23}$ and reduces type II collagen degradation. ${ }^{15}$

It is more difficult to find an appropriate explanation for the different relationships of CTX-I and II with radiological damage and -progression. Radiographic damage and -progression, as measured by the mSASSS, mainly reflects the formation and growth of syndesmophytes, which is a proliferative -rather than a destructive- process. Usually, bone homeostasis is maintained by a tight coupling of bone formation and bone degradation, implying that a shift in one of both is followed by a concurrent shift in the other. The lack of association between CTX-I and mSASSS suggests that bone degradation (CTX-I) and bone proliferation (syndesmophytes measured by mSASSS) are not increased concurrently. It looks as if bone proliferation and bone degradation are uncoupled in AS. Further evidence supporting this uncoupling can be found in recent studies in the literature: States of bone degradation (low BMD, osteoporosis) and bone proliferation (syndesmophyte formation and growth) occur simultaneously in $\mathrm{AS}^{24}$ and profound and sustained suppression of inflammation, for example by TNF-blocking drugs, which reverses low BMD, does not result in an inhibition of radiological progression as measured by mSASSS (syndesmophytes). ${ }^{25,26}$ Bone turnover has also been studied in detail in AS, supporting the picture of uncoupling. ${ }^{27,28}$ In these studies markers of bone formation (osteocalcin and type I procollagen carboxy-terminal propeptide (P1CP)) and bone resorption (pyridinium cross-links pyridinoline (PYD) and deoxy-pyridinoline (DPYD)) were investigated in conjunction with inflammatory markers (acute-phase response). In both studies increased levels of markers of bone resorption were found without a concomitant increase in levels of markers of bone formation.

Somewhat surprisingly, CTX-II was to some degree correlated with radiological damage and progression, and this association remained after the adjustment for 
markers of inflammation, with which CTX-II was also correlated. One may conclude from this observation that cartilage degradation is somehow related to the process of syndesmophyte formation. The type of analysis that we have done does not allow any conclusion about causality in the relationship between CTX-II release and radiological progression, which implies that cartilage degradation either precedes or follows syndesmophyte formation or growth. The absence of any relationship between inflammatory markers and radiological progression, and the presence of such a relationship between CTX-II and inflammatory markers, may add to the suggestion that cartilage degradation is a secondary effect of syndesmophyte formation and -growth in the spine. One could imagine, for example, that ossification of the facet joints, the intervertebral discs and the ligaments goes along with the destruction of the existing cartilage. In a different context, Garnero et al have described an association between CTX-II and spinal disc degeneration. ${ }^{29}$ They found that postmenopausal women with lumbar spine disc degeneration (radiological intervertebral space narrowing) had an increase in urinary CTX-II levels. Interesting in this regard is the recent observation, in biopsies of patients with knee osteoarthritis, that CTX-II is primarily localized at the interface of bone and cartilage. Accordingly, urinary CTX-II may reflect at least in part degradation of calcified cartilage, which may imply that the source of CTX-II in this study could be the vertebral bone - intervertebral disc interface, a locus of pathology in AS. ${ }^{30}$

A number of limitations of this study can be mentioned. A first limitation may be that urine sampling in OASIS was not systematically performed so that in only 83 patients urine samples were ultimately available. However, the selection of patients was completely random, and this should not have had any impact on the results. Another consequence of a small sample size is that the power to detect subtle relationships was not extremely high. However, we were able to statistically support weak associations (correlation coefficients of approximately 0.20) and smaller correlations, even if they are statistically significant, are hardly if ever clinically informative. A methodological aspect in studies exploring associations that is more important than sample size is the presence of a broad spectrum of the phenotype of the disease under study. Our study meets this criterion, since we have included patients with zero radiological progression as well as with major progression (12 mSASSS units in two years) and all values in between. A third limitation is that we were not able to longitudinally collect urine samples in this cohort, in order to check for variability in levels and correlations. Finally, the contribution of CTX-II in explaining radiological damage and progression, though statistically significant, is rather small, implying that other and unknown processes 
different from cartilage degradation contribute to syndesmophyte growth and formation in AS.

In conclusion, AS is characterized by bone and cartilage degradation. The former reflects the systemic inflammatory effects on bone density and can be influenced by TNF- $\alpha$ blocking agents, while the latter is somehow associated with syndesmophyte formation, which is not influenced by anti-inflammatory treatment modalities. This underlines the suggestion that bone degradation and new bone formation are separate processes in AS. Our findings suggest that bone resorption, reflected by CTX-I, and extra-osseous new bone formation, reflected by mSASSS and associated with cartilage damage (CTX-II), are different aspects of structural changes in AS. Future treatment strategies should take these differences into account. 


\section{REFERENCES}

1. Bessant R, Keat A. How should clinicians manage osteoporosis in ankylosing spondylitis? J Rheumatol 2002;29:1511-9

2. Deodhar AA, Woolf AD. Bone mass measurement and bone metabolism in rheumatoid arthritis: a review. Br J Rheumatol 1996;35:309-22

3. Bronson WD, Walker SE, Hillman LS, Keisler D, Hoyt T, Allen SH. Bone mineral density and biochemical markers of bone metabolism in ankylosing spondylitis. J Rheumatol 1998;25:929-351

4. Gratacos J, Collado A, Pons F, et al. Significant loss of bone mass in patients with early, active ankylosing spondylitis: a follow up study. Arthritis Rheum 1999;42:2319-24.

5. Vosse D, van der Heijde DMFM, Landewé R, Geusens P, Mielants H, Dougados M, van der Linden S. Determinants of hyperkyphosis in patients with ankylosing spondylitis. Ann Rheum Dis 2006;65:770-4. doi 10.1136/ard.2005.044081

6. Wilkinson M, Bywaters EGL. Clinical features and course of ankylosing spondylitis. Ann Rheum Dis 1958; 17:209-16

7. Maghraoui A, Borderie D, Cherruau B, Eduoard R, Dougados M, Roux C. Osteoporosis, body composition and bone turnover in Ankylosing Spondylitis. J Rheumatol 1999;26:2205-9

8. Geusens P, Vosse D, van der Heijde DMFM, Vanhoof J, van Tubergen A, Raus J, van der Linden SM. High prevalence of thoracic vertebral deformities and discal wedging in ankylosing spondylitis patients with hyperkyphosis. J Rheumatol 2001;28:1856-61

9. Garnero P, Gineyts E, Christgau S, Finck B, Delmas PD. Association of baseline levels of urinary glucosyl-galactosyl-pyridinoline and type II collagen C-Telopeptide are associated with progression of joint destruction in patients with early rheumatoid arthritis. Arthritis Rheum 2002;46:21-30.

10. Garnero P, Landewe R, Maarten B, Verhoeven A, van der Linden S, Christgau S, van der Heijde D, Boonen A, Geusens P. Association of baseline levels of markers of bone and cartilage degradation are associated with long-term progression of joint damage in patients with early rheumatoid arthritis: the Cobra study. Arthritis Rheum 2002;46:2847-56.

11. Landewé RB, Geusens P, van der Heijde DM, Boers M, van der Linden SJ, Garnero P. Arthritis instantaneously causes collagen type I and type II degradation in patients with early rheumatoid arthritis: a longitudinal analysis. Ann Rheum Dis. 2006;65:40-4 doi: 10.1136/ ard.2004.035196 doi: 10.1136/ard.2007.071159

12. Garnero P, Delmas PD. Noninvasive techniques for assesing skeletal changes in inflammatory arthritis: bone biomarkers. Curr Opin Rheumatol 2004;16:428-34.

13. Toussirot E, Ricard-Blum S, Dumoulin G, Cedoz JP, Wendling D. Relationship between urinary pyridinium crosslinks, disease activity and disease subsets of ankylosing spondylitis Rheumatology 1999;38:21-27

14. Kim TH, Stone M, Payne U, Zhang X, lonescu M, Lobanok T, et al. Cartilage biomarkers in ankylosing spondylitis relationship to clinical variables and treatment response. Arthritis Rheum 2005; 52: 885-91.

15. Maksymowych WP, Poole AR, Hiebert L, Webb A, lonescu M, Lobanok T, et al. Etanercept exerts beneficial effects on articular cartilage biomarkers of degradation and turnover in patients with ankylosing spondylitis. J Rheumatol 2005; 32: 1911-7

16. Spoorenberg A, van der Heijde D, de Klerk E, Dougados M, deVlam K, Mielants $H$, van der Tempel $\mathrm{H}$, van der Linden Sj. A comparative study of the usefulness of the Bath Ankylosing spondylitis Functional Index and the Dougados Functional Index in the assessment of ankylosing spondylitis. J Rheumatol 1999;26:961-5

17. Calin A, Nakache JP, Gueguen A, Zeidler H, Mielants, H, Dougados M. Defining disease activity in ankylosing spondylitis: is a combination of variables (Bath ankylosing spondylitis disease activity index) an appropriate instrument? J Rheumatol 1999;38:878-82 
18. Calin A, Garrett S, Whitelock H, Kennnedy G, O'Hea J, Mallorie P, Jenkinson T. A new approach to defining functional ability in Ankylosing Spondylitis: the development of the Bath ankylosing spondylitis functional index. J Rheumatol 1994;21:2281-5

19. Creemers MCW, Franssen MJAM, van 't Hof MA, Gribnau FWJ, van de Putte LBA, van Riel PLCM. Assessment of outcome in Ankylosing Spondylitis: an extended radiological scoring system. Ann Rheum Dis 2005;64:127-9. doi:10.1136/ard.2004.020503

20. Wanders AJB, Landewé RBM, Spoorenberg A, Dougados $M$, van der Linden S, Mielants $H$, van der Tempel $\mathrm{H}$, van der Heijde DMFM. What is the most appropriate radiological scoring method for Ankylosing Spondylitis? A comparison of the available methods based on the OMERACT filter. Arthritis Rheum. 2004;50:2622-32.

21. Bonde M, Qvist, P, Fledelius C, Riis BJ, Christiansen, C. Immunoassay for quantifying type I collagen degradation products in urine evaluated. Clin Chem 1994;40:2022-5

22. Christgau S, Garnero P, Fledelius C, Moniz C, Ensig M, Gineyts E, Rosenquist C, Qvist P. Collagen type II C-telopeptide fragments as an index of cartilage degradation. Bone 2001;29:209-215

23. Briot K, Garnero P, Le Henanff A, Dougados M, Roux C. Body weight, body composition and bone turnover changes in patients with spondylarthropathy receiving anti- tumor necrosis factor $\alpha$ treatment. Ann Rheum Dis 2005;64:1137-40. doi 1136/ard.2004.028670

24. Karberg K,Zochling J, Sieper J, Felsenberg D, Braun J. Bone loss is detected more frequently in patients with ankylosing spondylitis with syndesmophytes. J Rheumatol 2005;32:1290-8

25. Schett $G$, Landewé $R$, van der Heijde $D$. Tumour necrosis factor blockers and structural remodelling in ankylosing spondylitis: what is reality and what is fiction? Ann Rheum Dis 2007;66:709-11. doi: 10.1136/ard.2007.071159

26. van der Heijde DM, Landewé RDM, Ory P, Vosse D, Zhou L, Tsuji W, Davis JC. Radiographic progression of ankylosing spondylitis after up to two years of treatment with etanercept. Arthritis Rheum 2008;58:1324-31

27. Marhoffer W, Stracke H, Masoud I et al. Evidence of impaired cartilage/bone turnover in patients with active ankylosing spondylitis. Ann Rheum Dis 1995;54:556-9

28. McDonald AG, Birkinshaw G, Durham B, Bucknall RC, Fraser WD. Biochemical markers of bone turnover in seronegative spondylarthropathy: relationship to disease activity. $\mathrm{Br} \mathrm{J}$ Rheumatol 1997;36:50-53

29. Garnero P, Sornay-Rendu E, Arlot M, Christiansen C, Delmas PD. Association between spine disc degeneration and type II collagen degradation in postmenopausal women: the OFELY study. Arthritis Rheum 2004;50:3137-3144

30. Bay-Jensen AC, Andersen TL, Charni-Ben Tabassi N, Kristensen PW, Kjaersgaard-Andersen P, Sandell L, Garnero P, Delaissé JM. Biochemical markers of type II collagen breakdown and synthesis are positioned at specific sites in human osteoarthritic knee cartilage Osteoarthritis Cartilage. 2008;16:615-23 
ChaPter 7 Bone- and cartilage Degradation markers 
(1) 41411

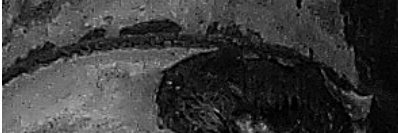

So

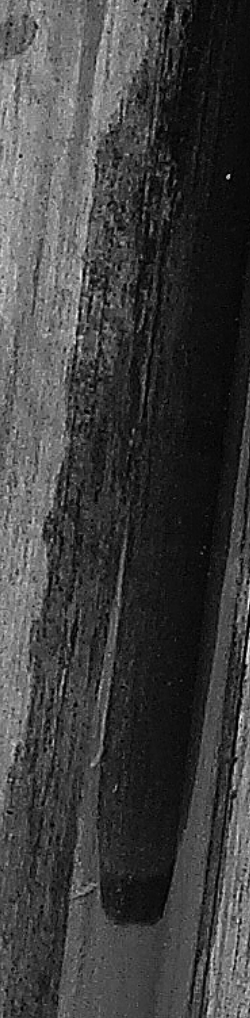

$$
\text { . }
$$
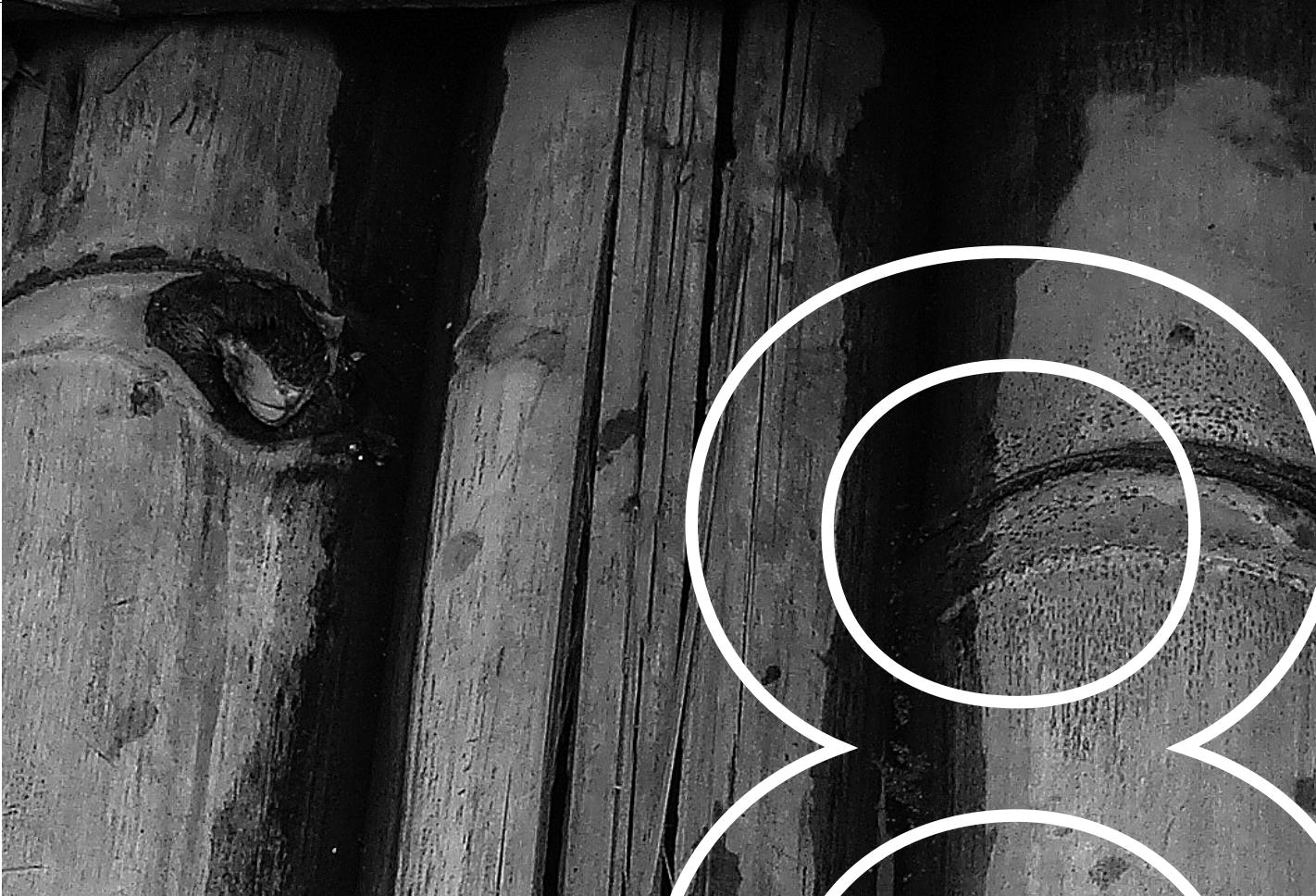


\section{General discussion and Summary}




\section{GENERAL DISCUSSION AND SUMMARY}

Bone is a target in many inflammatory rheumatic diseases, such as rheumatoid arthritis (RA) and ankylosing spondylitis (AS). The interaction between inflammation and bone is characterized by a wide range of changes in bone structure and is associated with an increased risk of fractures. Rather than considering bone fragility as a result of reduced bone mineral density (BMD), there is increasing evidence that bone fragility is the consequence of changes in material and structural properties of bone that are only partially reflected by BMD. In this thesis we have described the role of these structural changes in one specific disease, ankylosing spondylitis.

In AS, bone involvement in the spine is characterized by intra-vertebral bone loss $^{1}$ and by a combination of bone destruction (erosions) and intra- and extraosseous new bone formation at the sites of erosion, the entheses, the ligamental structures and the disco-vertebral junctions (the vertebral endplate). We have addressed two main questions: firstly, do patients with AS have an increased risk of vertebral fractures, and secondly, do the alterations in bone in the spine play a role in the typical deformities (i.e. hyperkyphosis) of the ankylosed spine.

We were able to show that patients with AS have more often clinical vertebral fractures, already after minor trauma, and that they suffer more frequently from neurological complications. In a large cohort we have also shown that the prevalence of non-vertebral fractures (eg. hip, wrist) is not increased, except in patients with concomitant disease. Furthermore, vertebral wedging deformities appear to be an independent determinant of hyperkyphosis of the spine, especially in the thoracic spine. Such a finding justifies a stronger focus on bone and bone quality in this group of patients. Bone mineral density, micro- architecture and material composition all seem to play a contributory role. There is increasing evidence that high disease activity in patients with inflammatory disorders is associated with localised and generalised bone loss and with radiological joint damage, but not with bone formation. Localised and generalised bone loss is caused by a similar mechanism, in which the ratio between receptor activator of nuclear factor kappa $B$ ligand (RANKL) and osteoprotegerin (OPG) is increased. This leads to an upregulation of osteoclast activity both at the local and at the systemic level. In RA, activated T-cells may produce RANKL and as such may contribute to the pathogenesis of erosions and local and generalized bone loss. Blockade of inflammation, for instance with TNF- blockers, suppresses disease activity and inhibits structural 
damage. Selective blockade of RANKL (by OPG or anti-RANKL antibodies) inhibits the occurrence of erosions in RA without influencing inflammatory activity.

AS seems to have a very different pattern of bone damage. In AS, bone erosions occur in the sacroiliac joints and at the entheses (in the axial skeleton and periphery) and are accompanied by new bone formation. Recently reported data on radiographic progression in patients with AS, who were treated with TNF-blocking agents, show no effect of TNF-blockade on structural damage (syndesmophytes). An interesting question therefore is what are the differences between peri-articular bone destruction in RA and raised bone turnover in AS, eventually leading to ankylosis.

The studies in this thesis focused on qualitative and quantitative aspects of bone in patients with AS. In the first part we examined the risk of fracture (vertebral and non-vertebral) in patients with AS and the morbidity due to these fractures. When we started this work, osteoporosis in AS was not a very well-recognized entity and little was known on fracture risk or deformities of the spine. For example, hyperkyphosis was usually considered to be the result of failing physical exercise programs.

In the first study we have looked at clinical vertebral fractures (CVF). ${ }^{2}$ A questionnaire distributed among German and Danish patients revealed vertebral fractures as being a relevant clinical problem. A significant number of AS patients turned out to have vertebral fractures, even after minor trauma, already early in the course of the disease. However, in addition to the classical fractures of the vertebral body, as seen in post menopausal osteoporosis (PMO), patients with AS can also suffer from fractures that are not classically seen in PMO, such as fractures at uncharacteristic levels of the spine (cervical and upper thoracic spine), transverse vertebral fractures, fractures located outside the vertebral body (in the dorsal arch) and vertebral deformations related to spondylodiscitis (Figure 8.1). In addition, fractures have also been documented in the newly formed bone in the ligamental structures and the inter-vertebral discs (Figure 8.2). Altogether, these findings indicate that AS is associated with a wide spectrum of vertebral deformations and spinal fractures, which are the clinical expression of bone failure. Fractures in the non-axial/ appendicular skeleton were not reported more frequently. In several studies a high prevalence of major neurological complications was reported and we also found frequent neurological complications, mostly followed by incomplete neurological recovery. This is in contrast to postmenopausal and senile osteoporosis, in which neurological complications are rarely described. A possible explanation could be that a (partially) ankylosed spine (bamboo-spine) 
acts like a long bone which contributes to fractures in the horizontal plane. The resulting luxations may easily harm the spinal cord and cause (irreversible) damage. Fractures in primary osteoporotic vertebra are more compressive and do usually not harm the spinal cord. These findings illustrate that clinical vertebral fractures can be a considerable clinical problem in patients with AS.

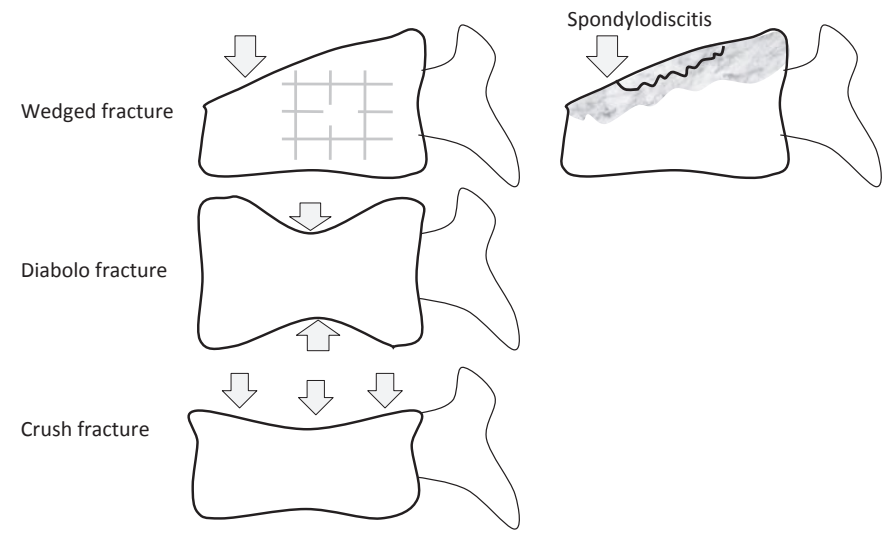

FIGURE 8.1 Vertebral body fractures.

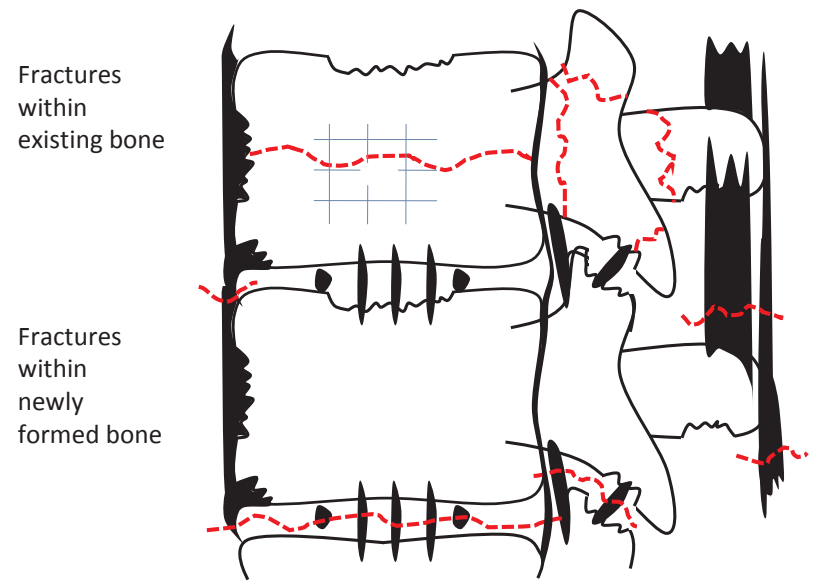

FIGURE 8.2 Fractures in bone and calcified ligaments in AS. 
Besides bone loss, AS is characterized by osteoproliferation that may increase the rigidity of the spine. Both the rigidity of the spine and bone loss in the vertebrae may contribute to an increased vulnerability of the spine in patients with AS. In order to evaluate the risk for clinical vertebral and non-vertebral fractures in AS, we analyzed the prevalence of fractures and AS in a large primary care-based nested case-control study. We used the UK General Practice Research Database to conduct a case-control study. In this study we have shown that patients with a diagnosis of AS have an increased risk of clinical vertebral fractures without an increased risk of non-vertebral fractures. ${ }^{3}$ This indicates that osteoporosis is merely confined to the spine. We also found that the risk of any clinical fracture was increased in AS patients with concomitant inflammatory bowel disease (IBD) or using oral glucocorticoids. In the literature IBD, especially Crohn's disease, is identified as a risk factor for low $\mathrm{BMD}^{4,5}$ and vertebral fractures. ${ }^{6}$ Furthermore, a high prevalence of vertebral deformities in Crohn's disease and ulcerative colitis was reported, which was associated with the use of glucocorticoids. So, AS is associated with a higher prevalence of vertebral fractures without an increase of nonvertebral fractures, whereas more generalized disease is associated with an increased risk of clinical vertebral fractures as well as non-vertebral fractures.

An interesting but yet unexplained finding that needs confirmation was that the risk of any clinical fracture was decreased in AS patients taking NSAID's. Relief of inflammatory back pain and stiffness by NSAID's, as well as the improved physical function, may help in maintaining bone mass by improved physical activity. An additional beneficial effect of improved physical condition could be a reduced risk of falling and subsequent fracture. ${ }^{7,8}$ NSAID's do not only seem to prevent fractures: it has recently been suggested that these drugs may also inhibit the formation and growth of syndesmophytes of AS in the spine. In a study comparing two treatment strategies, continuous NSAID-use versus NSAID-use on demand, it was reported that continuous treatment reduced radiographic progression as compared to on demand treatment ${ }^{9}$ which suggests an association between NSAID use and new bone formation in AS. An earlier study had already suggested that continuous use of phenylbutazone might reduce the progression of ankylosis of the spine. ${ }^{10}$ NSAID's may play a role in the formation and/or growth of syndesmophytes. These drugs interfere with the prostaglandin metabolism and the inhibitory effect on radiographic progression may be achieved via this pathway. It is obvious that, if the divergent inhibitory effects of NSAID's on osteoporotic fractures (bone loss) and progression of syndesmophytes (bone formation) can be confirmed, this may be an important clue in further elucidating pathophysiological mechanisms in AS. 
In contrast to the treatment of osteoporosis in patients with RA, treatment of osteoporosis in patients with AS is not yet common. Data supporting the efficacy of this treatment in AS are rare. Of all bisphosphonates alendronate and risedronate are found to be effective in increasing BMD in men. Alendronate and risedronate significantly increase BMD in both vertebrae and femur, with a significant reduction of vertebral fractures. ${ }^{11-15}$

More recently teriparatide was tested with the same aims, but only a positive effect on BMD could be shown. ${ }^{16}$ It is a clear that there is a need for evidencebased knowledge in these fields in the near future. Our studies highlight the need to develop strategies to identify high-risk patients with AS. Research on the treatment of osteoporosis to prevent vertebral fractures in these patients is urgently needed.

Vertebral deformities are a hallmark of osteoporosis, and hyperkyphosis of the upper part of the spine is a frequent clinical problem in AS. In patients with AS the same bended forward posture is often seen. In the next part of our study we questioned the reliably of measurement and follow-up of hyperkyphosis in clinical practice. Applying the so-called "Outcome Measures in Rheumatology Clinical Trials" (OMERACT) filter we compared two methods of assessing hyperkyphosis of the spine: occiput-to-wall distance (OWD) and tragus-to-wall distance (TWD). We concluded that both methods were equally reliable, but for practical reasons and research purposes we recommend OWD measurements. ${ }^{17}$ Another technical question concerned the measurement of vertebral deformities. Several methods are available to establish vertebral deformities and fractures and to distinguish them from vertebrae with a normal shape. One of the most common approaches is described by Genant et al, in which a semiquantative technique to assess vertebral deformities on conventional radiographs is used together with the general interpretation of the image. ${ }^{18}$ This method uses fixed values of deformities and describes wedged deformities, diabolo and crush deformities.

In our AS study we used the Genant method to compare morphometric radiography (MRX) and morphometric X-ray absorptiometry (MXA). We have demonstrated that measuring vertebral deformities on MRX and MXA expressed as APratio's is reliable if performed by trained readers. But, although the agreement between MRX and MXA in measuring global vertebral deformities expressed as (mean) AP-ratio was acceptable, both measures did not reliably assess whether or not there was a fracture. ${ }^{19}$ The results obtained by one method did not comply with the results obtained by the other technique. A problem in our study popula- 
tion remains the specific spondylitic changes. A more recent article concerning morphometry and assessment of fractures ${ }^{20}$ showed better agreement between both methods, mainly in the lower spinal regions but in the region of our interest, the upper thoracic part of the spine, they have described the same difficulties (poor image quality). A gold standard in vertebral morphometry in AS is warranted and further studies will be needed to demonstrate the degree of mutual exchangeability of both techniques.

After describing the clinical problems and achieving the proper tools to assess deformities, we have used them in a study to determine predictive factors in relation to the hyperkyphosis in AS patients. Hyperkyphosis of the upper part of the spine is a frequent clinical problem among patients with $\mathrm{AS}^{21-23}$ In our prevalence cohort of patients with AS (Outcome in AS International Study (OASIS) cohort), 49\% of the patients had some degree of hyperkyphosis, when expressed as an OWD of more than $0 \mathrm{~cm} .{ }^{24}$ The prominent position of the head and neck may give functional and psychological impairments for the patients. ${ }^{25,26}$ They may be unable to see straight ahead, may have difficulties in activities of daily living. For example, in our study we found a significant correlation between increased OWD and the limitations as assessed by the Bath Ankylosing spondylitis Functional Index $(\rho=0.43$; $p<0.01$ ). Although we know that half of our patients might suffer from this potentially disabling condition, we know very little of the origin of hyperkyphosis. It is known that hyperkyphosis it correlated with radiological damage of the cervical and lumbar spine as measured with the modified Stoke Ankylosing spondylitis Spine Score (mSASSS) ${ }^{27}$ but further insight in the mechanism was not available. In parallel with the postural changes in primary osteoporosis we hypothesized that the same wedging deformities that occurred in the osteoporotic spine were (partly) responsible for the fixed hyperkyphosis in patients with AS. A first pilot-study supported our hypothesis and in a second, larger study we confirmed the role of structural damage of the spine. We have shown in a cross-sectional study that wedging of thoracic vertebrae and disease activity were independent contributory factors to explaining hyperkyphosis. ${ }^{28.29}$ Therefore, in order to prevent or limit functional decline, future studies on new therapies in the treatment of AS should aim at prevention of the development of structural damage (syndesmophytes) as well as prevention of the development of vertebral osteoporosis, and its effect on the development of hyperkyphosis including the effect due to disease activity.

The last part of this thesis concerned the possible prediction of radiological damage and postural deformities. Since hyperkyphosis is associated with decreased physical function, and is related to bone involvement in AS, it is of clinical importance to 
predict such bad outcomes. Since radiological progression of damage in patients with AS is usually a slow process, and not easy to measure, the use of biomarkers might be of great help. We examined two biomarkers, C-terminal cross linking telopeptide of type I (CTX-1) and C-terminal cross linking telopeptide of type II (CTX-II). CTX-I is associated with the degradation of bone, CTX-II is associated with the degradation of cartilage. Both markers have proven their usefulness in studies with patients with RA. It was shown that CTX-I and CTX-II were significantly associated with radiological progression, and that progression could be predicted from the biomarker levels to a certain extent. ${ }^{30-32}$ In our study we showed that both CTX-I and CTX-II were increased in patients with AS as compared to the age- and sex-matched unaffected population. ${ }^{33}$ Further, we found a significant correlation between CTX-I and BMD, as was already reported in primary osteoporosis or osteoporosis secondary to RA. ${ }^{34}$ This reflects the systemic inflammatory effects on bone density which can be reversed by TNF- $\alpha$ blocking agents. There is no obvious reason to assume that peri-inflammatory reduced BMD in patients with AS is different from inflammation-induced osteoporosis in RA. However, while CTX-I was directly associated with radiological progression in RA, we did not find such a correlation in patients with AS. In contrast, we found that CTX-II, a marker of cartilage degradation, is associated with radiological damage and -progression in AS. In RA, erosive radiological progression can be stopped and probably even be repaired to some extent by TNF- $\alpha$ blocking agents. ${ }^{35}$ The process of syndesmophyte formation and bridging, both the result of bone proliferation, seems not to be influenced by TNF- $\alpha$ blocking agents ${ }^{36}$ This underlines the suggestion that in AS bone degradation and new bone formation are separate processes. Others have confirmed our findings showing that treatment of AS animal models with TNF- $\alpha$ blocking agents does not inhibit the incidence or severity of ankylosis. ${ }^{37}$ Also, results from a study to develop a radiographic scoring system in psoriatic arthritis support the existence of two different processes. ${ }^{38}$ The authors found no correlation between the change in destruction and the change in proliferation in the joints. We hypothesize a different sequence of events in AS as compared to RA with respect to radiological damage. In both diseases inflammation is assumed to trigger bone destruction and in RA a direct correlation with both forms of destruction (i.e. decrease in BMD and radiological damage) is known. In AS however, there is no close correlation between inflammation and radiological damage as measured by the mSASSS. Our findings suggest that bone resorption, reflected by CTX-I, and extra-osseous new bone formation, reflected by mSASSS and associated with cartilage damage (CTX-II), are different aspects of structural changes in AS. In light 
of this observation, alternative pathways of bone metabolism should be considered. In recent literature several factors have been identified as playing a role in bone metabolism. ${ }^{39}$ The main players in this field seem to be the (osteoclastic) RANK/RANKL/OPG pathway and the (osteoblastic) wingless (Wnt) genes system. $^{40-43}$ One of these Wnt families of proteins is Dickkopf (Dkk), with at least 4 known subforms. Both systems are influenced by TNF- $\alpha$, and Dkk-1 seems to have a dual action as a key regulator of pathological joint remodeling, which is based on the interplay between catabolic and anabolic pathways. This is supported by the finding that Dkk-1 levels are increased in the early inflammatory (destructive) phase of joint disease, and decreased in later (osteoproliferative) stages of disease. ${ }^{40}$ As CTX-II was related to the presence and progression of syndesmophytes, cartilage destruction is presumably a step between inflammation and new extraskeletal bone formation at the entheses. This can be explained by the anatomical characteristics of the enthesis, which contains cartilage (Figure 8.3), collagen-II and the histological presence of endochondral bone formation in the formation of syndesmophytes (Figure 8.4). Further insights in the cellular and molecular mechanisms of enthesitis are needed.

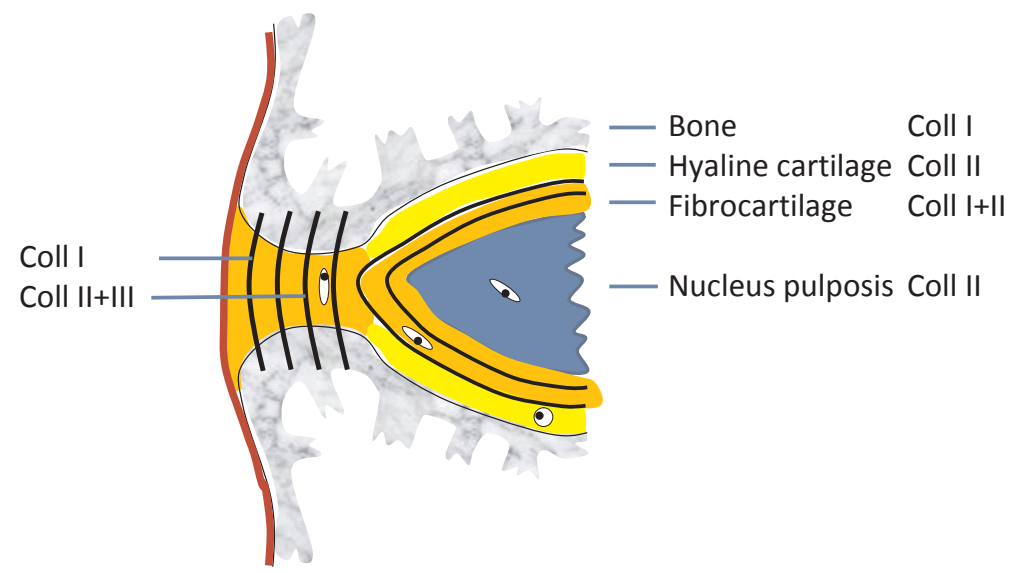

FIGURE 8.3 Characteristics of the enthesis. 

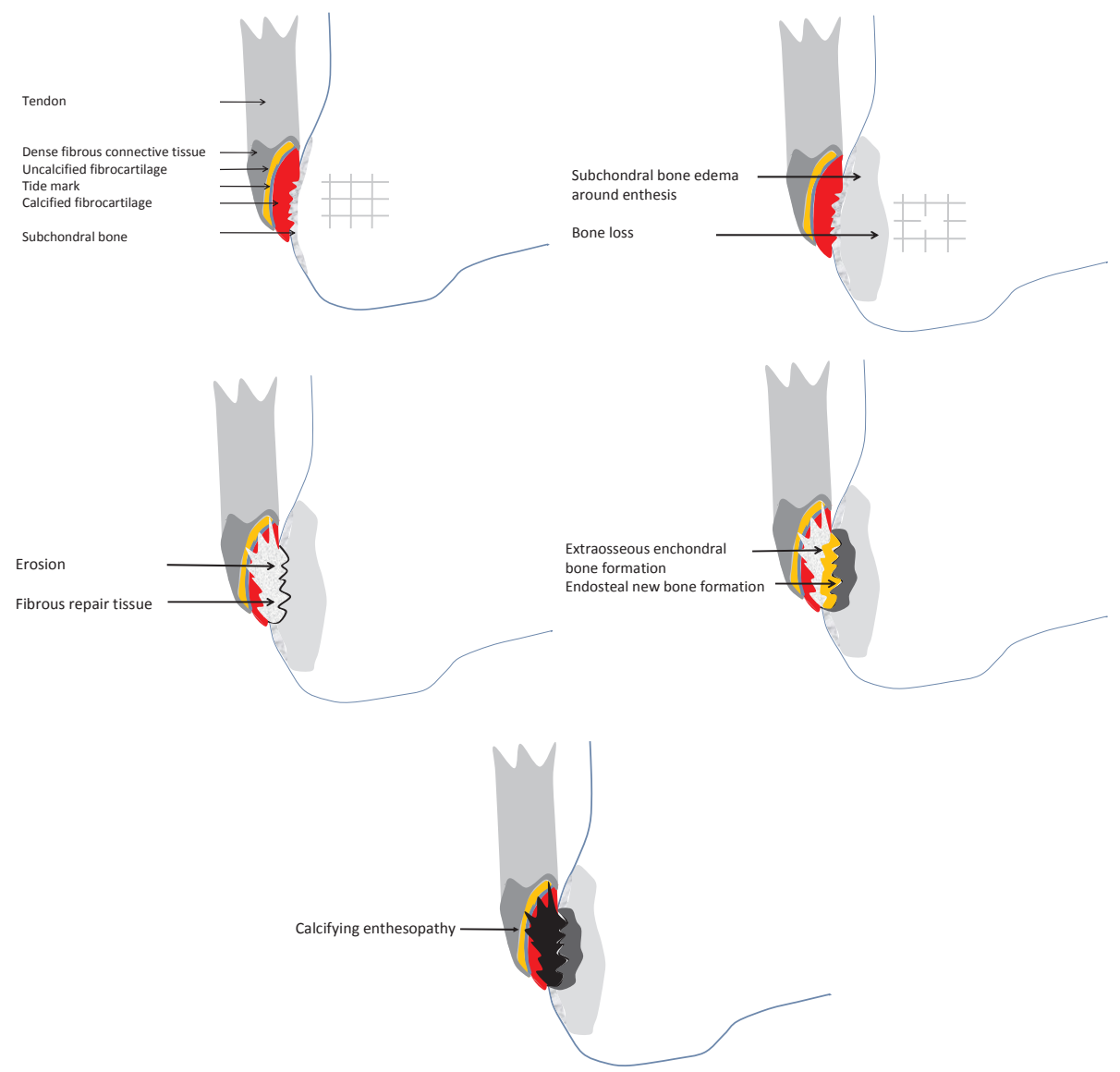

FIGURE 8.4 Pathophysiology of erosive enthesitis

In conclusion, deformities and fractures of the vertebrae are a clinical characteristic of AS. They are related to (radiographic) damage of the spine and disease activity, which independently contribute to hyperkyphosis. Fractures may result in neurologic sequels. Cartilage degradation is involved in extra-osseous new bone formation in the syndesmophytes, which may contribute to stiffening of the spine and to rendering the vertebral body, its dorsal arch components and the calcified ligaments, vulnerable to fracture. Future treatment strategies should take these findings and differences in comparison with RA into account. 


\section{REFERENCES}

1. Lee YS, Schlotzhauer T, Ott SM, van Vollenhoven RF, Hunter J, Marcus R, McGuire JL. Skeletal status of men with early and late ankylosing spondylitis. Am J Med 1997;103:233-41

2. Vosse D, Feldtkeller E, Erlendsson J, Geusens P, van der Linden S. Clinical vertebral fractures in patients with Ankylosing Spondylitis. J Rheumatol. 2004;31:1981-5.

3. Vosse D, Landewé R, vander Heijde D, van der Linden S, van Staa TP, Geusens P. Ankylosing spondylitis and the risk of fracture: results from a large primary care-based nested case control study. Submitted

4. Schoon EJ, van Nunen AB, Geusens $P$, Stockbrügger RW, Russel MGVM. Clinical determinants of bone mineral density in Crohn's disease. (thesis) Maastricht (the Netherlands): University of Maastricht; 2001

5. Schoon EJ, Blok BM, Geerling BJ, Russel MG, Stockbrügger RW, Brummer R-JM. Bone mineral density in patients with recently diagnosed inflammatory bowel disease. Gastroenterology 2000;199:1203-8

6. Heijckmann AC, Huijberts MSP, Scoon EJ, Geusens P, d Vries J, Menheere PPCA, van der Veer E, Wolffenbuttel BH, Stockbrügger RW, Dumitrescu B, Nieuwenhuijzen Kruzeman AC. High prevalence of morphometric vertebral deformities in patients with inflammatory bowel disease. Eur J Gastroenterol Hepatol 2008;20:740-7

7. Gillespie LD, Gillespie WJ, Robertson MC, Lamb SE, Cumming RG, Rowe BH. Interventions for preventing falls in elderly people. Cochrane Database Syst Rev 2003;(4):CD000340.

8. Wolf SL, Sattin RW, Kutner M, O'Grady M, Greenspan Al, Gregor RJ. Intense tai chi exercise training and fall occurrences in older, transitionally frail adults: a randomized, controlled trial. J Am Geriatr Soc 2003;51:1693-701.

9. Wanders A, van der Heijde D, Landewé R, Béhier J-M, Calin A, Olivieri I, Zeidler H, Dougados M. Non-steroidal anti-inflammatory drugs inhibit radiographic progression in patients with ankylosing spondylitis: A randomised clinical trial. Arthritis Rheum 2005;52:1756-65

10. Boersma JW. Retardation of ossification of the lumbar vertebral column in ankylosing spondylitis by means of phenylbutazone. Scand J Rheumatol. 1976;5:60-4.

11. Orwoll E, Ettinger M, Weiss S, Miller P, Kendler D, Graham J, Adami S, Weber K, Lorenc R, Pietschmann P, Vandormael K, Lombardi A. Alendronate for the treatment of osteoporosis in men. N Engl J Med 2000;343:604-610

12. Lems WF, Zillikens MC, van den Bergh JPW, Valk Nk, Stalenhoef PA, Geusens PPMM. Osteoporose bij mannen: een onderschat probleem. NT Reumatol 2008:45-53

13. Majima T, Shimatsu A, Komatsu Y, Satoh N, Fukao A, ninomiya K, Matsumura T, Nakao K. Efficacy of risedronate in Japanese male patients with primary osteoporosis. Internal medicine 2008;47:717-23

14. Boonen S, Wederoth D, Schofield PJ, Oral risedronate in men with osteoporosis: study design and baseline characteristics. JBMR 2005;SU 404

15. Ringe JD, Faber $H$, Farahmand $P$, Dorst A. Efficacy of risedronate in men with primary and secondary osteoporosis \: results of a 1-year study. Rheumatolo Int 2006;26:427-31

16. Kaufman JM, Orwoll E, Goemaere S, San Martin S, Hossain A, Dalsky GP, Lindsay R, Mitlak BH. Teriparatide effects on vertebral fractures and bone mineral density in men with osteoporosis: treatment and discontinuation of therapy. Osteoporos Int 2005;16:510-6

17. Heuft-Dorenbosch L, Vosse D, Landewé R, Spoorenberg A, Dougados $M$, Mielants $H$, van der Tempel H, van der Linden S, van der Heijde D. Measurement of Spinal Mobility in Ankylosing Spondylitis: comparison of occiput-to-wall and tragus-to-wall distance. J Rheumatol 2004;31:1779-84

18. Genant HK, Wu CY, Kuijk van C, Nevitt MC. Vertebral fracture assessment using a semi quantitative technique. J Bone Miner Res 1993;8:1137-48 
19. Vosse D, Heijckmann AC, Landewé R, van der Heijde D, van der Linden S, Geusens P. Comparing morphometric X-Ray absorptiometry and radiography in defining vertebral wedge fractures in patients with Ankylosing Spondylitis. Rheumatology 2007;46:1667-71

20. Koolhaas W, Prak A, Stiekema HM, Kreeftenberg HG, Wolffenbuttel BHR, Jager PL. Efficiënte en verbeterde diagnostiek van osteoporose door simultane botdichtheidmeting en wervelmorfometrie. Ned Tijdschr Geneeskd 2008;152:938-43

21. Carette S, Graham D, Little H, Rubenstein J, Rosen P. The natural disease course of ankylosing spondylitis. Arthritis Rheum 1983; 26:186-90

22. Wilkinson M, Bywaters EGL. Clinical features and course of ankylosing spondylitis. Ann Rheum Dis 1958; 17:209-16

23. Spencer DG, Park WM, Dick HM, Papazoglou SN, Buchanan WW. Radiological manifestations in 200 patients with ankylosing spondylitis: correlation with clinical features and HLA-B27. J Rheumatol 1979;6:305-15

24. Spoorenberg A, van der Heijde D, de Klerk E, Dougados M, deVlam K, Mielants H, van der Tempel $\mathrm{H}$, van der Linden $\mathrm{Sj}$. A comparative study of the usefulness of the Bath Ankylosing spondylitis Functional Index and the Dougados Functional Index in the assessment of ankylosing spondylitis. J Rheumatol 1999;26:961-5

25. McMaster MJ. Osteotomy of the cervical spine in ankylosing spondylitis. J Bone Joint Surg [Br] 1997;79:197-203

26. Kim KT, Suk KS, Cho YM, Hong GP, Park BJ. Clinical outcome Results of pedicle subtraction osteotomy in Ankylosing spondylitis with kyphotic deformity. Spine 2002;27:612-8

27. Creemers MCW, Franssen MJAM, van 't Hof MA, Gribnau FWJ, vd Putte LBA, vRiel PLCM. Assessment of outcome in Ankylosing Spondylitis: an extended radiological scoring system. Ann Rheum Dis 2005;64:127-9

28. Geusens P, Vosse D, van der Heijde DM, Vanhoof J, van Tubergen A, Raus J, van der Linden SM. High prevalence of thoracic vertebral deformities and discal wedging in ankylosing spondylitis patients with hyperkyphosis. J Rheumatol 2001;28:1856-61

29. Vosse D, van der Heijde DM, Landewé R, Geusens $P$, Mielants $M$, Dougados $M$, van der Linden $S$. Determinants of hyperkyphosis in patients with Ankylosing Spondylitis. Ann Rheum Dis 2006;65:770-4. doi:10.1136/ard.2005.044081

30. Garnero P, Gineyts E., Christgau S., Finck B., Delmas P.D. Association of baseline levels of urinary glucosyl-galactosyl-pyridinoline and type II collagen C-Telopeptide are associated with progression of joint destruction in patients with early rheumatoid arthritis. Arthritis Rheum 2002;46:21-30.

31. Garnero P., Landewe R., Maarten B., Verhoeven A., van der Linden S., Christgau S., van der Heijde D., Boonen A., Geusens P. Association of baseline levels of markers of bone and cartilage degradation are associated with long-term progression of joint damage in patients with early rheumatoid arthritis: the Cobra study. Arthritis Rheum 2002;46:2847-56.

32. Landewé RB, Geusens P, van der Heijde DM, Boers M, van der Linden SJ, Garnero P. Arthritis instantaneously causes collagen type I and type II degradation in patients with early rheumatoid arthritis: a longitudinal analysis. Ann Rheum Dis. 2006;65:40-4 doi: 10.1136/ ard.2004.035196

33. Vosse D, Landewé R, Garnero P, van der Heijde D, van der linden S, Geusens P. association of markers of bone- and cartilage degradation with radiological changes at baseline and after 2 yrs follow-up in patients with ankylosing spondylitis. Rheumatol 2008;47:1219-22

34. Deodhar AA, Woolf AD. Bone mass measurement and bone metabolism in rheumatoid arthritis: a review. Br J Rheumatol 1996;35:309-22

35. Klareskoq L, van der Heijde D, de Jager JP, Gough A, Kalde J, Malaise M, Martín Mola E, Pavelka K, Sany J, Settas L, Wajdula J, Pedersen R, Fatenejad S, Sanda M; TEMPO (Trial of Etanercept and Methotrexate with Radiographic Patient Outcomes) study investigators. Therapeutic effect of the combination of etanercept and methotrexate compared with each treatment alone in patients with rheumatoid arthritis: double-blind randomised controlled trial. Lancet 2004;363:675-81 
36. van der Heijde DM, Landewé RDM, Ory P, Vosse D, Zhou L, Tsuji W, Davis JC. Two-year etanercept therapy does not inhibit radiographic progression in patients with ankylosing spondylitis. Arthritis Rheum 2008;58:1324-31

37. Lories RJU, Derese I, De Bari C, Luyten FP. Evidence for uncoupling of inflammation and joint remodelling in a mouse model of spondylarthritis. Arthritis Rheum 2007;56:489-97

38. Wassenberg S, Fisher-Kahle V, Herborn G, Rau R. A method to score radiographic change in psoriatic arthritis. Z Rheumatol 2001;60:156-66

39. Canalis E, Giustina A, Bilezikian JP. Mechanisms of anabolic therapies for osteoporosis. N engl J Med 2007;357:905-16

40. Diarra D, Stolina M, Polzer K, Zwerina J, Ominsky MS, Dwyer D, Korb A, Smolen J, Hoffmann M, Scheinecker C, van der Heijde D, Landewe R, Lacey D, Richards WG, Schett G. Dickkopf-1 is a master regulator of joint remodeling. Nat Med. 2007;13:156-63

41. Loddenkemper K, Burmester GR. What is the rank of RANKL in spondylarthritis? Arthritis Rheum 2008;58:641-44

42. Vandooren B, Cantaert T, Noordenbos T, Tak PP, Baeten D. The abundant synovial expression of the RANK/RANKL/Osteoprotegerin system in peripheral spondylarthritis is partially disconnected from inflammation. Arthritis Rheum 2008;58:718-29

43. Zwerina J, Hayer S, Tohidast-Akrad M, Bergmeister H, Redlich K, Feige U, Dunstan C, Kollias G, Steiner G, Smolen J, Schett G. Single and combined inhibition of tumor necrosis factor, interleukin1 , and RANKL pathways in tumor necrosis factor-induced arthritis: effects on synovial inflammation, bone erosion, and cartilage destruction. Arthritis Rheum. 2004;50:277-90. 
(1)
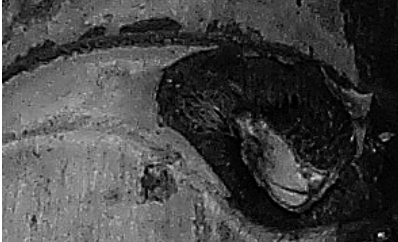

th

$-2$

(4)

p 18
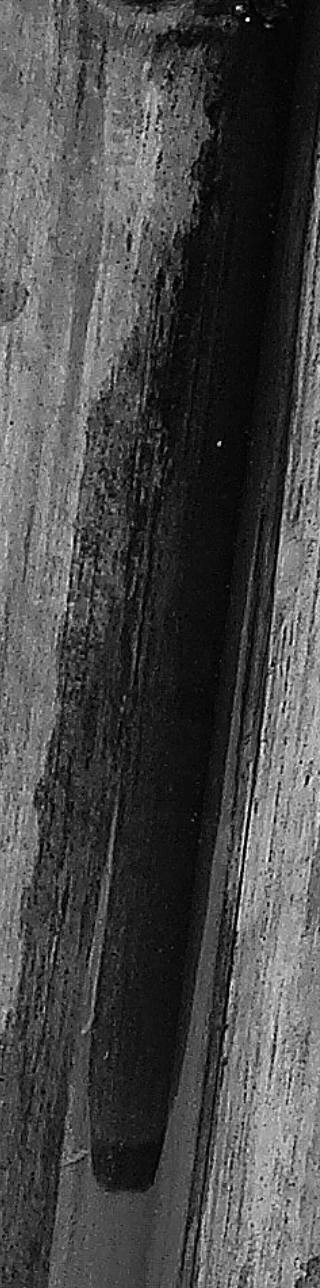


\section{Samenvatting}

Eigenschappen van het bot bij ankyloserende spondylitis 


\section{INLEIDING}

Tegenwoordig is ankyloserende spondylitis (AS), ook bekend als Morbus Bechterew of de ziekte van Bechterew, een alom bekende ziekte-entiteit, maar we mogen niet vergeten dat AS lange tijd (tot in de vroege jaren zestig van de vorige eeuw) werd gezien als een variant van reumatoïde artritis (RA). ${ }^{1,2}$ De ziekte werd toen ook wel reumatoïde spondylitis genoemd. In die tijd lanceerden Moll en Wright het concept van de spondyl(o)artropathieën of spondylartritiden. ${ }^{3}$ Met het vaststellen van de classificatie criteria voor AS, door gedegen klinisch-epidemiologisch onderzoek, en bevestigd door de belangrijke ontdekking van de associatie van AS met de genetische marker HLA-B27 werd snel duidelijk dat AS in feite het prototype is van deze groep van onderling gerelateerde ziektebeelden. ${ }^{4}$ De (gemodificeerde) New York classificatie criteria voor AS hebben gezorgd voor standaardisatie van onderzoek naar deze ziekte in bevolkingsgroepen, en voor wijdverbreide acceptatie van het concept. ${ }^{5}$ Tegenwoordig weten wij dat AS een chronische reumatische aandoening waarbij primair het axiale skelet is betrokken. Sacro-iliitis is het hoofdkenmerk van de ziekte en veroorzaakt tezamen met ontsteking van de wervelkolom, het meest in het oog springende klinische symptoom van AS: inflammatoire lage rugpijn (IBP). Het tweede karakteristieke kenmerk van AS is de spondylitis. Hierbij treedt inflammatie op van de vertebrale ligamenten, zowel aan de voorkant als aan de achterkant van de wervels, en in de facetgewrichten. De ontsteking op deze plaatsen kan leiden tot hoekerosies, bothaken en uiteindelijk verbening van de ligamentaire structuren. Dit proces kan ook leiden tot totale verbening van de wervelkolom (bamboo-spine), en kan uiteindelijk leiden tot de voor AS karakteristieke voorovergebogen houding. Een manier om deze röntgenschade te meten is de gemodificeerde Stoke Ankylosing spondylitis Spine Score (mSASSS, Figuur 9.1). ${ }^{6}$ Met deze score kan röntgenschade worden vastgelegd en vervolgd in het ziektebeloop. Naast deze radiologische maat zijn er, net als bij RA, ook klinische maten ontwikkeld om ziekteactiviteit en functionaliteit vat te leggen. Hier voor worden met name de Bath Ankylosing spondylitis Disease Activity Index (BASDAI) en de Bath Ankylosing spondylitis Functional Index (BASFI) gebruikt. ${ }^{7,8}$

Snel toenemend inzicht in klinische, cellulaire en moleculaire mechanismen van interactie tussen inflammatie en bot (het nieuwe vakgebied 'osteo-immunologie'), heeft geleid tot het postuleren van hypothesen betreffende het ontstaan van deze syndesmofieten. ${ }^{9-11}$ Bot is doelwit in vele inflammatoire reumatische ziekten, zoals $\mathrm{RA}^{1,2}$ en $A S^{3,4}$ De interactie tussen inflammatie en bot wordt gekarakteriseerd door een grote verscheidenheid aan veranderingen in botremodelering ${ }^{9}$ en is geassoci- 
eerd met een verhoogd risico op botbreuken, zowel bij RA- als bij AS patiënten. ${ }^{13}$ De vanzelfsprekendheid waarmee we tegenwoordig over osteoporose bij AS spreken doet vermoeden dat deze associatie reeds lang bekend is, maar het betreft hier feitelijk een relatief nieuw inzicht. In eerste instantie werd de kwetsbaarheid van het bot vooral beschouwd als zijnde het gevolg van afgenomen bot mineraal dichtheid (BMD). Tegenwoordig is er toenemend bewijs dat zij mede het gevolg is van veranderingen in de eigenschappen van de mineralen en de structuur van het bot. $^{11}$

In dit artikel proberen wij antwoord te geven op een aantal klinisch relevante vragen die verwijzen naar de interactie tussen inflammatie en botkwaliteit en naar het meten van deze eigenschappen.

\section{mSASSS}

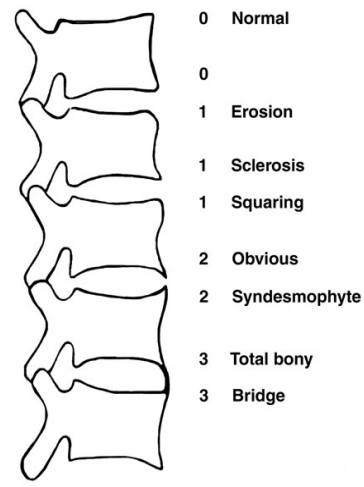

FIGUUR 9.1 gemodifiseerde Stoke Ankylosing spondylitis Spine Score.

\section{Wat is de prevalentie van wervelfracturen bij patiënten met AS en is dit een} klinisch relevant probleem?

Het vaststellen van een wervelfractuur wordt bemoeilijkt door verschillende factoren. Ten eerste wordt slechts één van de 3-4 wervelfracturen in de praktijk opgemerkt met de typische klachten en symptomen van een fractuur. ${ }^{14}$ Maar zelfs als de verschijnselen typisch zijn voor een wervelfractuur, kan zo'n fractuur gemist worden bij patiënten met AS, omdat zowel acute als chronische rugpijn veel voorkomen bij deze patiënten. Een wervelfractuur kan dan worden toegeschreven aan bijvoorbeeld een opvlamming van ziekteactiviteit. Dit kan gebeuren zolang een wervelfractuur niet wordt opgenomen in de differentiaal diagnose van rugpijn bij 
patiënten met AS. Ten tweede worden fracturen van wervellichamen vaak gemist op röntgenfoto's. ${ }^{15}$ Ook worden er in cohort-onderzoeken van patiënten met AS, zoals het OASIS cohort, niet altijd röntgenfoto's gemaakt van de thoracale wervelkolom, omdat de beeldkwaliteit vaak te slecht is om de foto's goed te beoordelen als gevolg van overprojecterende weke delen en ribben. Wij deden onderzoek naar de prevalentie van klinische wervelfracturen (CVF) bij patiënten met AS. ${ }^{16}$ Met de hulp van Duitse en Deense patiëntenverenigingen werden enquêtes verstuurd naar ruim 15.000 patiënten. Hierin werd gevraagd naar leeftijd, diagnose, ziekteduur, HLA-B27 status en fracturen. Ook werden vragen gesteld over de oorzaak en lokalisatie van fracturen. Tenslotte bevatte de enquête vragen over het huidige functioneren van de patiënten. Op deze manier werden 66 patiënten met een gedocumenteerde wervelfracturen verzameld, met een gemiddelde leeftijd van 50 jaar (ten tijde van de fractuur) en een gemiddelde ziekteduur van 18 jaar na het stellen van de diagnose (Figuur 9.2). Het is opvallend dat aan de fractuur meestal geen adequaat trauma vooraf gaat, en dat bijna de helft van de patiënten neurologische verschijnselen heeft, die in 2/3 van de gevallen permanent is. In vergelijkbare studies bij "gewone" osteoporose komt dit zelden voor. Vervolgens hebben wij een populatie-onderzoek gedaan naar de prevalentie van fracturen bij patiënten met AS. Hiervoor is gebruik gemaakt van een huisartsendatabase (GPRD) in Engeland. Ruim 231.000 klinische fracturen werden vergeleken met gematchte controles. ${ }^{17,18}$ Het blijkt dat bij patiënten met AS de fractuurincidentie hoger ligt dan bij controles. Dit geldt alleen voor wervelfracturen (Odds Ratio=3.3, $\mathrm{Cl}$ 1.5-7.0); perifere fracturen komen niet vaker voor bij patiënten met AS dan in de controlepopulatie. Beide studies bevestigen dat de kans op wervelfracturen verhoogd is bij AS en kan leiden tot functionele beperkingen bij patiënten met AS.

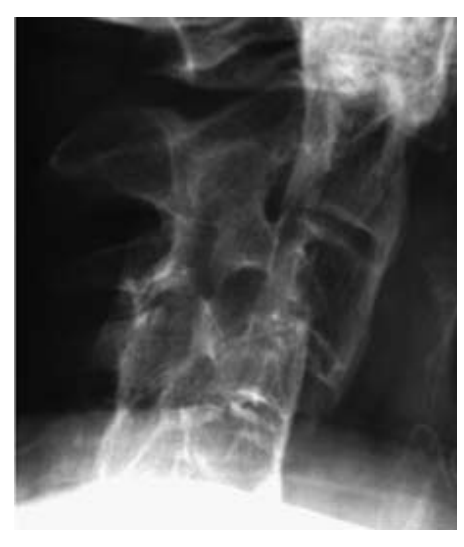

\section{FIGUUR 9.2}

Fractuur in de cervicale wervelkolom bij een bamboo-spine na klein trauma. 


\section{Kan een gebogen houding voorspeld worden en/of zelfs voorkomen worden?}

Een van de meest opvallende klinische verschijnselen van patiënten met evoluerende AS is hun hyperkyfotische thoracale wervelkolom. Dit kan leiden tot ernstige functionele beperkingen, maar toch is er weinig bekend over het ontstaan van deze voorovergebogen houding. Al eerder is de methode beschreven hoe hyperkyfose betrouwbaar te meten is. ${ }^{19} \mathrm{Er}$ is gekeken is naar de achterhoofd-muur afstand (OWD) en naar de tragus-muur afstand (TWD). Hoewel beide methoden even betrouwbaar zijn, is om praktische redenen gekozen voor de achterhoofd-muur afstand (OWD). Deze parameter hebben wij vervolgens gebruikt in een studie naar determinanten van de OWD bij patiënten met AS. Uit eerder onderzoek is al gebleken dat hyperkyfose gerelateerd is aan radiologische schade. ${ }^{20,21}$ Echter, we weten ook dat osteoporose kan bijdragen aan thoracale hyperkyfose, met name door de wigvormige deformiteiten van de wervellichamen. Met gebruik maken van de methode van Genant ${ }^{22}$ hebben wij bij de patiënten uit het OASIS cohort werveldeformiteiten, i.c. de antero-posterieure hoogteratio gemeten (Figuur 9.3), en deze vervolgens gecorreleerd met klinische en radiologische parameters (leeftijd, geslacht, ziekteduur, BASDAI, BASFI, mSASSS). Het blijkt dat er inderdaad een correlatie is tussen de OWD en de mSASSS, maar ook tussen werveldeformiteiten en OWD. Met name wigvorming in de thoracale wervelkolom is geassocieerd met een afwijkende OWD (Figuur 9.4). De conclusie van deze bevinding is dat osteoporose bij AS bijdraagt aan de kenmerkende hyperkyphose. ${ }^{23}$ Deze bevinding biedt kansen voor verder onderzoek naar de rol van osteoporose bij de functionele beperkingen als gevolg van het ontstaan van deze voorovergebogen houding.

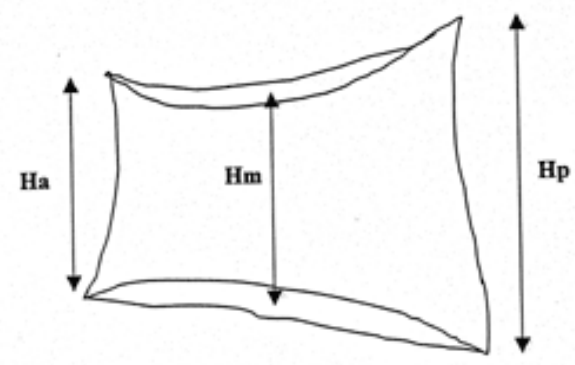

FIGUUR 9.3

Het meten van de antero-posterieur hoogte. 


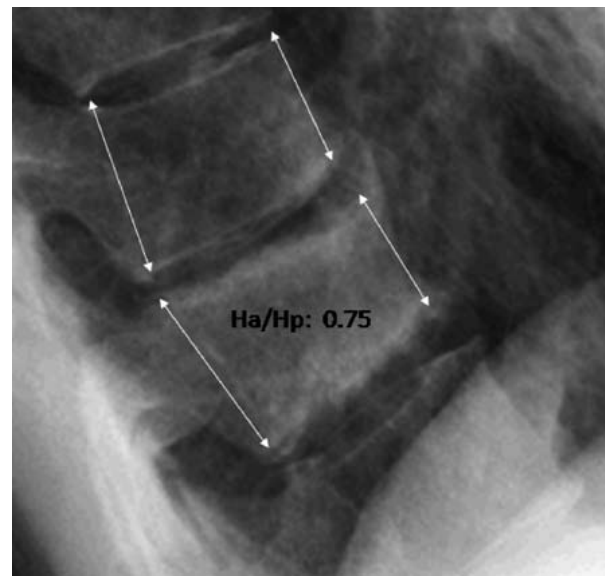

FIGUUR 9.4

Het meten van de anteroposterieure hoogteratio op röntgenfoto (MRX).

\section{Kunnen verschillende technieken naast elkaar gebruikt worden om wervel- misvormingen te meten en te vervolgen?}

Alhoewel er consensus is over het belang van het vaststellen van wervel-fracturen, zijn er verschillende methodes beschikbaar om wervelfracturen of deformiteiten vast te stellen en deze te onderscheiden van normale wervels. Deze methodes verschillen in de techniek die gebruikt wordt en in de definitie van een fractuur. ${ }^{23,24}$ Eén manier van het meten van wervelfracturen is middels conventionele radiologie; semikwantitatieve en kwantitatieve morfometrie van de wervels (MRX). Een andere beeldvormende techniek is bijvoorbeeld bot densitometrie (DXA), een techniek waarbij het ook mogelijk is om wervel fracturen te meten (morphometric $\mathrm{X}$-ray absorptiometry (MRA). Wij hebben een vergelijking gemaakt tussen morfometrie verkregen met behulp MXA en morfometrie verkregen met behulp van MRX bij het zoeken naar een adequate definitie van wigvormige wervelfracturen bij patiënten met AS. Opnieuw is gebruik gemaakt van patiënten uit het OASIS cohort. Van een deel van de patiënten konden we naast de eerder genoemde gegevens beschikken over DXA metingen; zowel kwalitatief als in de vorm van MXA. ${ }^{25}$ Het blijkt dat antero-posterieure hoogteratio's betrouwbaar te meten zijn door getrainde lezers (Figuur 9.5). Dit geldt zowel voor de röntgenopnames als voor de DXA beelden. Echter, overeenkomst tussen beide methodes over de definitie van een wervelfractuur is laag, maar de negatieve predictieve waarde is hoog. Tot op heden is er geen universeel geaccepteerde gouden standaard voor het diagnosticeren van wervelfracturen en in toekomstig onderzoek moet men, afhankelijk van de vraag, kiezen voor een van beide methodes of voor allebei. 


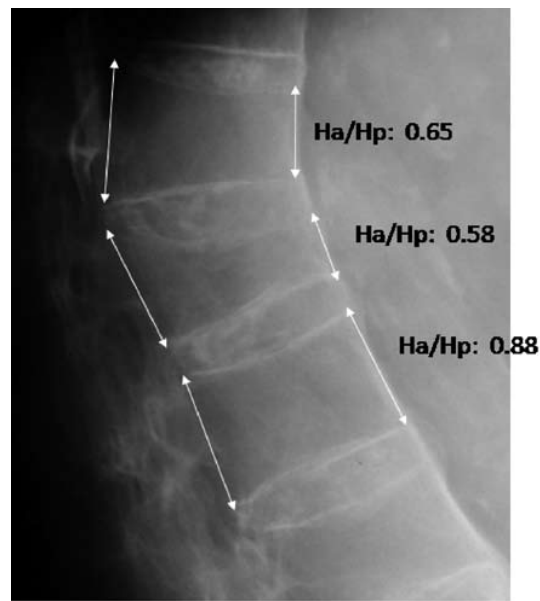

FIGUUR 9.5

Het meten van de vertebrale morfometrie op röntgenfoto (MRX).

\section{Kan radiologische schade (osteoporose, syndesmofyten) voorspeld worden?}

Tegenwoordig is osteoporose een duidelijk omschreven klinisch probleem bij patiënten met AS. Lage BMD en botverlies zijn goed beschreven bij AS, zowel in de wervelkolom als in de heup, en al vroeg in het ziektebeloop. ${ }^{26-33}$ Echter, bij patiënten met ernstige ziekte, wordt het gebruik van DXA in de wervelkolom bemoeilijkt door de aanwezigheid van syndesmofyten en periostale botformatie. Een andere manier om naar botkwaliteit te kijken is middels biomarkers. Bij RA worden radiologische schade (kraakbeenschade en boterosies) en osteoporose beschouwd als het resultaat van chronische inflammatie. Het is aangetoond dat markers van collageen type I (CTX-I) degradatie, passend bij botafbraak, en collageen type II (CTX-II)degradatie, passend bij kraakbeenafbraak, radiologische progressie kunnen voorspellen bij patiënten met RA. ${ }^{34-36}$ Bij AS is het pathofysiologische proces dat ten grondslag ligt aan radiologische schade nog grotendeels onduidelijk. Daarom hebben wij, naar analogie van de studies bij RA, bij patiënten met AS gekeken naar de relaties tussen CTX-I en CTX-II en ziekteactiviteit, radiologische schade en radiologische progressie na twee jaar. Radiologische schade bij het begin van de meting correleert met CTX-II , maar niet met CTX-I. CTX-II correleert ook met ontstekingsparameters, maar niet met BASDAI of BMD bij de beginmeting. In een multivariate analyse heeft CTX-II een kleine, maar significante en onafhankelijke bijdrage aan de verklaring van verschillen in radiologische schade en progressie tussen patiënten.Dit zou kunnen betekenen dat kraakbeenafbraak, op enigerlei wijze een rol speelt bij het ontstaan van de typische AS-deformiteiten. De bekende associatie tussen AS en osteoporose bleek in dit onderzoek uit een negatieve correlatie 
tussen BMD en CTX-I (botafbraak; osteoporose). Uit onderzoek bij RA weten we dat CTX-I spiegels goed correleren met schade en zelfs schade kunnen voorspellen. Echter, bij AS lijkt dit niet het geval te zijn. Mogelijk zijn de processen van inflammatie en röntgenschade bij AS niet zo fraai of op andere manieren gekoppeld als bij RA. $^{37,38}$ Waarschijnlijk leidt het behandelen van de inflammatie wel tot een verbeterde botkwaliteit en zo tot minder fracturen en hyperkyfose. Hiervoor zal verder onderzoek nodig zijn

\section{CONCLUSIE}

Net als bij reumatoïde artritis speelt bij AS de botkwaliteit een belangrijke rol. Het blijkt dat door inflammatie in- en rond de wervelkolom de kwaliteit van het bot, met name in het wervellichaam, afneemt. In combinatie met de toegenomen starheid van de wervelkolom maakt dit gegeven dat patiënten sneller en gemakkelijker een wervel breken, en dat dit veel vaker dan bij postmenopauzale osteoporose, leidt tot neurologische schade. Ook blijkt dat de wigvormige misvormingen van de wervellichamen, naast de voor AS karakteristieke röntgenafwijkingen, bijdragen aan de voorovergebogen houding van de patiënten met AS. Deze bevindingen leiden automatisch tot nieuwe onderzoeksvragen zoals: 'Kunnen we de botkwaliteit bij AS positief beïnvloeden en zo genoemde schade en mogelijke de functionele achter-uitgang voorkomen?'

Verder hebben we gezien dat wervelafmetingen op verschillende manieren vast te stellen zijn, maar dat methodes niet goed onderling uitwisselbaar zijn. De gouden standaard voor de wervelfractuur ontbreekt. Ook dit is een ingang voor verder onderzoek.

Voorts zal het onderzoek van AS de komende tijd in het teken staan van de ontrafeling van de pathofysiologie van syndesmofietvorming, waarbij de intrigerende en vooralsnog onverklaarde bevinding van het bestaan van botafbraak (osteoporose) en botnieuwvorming (syndesmofieten) centraal zal staan. Staat de vorming van syndesmofieten onder invloed van ontsteking, of is er een onafhankelijk proces gaande? Is er genetische controle van syndesmofietvorming? Is de vorming en groei van syndesmofieten gevoelig voor beïnvloeding door medicamenten, en wat is de beste timing voor medicamenteuze beïnvloeding? Wij hopen $U$ hierover in de komende jaren te kunnen berichten. 


\section{REFERENTIES}

1. Wright V. Aspects of ankylosing spondylitis. Br J Rheumatol 1991;30:1-4

2. Copeman WSC. Introductory note on the nomenclature and classification of the rheumatic diseases. In: WSC Copeman (Ed). Textbook of the rheumatic diseases. Fourth edition. Livingstone. Edinburgh and London 1969:12-18

3. Wright V, Moll JMH. Seronegative polyarthritis. North Holland Publishing Company. Amsterdam, New York, Oxford 1976

4. Dougados M, van der Linden S, Juhlin R, Huitfeldt B, Amor B, Calin A, Cats A, Dijkmans B, Olivieri I, Pasero G, et al. The European Spondylarthropathy Study Group preliminary criteria for the classification of spondylarthropathy. Arthritis Rheum 1991;34:1218-27

5. van der Linden S, Valkenburg HA, Cats A. Evaluation of diagnostic criteria for ankylosing spondylitis. A proposal for modification of the New York criteria. Arthritis Rheum 1984;27: 361-8

6. Creemers MCW, Franssen MJAM, van 't Hof MA, Gribnau FWJ, vd Putte LBA, v Riel PLCM. Assessment of outcome in Ankylosing Spondylitis: an extended radiological scoring system. Ann Rheum Dis 2005;64:127-9. doi:10.1136/ard.2004.020503

7. Calin A, Nakache JP, Gueguen A, Zeidler H, Mielants, H, Dougados M. Defining disease activity in ankylosing spondylitis: is a combination of variables ( Bath ankylosing spondylitis disease activity index) an appropriate instrument? J Rheumatol 1994;38:878-82

8. Calin A, Garrett S, Whitelock H, Kennnedy G, O'Hea J, Mallorie P, Jenkinson T. A new approach to defining functional ability in Ankylosing Spondylitis: thr development of the Bath ankylosing spondylitis functional index. J Rheumatol 1994;21:2281-5

9. Walsh NC, Crotti TN, Goldring SR, Gravallese EM. Rheumatic diseases: the effects of inflammation on bone. Immunol Rev. 2005;208:228-51

10. Pettit AR, Walsh NC, Manning C, Goldring SR, Gravallese EM. RANKL protein is expressed at the pannus-bone interface at sites of articular bone erosion in rheumatoid arthritis. Rheumatology 2006;45:1068-76

11. Diarra D, Stolina M, Polzer K, Zwerina J, Ominsky MS, Dwyer D, Korb A, Smolen J, Hoffmann M, Scheinecker C, van der Heijde D, Landewe R, Lacey D, Richards WG, Schett G. Dickkopf-1 is a master regulator of joint remodeling. Nat Med. 2007;13:156-63

12. Chavassieux P, Seeman E, Delmas PD. Insights into material and structural basis of bone fragility from diseases associated with fractures. How determinants of the biomechanical properties of bone are compromised by disease. Endocr Rev. 2007;28:151-64

13. Sinigaglia et al. Epidemiology of osteoporosis in rheumatic diseases. Rheumatic disease clinics of $\mathrm{N}$ America. 2006, 631-58

14. Cooper C, Atkinson EJ, O'Fallon M, Melton LJ III. Incidence of clinically diagnosed vertebral fractures: a population based study in Rochester, Minnesota. J Bone Miner Res 1992;7:221-7

15. Delmas PD, van de Langerijt L, Watts NB, Eastell R, Genant H, Grauer A, et al. Underdiagnosis of VFs is a worldwide problem: the IMPACT study. J Bone Miner Res 2005;20:557-63.

16. Vosse D, Feldtkeller E, Erlendsson J, Geusens P, van der Linden S. Clinical vertebral fractures in patients with Ankylosing Spondylitis. J Rheumatol. 2004;31:1981-5.

17. Vosse D, Geusens P, van der Heijde D, van der Linden Sj, Cooper C, van Staa T. Ankylosing spondylitis and the risk of fracture. Arthritis Rheum 2004;50 (9 supplement):S212-3

18. Cooper C, Carbone L, Michet CJ, Atkinson EJ, O'Fallon WM, Melton $\sqcup$ 3rd. Fracture risk in patients with ankylosing spondylitis: a population based study. J Rheumatol. 1994;21:1877-82.

19. Heuft-Dorenbosch L, Vosse D, Landewé R, Spoorenberg A, Dougados M, Mielants $H$, van der Tempel H, van der Linden S, van der Heijde D. Measurement of Spinal Mobility in Ankylosing Spondylitis: comparison of occiput-to-wall and tragus-to-wall distance. J Rheumatol 2004;31:1779-84 
20. Averns HL, Oxtoby J, Taylor HG, Jones PW, Dziedzic K, Dawes PT. Radiological outcome in ankylosing spondylitis: use of the Stoke Ankylosing spondylitis Spine Score (SASSS). Br J Rheumatol 1996; 35:373-6

21. Geusens P, Vosse D, van der Heijde D, Vanhoof J, van Tubergen A, Raus J, van der Linden S. High prevalence of thoracic vertebral deformities and discal wedging in ankylosing spondylitis patients with hyperkyphosis. J Rheumatol. 2001;28:1856-61

22. Genant HK, Wu CY, Kuijk van C, Nevitt MC. Vertebral fracture assessment using a semi quantitative technique. J Bone Miner Res 1993;8:1137-48

23. Vosse D, van der Heijde D, Landewe R, Geusens $P$, Mielants $H$, Dougados $M$, van der Linden S. Determinants of hyperkyphosis in patients with ankylosing spondylitis. Ann Rheum Dis. 2006;65:770-4

24. Duboeuf F, Bauer DC, Chapurlat RD, Dinten JMP, Delmas P. Assessment of vertebral fracture using densitometric morphometry. J Clin Densitom. 2005;8:362-8

25. Vosse D, Heijckmann C, Landewe R, van der Heijde D, van der Linden S, Geusens P. Comparing morphometric $\mathrm{X}$-ray absorptiometry and radiograhpy in defining vertebral wedge fractures in patients with Ankylosing Spondylitis. Rheumatol 2007;46:1667-71. doi:10.1093/rheumatology/ kem135

26. Sambrook P, Cooper C. Osteoporosis. Lancet. 2006;367:2010-8

27. Lange U, Kluge A, Strunk J, Teichmann J, Bachmann G. Ankylosing spondylitis and bone mineral density--what is the ideal tool for measurement? Rheumatol Int. 2005;26:115-20.

28. Baek HJ, Kang SW, Lee YJ, Shin KC, Lee EB, Yoo CD, Song YW. Osteopenia in men with mild and severe ankylosing spondylitis. Rheumatol Int. 2005;26:30-4

29. Jun JB, Joo KB, Her MY, Kim TH, Bae SC, Yoo DH, Kim SK. Femoral bone mineral density is associated with vertebral fractures in patients with ankylosing spondylitis: a cross-sectional study. J Rheumatol. 2006;33:1637-41.

30. Feldtkeller E, Vosse D, Geusens $P$, van der Linden S. Prevalence and annual incidence of vertebral fractures in patients with ankylosing spondylitis. Rheumatol Int. 2006;26:234-9.

31. Bouxsein ML. Determinants of skeletal fragility. Best Pract Res Clin Rheumatol. 2005;19:897-911.

32. Karberg K, Zochling J, Sieper J, Felsenberg D, Braun J. Bone loss is detected more frequently in patients with ankylosing spondylitis with syndesmophytes. J Rheumatol. 2005;32:1290-8.

33. Lee YS, Schlotzhauer T, Ott SM, van Vollenhoven RF, Hunter J, Shapiro J, Marcus R, McGuire JL. Skeletal status of men with early and late ankylosing spondylitis. Am J Med. 1997;103:233-41.

34. Garnero P, Gineyts E, Christgau S, Finck B, Delmas PD. Association of baseline levels of urinary glucosyl-galactosyl-pyridinoline and type II collagen C-Telopeptide are associated with progression of joint destruction in patients with early rheumatoid arthritis. Arthritis Rheum 2002;46:21-30.

35. Garnero P, Landewe R, Maarten B, Verhoeven A, van der Linden S, Christgau S, van der Heijde D, Boonen A, Geusens P. Association of baseline levels of markers of bone and cartilage degradation are associated with long-term progression of joint damage in patients with early rheumatoid arthritis: the Cobra study. Arthritis Rheum 2002;46:2847-56.

36. Landewé RB, Geusens P, van der Heijde DM, Boers M, van der Linden SJ, Garnero P. Arthritis instantaneously causes collagen type I and type II degradation in patients with early rheumatoid arthritis: a longitudinal analysis. Ann Rheum Dis. 2006;65:40-4 doi: 10.1136/ard.2004.035196 doi: 10.1136/ard.2007.071159

37. Schett G, Landewé R, van der Heijde D. Tumour necrosis factor blockers and structural remodelling in ankylosing spondylitis: what is reality and what is fiction? Ann Rheum Dis 2007;66:709-11. doi: 10.1136/ard.2007.071159

38. van der Heijde DM, Landewé RDM, Ory P, Vosse D, Zhou L, Tsuji W, Davis JC. Radiographic progression of ankylosing spondylitis after up to two years of treatment with etanercept. Arthritis Rheum 2008;58:1324-31 


\section{Dankwoord}

Hier is het dan, mijn proefschrift. Velen van $U$ zullen nooit gedacht hebben dat het ooit zover zou komen. Ik eerlijk gezegd ook niet, want "van promoveren word je doctor en geen betere dokter". Maar het is er toch van gekomen, en ik ben er trots op! En misschien toch ook wel een betere dokter...

Dit is dé plaats om een aantal mensen te bedanken, voor hun steun, hulp en medewerking.

Allereerst de patiënten die in het kader van het OASIS cohort al ruim10 jaar hun medewerking verlenen om zoveel gegevens te verzamelen. En ook de patiënten in het VUSO onderzoek die mij in staat stelden onderzoek te doen naar de rol van botmetingen bij AS. Furthermore, I'd like to thank all German and Danish patients who were willing to cooperate in the fracture study and send me piles of X-rays. Het blijft gezegd dat zonder de vrijwillige medewerking van patiënten veel onderzoek niet gedaan kan worden.

Professor van der Linden, beste Sjef. Veel dank dat je mij in 1998 hebt aangenomen op een plek waar ik eigenlijk niet in paste, en mij de gelegenheid hebt gegeven verder te groeien als reumatoloog. Ik heb het erg naar mijn zin in Maastricht, waar je een fantastische groep mensen hebt verzameld. En waarschijnlijk wist je toen al dat je mij nog wel zover zou krijgen... Ten tweede wil ik je bedanken voor de begeleiding bij het onderzoek. Met veel geduld heb je mij de beginselen van de wetenschap bijgebracht. Ik verbeeld me dat ik nu kritischer kan lezen.

Professor Geusens, beste Piet. Waarom zijn de bananen krom? Ik mocht het zo niet noemen, maar op deze plaats doe ik het toch even. Ik heb veel bewondering voor jou eindeloze creativiteit en werklust. Als bruggenbouwer heb je veel disciplines (snijdend en niet-snijdend) in ons ziekenhuis bij elkaar gebracht. Hoewel je mij af en toe aan de rand van mijn kunnen bracht, is het een genot met je samen te werken. Ik hoop dat we nog veel mooi onderzoek zullen doen hierna. 
Professor Landewé, beste Robert. Mijn kamer was net ingericht toen jij ook naar Maastricht kwam. Ik had toen niet kunnen vermoeden hoe leuk het was om met jou de kamer te delen. Onze kamer was vaak het centrum van de reumatologie, waar iedereen binnenliep met zijn of haar vragen. Ondertussen leerde je mij van alles over statistiek, epidemiologie, schrijven, kortom: onderzoek doen. Daarnaast was het erg gezellig om onder het genot van een kop koffie de rest van de wereld de revue te laten passeren. Je bent voor mij onmisbaar geweest bij het schrijven van dit boek. En ik weet zeker dat je dat ook voor onze werkgroep bent. Ik ben er trots op dat ik bij jou, als kersverse hoogleraar, kan promoveren.

De leden van de beoordelingscommissie, prof Nieuwenhuijzen Kruseman, prof Dinant, prof Lems en dr. Weijers dank ik voor de kritische beoordeling van mijn proefschrift. Ik verheug me op een geanimeerde verdediging. Prof Braun, thank you for the critical judgement of my thesis. I'm looking forward to discuss it with you in public.

Professor Stehouwer, beste Coen, als hoofd van de afdeling Interne Geneeskunde is het jouw taak de heilige 3-eenheid van de academie te bewaken. Dank dat je mij de ruimte hebt gegeven dit proefschrift in mijn tempo af te ronden.

Professor Feldtkeller, dr. Erlendsonn, professor Dougados, professor Mielants, dr. Garnero, dr.van Staa, my foreign co-authors in the past years. I want to thank you for your cooperation in the studies we performed together. It gives extra meaning to work with such distinguished people from abroad.

Anneke Spoorenberg en Liesbeth Heuft, hoewel ik niet echt een oppasmoeder ben van OASIS, heb ik me toch altijd erg verbonden gevoeld met jullie werk. En stiekem heb ik jullie boekjes er regelmatig bij gehad. Jullie waren gezellige collega's en ik vind het altijd erg leuk jullie in het land te ontmoeten. Hopelijk werken we nog eens samen in een AS project.

Caroline Heijckmann, Sven van Helden, Bianca Dumitrescu, Tineke van Geel, als mede-promovendi van professor Piet hebben we regelmatig contact gehad. Met Caroline heb ik geleden onder moeilijke databases, maar het heeft toch een artikel opgeleverd! Met Sven ben ik op stap geweest om te debatteren over osteoporose; misschien komen we elkaar bij volgend onderzoek (of op het hockeyveld) weer tegen. Bianca, you were a great help in the process of reading all the DXA's. I wish you good luck finishing your thesis. Tineke, veel contact was er niet, maar al wachtend op mijn beurt bij professor Geusens heb ik een en ander meegekregen van jouw werk. Succes in je verdere loopbaan.

Marijke, Annelies, Thea, Simone, Astrid, Hatice, Dianat, Theo, Dorien, Caroline, collega-reumatologen (io). Ik wil jullie allemaal hartelijk bedanken voor de ruimte 
die ik kreeg om dit boek te schrijven. Het is heerlijk te werken in een groep die samenwerkt en iets voor elkaar over heeft. Dat hebben we de afgelopen tijd ook wel nodig gehad! In onze groep doet iedereen vooral waar zij/ hij goed in is en op deze manier leren we continu veel van elkaar. Gelukkig is er daarnaast ook veel tijd om leuke dingen te doen. Wat mij betreft is het weer tijd voor een survival in de Alpen!

Professor van der Heijde, beste Désirée. Om allerlei redenen sta je hier, toch vlakbij de collega's uit Maastricht. Jouw rol bij de totstandkoming van dit proefschrift is natuurlijk erg groot geweest. Als moeder van OASIS ben je onmisbaar en als superwetenschapper evenzeer. Ik heb al zo veel van je geleerd! Ik hoop dat we elkaar regelmatig zullen blijven zien; langs de lijn, samen shoppen (hier of overzee) en later als onze kinderen die truien toch erg nodig blijken te hebben!

Karin, Astrid, Cedric, Merdan, Marloes, Inge, AIO/AIOS/ fellow/GEZP/WESP, veel afkortingen maar vooral gezellige collega's. Onze wegen lopen inmiddels ver uiteen, maar ik heb goede herinneringen aan de samenwerking met jullie. En sommigen van jullie komen ook weer terug! Cher Cedric, quelques mois à Maastricht sont devenu un an entier. J'ai bien aimée de parler français avec toi, du travail mais privé aussi; depuis le petit repas chez nous la clafoutis (aux cerises, je n'ai pas de mirabelles dans le jardin) est devenu le dessert préféré des enfants!

Ilse en Mehmet, onze reumaverpleegkundigen, maar inmiddels veel meer. Nog even en jullie doen hele spreekuren zelfstandig. Geweldig, jullie zijn fijne collega's. Ik vind het erg leuk om samen de zorg voor onze patiënten op alle fronten zo goed mogelijk met jullie te organiseren; in het azM en daarbuiten.

Yolanda, Marian, Femke, Peggy, een soepel secretariaat ; Dyonne, Els, Janine, goede research ondersteuning. Deze zaken maken het leven van een dokter erg aangenaam. Jullie zijn onmisbaar voor onze hele groep. Maar vooral zijn jullie fantastische collega's, die een centrale plek innemen waar het goed toeven is voor een kop koffie, een praatje of om je hart te luchten.

Maddy, Edith, Dana. Maar ook Ingrid, Sabine en alle andere polimedewerksters, een gezellige en goed functionerende polikliniek is van levensbelang voor een ziekenhuis. Ik hoop dat we er samen iets heel moois van kunnen maken!

Paulien, helemaal in het begin hebben we genoeglijke uurtjes doorgebracht achter jouw computer. Jij hebt mij geleerd DXA morfometrie te lezen en samen zijn we tot mooie data gekomen! Bedankt. 
Sietske, als eerste oppasmoeder in ons gezin heb je Rijn en mij wegwijs gemaakt in het ouderschap. Het is indrukwekkend hoe weinig je weet als je daar aan begint. Noor en Huygen hebben een prima start gehad onder jouw hoede.

Maria, al ruim 10 jaar regel jij ons huishouden, eerst in Maastricht en nu in Bemelen. We hebben al heel wat meegemaakt samen, veel goede maar ook mindere tijden. Voor de kinderen ben jij een baken van rust en warmte, voor Rijn en mij de onmisbare steunpilaar waarop het kaartenhuis rust. Zonder jou zouden wij nooit zover gekomen zijn. Ik hoop dat we nog even van je zorg mogen genieten, heel veel dank.

Vrienden, buren, ver weg of dichtbij. Ik ben de laatste jaren niet altijd de meest trouwe vriendin of buur geweest maar ik hoop dat ik het nu weer goed kan maken. Jullie hebben mij met alle gezelligheid en afleiding bij de tijd gehouden en me eraan herinnerd dat het leven niet alleen werken is. Dat is onmisbaar. Laten we straks champagne drinken en feest vieren, wat mij betreft tot in lengte van dagen.

Job en Renée, voor ons is "Bloemendaal" de spil van de Jöbsis-clan. Geweldige (schoon)ouders en grootouders voor alle (klein)kinderen. Een warm nest en wijze raad voor iedereen die erom vraagt. Ik vind het fantastisch dat jullie vandaag bij mij zijn en hoop nog lang van jullie te mogen genieten.

Joost, Lisan, Jasper, Irene, Mette en Jonas. Heerlijk, zulke schoonbroers en zussen (lekker Limburgs hè?). Dank voor al jullie steun en gezelligheid. Het houdt je onder de mensen in drukke tijden. Ik hoop wel dat jullie, met je gezinnen, in de toekomst nóg vaker naar Bemelen willen komen; ik vind dat zo gezellig....

Erwin en Marcel, broertjes. Ik weet niet of er veel broers en zussen zijn die zo goed met elkaar kunnen opschieten. Ik ben er trots op dat jullie mijn broertjes zijn. Zelfs nu we zo ver uit elkaar wonen is het contact altijd vanzelfsprekend. We doen alle drie iets totaal anders, maar toch lijken we veel op elkaar. Vroeger al, als we uitgingen zorgden jullie voor je zus, en dat doen jullie nog steeds. Ik vind het fantastisch dat jullie mij op deze zo belangrijke dag (weer) bij willen staan. Julie en Ingrid, schoonzusjes. Je moet het doen met wat je wordt toegeschoven maar ik ben erg blij met de keuze van mijn broers. Jullie zijn echte zussen!

Mamma, zonder twijfel de slimste van ons gezin. In dat opzicht is het jammer dat jij destijds niet de kans hebt gehad je vleugels verder uit te slaan. Je zou het ver geschopt hebben. Maar nu heb je alles gegeven om ons de mooiste jeugd te bezorgen en nog steeds ben je de spil van onze familie.

Pappa, als geen ander leer je ons iedere dag van het leven te genieten. Wat een levenskunst! 
Samen hebben jullie ons een warm en geborgen nest gegeven. Al eerder heb ik gezegd dat als er voor het ouderschap een top-10-lijstje zou bestaan, jullie altijd bovenaan zouden staan. Wij hebben alle kansen gekregen om ons te ontplooien en onze weg te vinden. Ik hoop dat we nog heel lang samen mogen genieten van al het goede van het leven.

Mijn paranymfen, Tineke en Wiepke. Tienus, we hebben geleden onder een ruim 80 -urige werkweek, we zagen zeelieden van alle wereldzeeën voorbij trekken en telefoneerden met mensen uit alle windstreken, op ieder uur van de dag(nacht). Maar ook hebben we samen genoten van een geweldige tijd in Rotterdam en is een hechte vriendschap geboren. Wiep, ons eerste gesprek duurde ruim een uur en toen hadden we elkaar nog niet eens ontmoet. Jij bent de enige vriendin in mijn voordeelnummers van de KPN! Gelukkig spreken we niet alleen over koetjes en kalfjes, maar delen we vele aspecten van het leven met elkaar. Ik vind het fantastisch dat jullie op deze voor mij zo bijzondere dag aan mijn zijde willen staan. Met jullie steun voel ik me veilig.

Noor en Huygen, op jullie ben ik ongelofelijk trots. Vrolijk, evenwichtig en vol levensgeluk zoeken jullie je weg. Eerst het boek van "pappa Rijn", nu het mijne. De carrières van jullie ouders lijken niet erg in de weg te staan, althans jullie proberen er de leukere kanten van te zien. Laten we samen de wereld verder verkennen. $\mathrm{Nu}$, en in de toekomst.

Rijn, mijn liefde, mijn leven. Wat zal ik zeggen. Er zijn is genoeg en jij bent er altijd. 



\section{Curriculum Vitae}

Debby Vosse werd geboren op 5 mei 1961 te 's Gravenhage. In 1979 haalde zij het VWO-Atheneum B diploma aan het Zaanlands Lyceum te Zaandam. In datzelfde jaar startte zij met de studie Geneeskunde aan de Gemeente Universiteit Amsterdam, waar zij in 1987 haar artsexamen haalde. In de periode 1984-1985 volgde zij aan dezelfde Universiteit colleges Rechtsgeleerdheid, afgesloten met het propedeuse in 1985. In het jaar voorafgaand aan de co-schappen deed zij een wetenschapsstage in het Jan van Breemeninstituut (prof J. van der Korst). Dit bleek het begin van haar reumatologische carrière.

In 1988 begon zij met de vooropleiding Interne Geneeskunde in het Havenziekenhuis te Rotterdam (opleider: prof P. Stuiver), en de opleiding Reumatologie werd in 1992 voortgezet in het Jan van Breemeninstituut/ Slotervaart Ziekenhuis te Amsterdam (opleider: mevr. dr. R.M. van Soesbergen). In 1995 werd zij geregistreerd als reumatoloog.

Na een positie als chef de kliniek in het Slotervaart Ziekenhuis begon zij in 1998 als staflid Reumatologie in het Academisch Ziekenhuis Maastricht (prof Sj. van der Linden). Hier zijn sinds 2001 de onderzoeken gedaan die zijn beschreven in dit proefschrift.

Van 1992 tot 1995 was zij juniorlid van het Consilium van de NVR, van 2001 tot 2005 was zij lid van de werkgroep DBC van de NVR en sinds 2004 is zij secretaris van de werkgroep kwaliteitsvisitaties reumatologenpraktijken van de NVR. Per 1 november 2008 is zij (mede) benoemd als chef de polikliniek van de afdeling Interne Geneeskunde van het MUMC.

Zij is sinds 1985 gelukkig met Rijn Jöbsis en zij zijn de trotse ouders van Noor (1994) en Huygen (1996). 


\section{Publications}

Vosse D, Wismans PJ. Glucose-6-fosfaat dehydrogenase deficiëntie bij een 81jarige.

Ned Tijdsch Geneeskd. 1994;138:1719-22.

Geusens P, Vosse D, van der Heijde DM, Vanhoof J, van Tubergen A, Raus J, van der Linden SM. High prevalence of thoracic vertebral deformities and discal wedging in ankylosing spondylitis patients with hyperkyphosis.

J Rheumatol 2001;28:1856-61.

Geusens P, Menten J, Vosse D, Vanhoof J, van der Linden S. Recovery from severe glucocorticoid-induced osteoporosis in an adolescent boy.

J Clin Densitom. 2001;4:389-94.

Heuft-Dorenbosch L, VosseD, Landewé, R, Spoorenberg A, Dougados M, Mielants $H$, van der Tempel $H$, van der Linden S, van der Heijde D. Measurement of spinal mobility in ankylosing spondylitis: Comparison of occiput-to-wall and tragus-to-wall distance.

J Rheumatol 2004;31:1779-84.

Vosse D, Feldtkeller E, Erlendsson J, Geusens P, van der Linden S. Clinical vertebral fractures in patients with ankylosing spondylitis.

J Rheumatol. 2004 Oct;31(10):1981-5.

Vosse D, van der Heijde D, Landewe R, Geusens P, Mielants H, Dougados M, van der Linden S. Determinants of hyperkyphosis in patients with ankylosing spondylitis.

Ann Rheum Dis. 2006 Jun;65(6):770-4.

Boonen A, van der Linden S, Geusens P, Vosse D. "Allegory of the world": the ankylosed back as a metaphor for coping in daily life.

Ann Rheum Dis. 2006;65:852.

Feldtkeller E, Vosse D, Geusens P, van der Linden S. Prevalence and annual incidence of vertebral fractures in patients with ankylosing spondylitis.

Rheumatol Int. 2006;26:234-9. 
Vosse D, van de Linden S. Ankylosing Spondylitis in 2015.

In: BJ van Royen, BAC Dijkmans, eds. Ankylosing Spondylitis. Diagnosis and treatment. New York : Taylor \& Francis Group 2006 p.343-51

Geusens P, Vosse D, van der linden S. Osteoporosis and vertebral fractures in ankylosing spondylitis.

Curr Opin Rheumatol. 2007:19 (4):335-9.

Vosse D, Heijckmann C, Landewe R, van der Heijde D, van der Linden S, Geusens P. Comparing morphometric $\mathrm{X}$-ray absorptiometry and radiograhpy in defining vertebral wedge fractures in patients with ankylosing spondylitis.

Rheumatol 2007 Nov;46(11):1667-71.

Vosse D, Landewé R, Garnero P, van der Heijde D, van der Linden S, Geusens P. Association of markers of bone- and cartilage degradation with radiological changes at baseline and after 2 years follow-up in patients with ankylosing spondylitis.

Rheumatol 2008;47(8):1219-22. Epub 2008 Jun 6.

van der Heijde DM, Landewé RDM, Ory P, Vosse D, Zhou L, Tsuji W, Davis JC. Twoyear etanercept therapy does not inhibit radiographic progression in patients with ankylosing spondylitis.

Arthritis Rheum 2008;58:1324-31.

Vosse D, Landewé R, van der Heijde D, van der Linden, van Staa P, Geusens P. Ankylosing spondylitis and the risk of fracture. Results from a large primary care -based nested case control study.

ARD 2008 doi: w.1136/ard 2008.100503. 